\title{
Risk Reduction with a Fuzzy Expert Exploration Tool
}

(Seventh Semi-Annual Technical Progress Report)

\author{
DOE Contract No. DE-AC-26-99BC15218
}

New Mexico Petroleum Recovery Research Center New Mexico Institute of Mining and Technology

Socorro, NM 87801

(505) 835-5142

Date of Report:

Contract Date:

Anticipated Completion Date:

Award Amount for Current Fiscal Year:

Project Manager:

Principal Investigator:

Contributors:

Contracting Officer's Representative:

Reporting Period:
November 1, 2002

March 15, 1999

March 15, 2004

$\$ 406,378$

James Barnes, NPTO

William W. Weiss

Ron Broadhead,

William R. Mundorf, FETC

April 1 through September 30, 2002 


\section{Table of Contents}

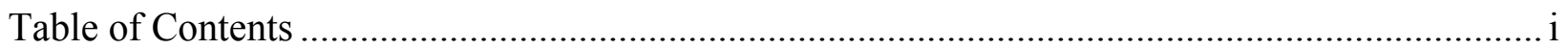

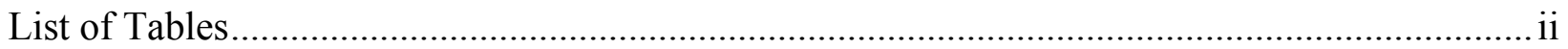

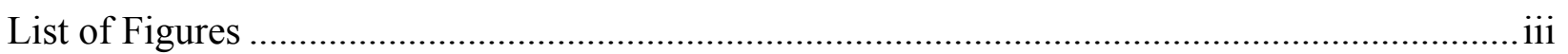

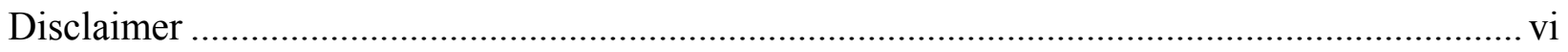

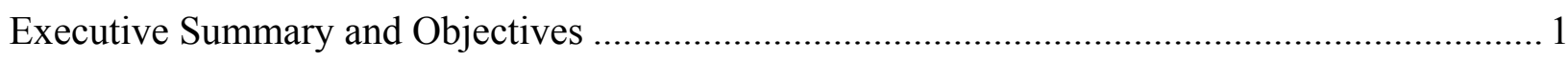

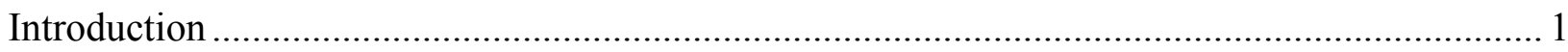

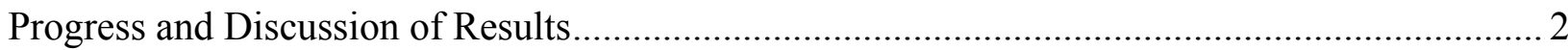

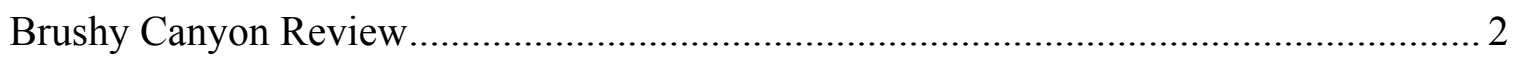

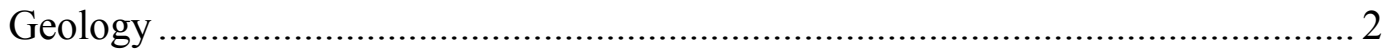

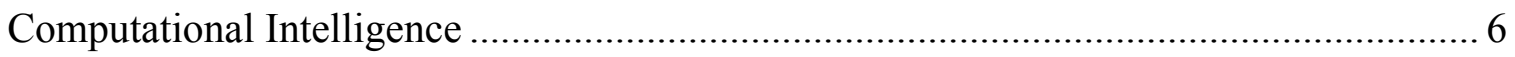

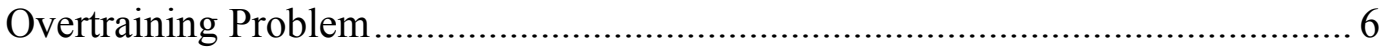

Overtraining investigated with synthetic datasets ...................................... 6

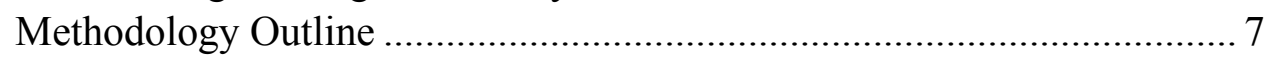

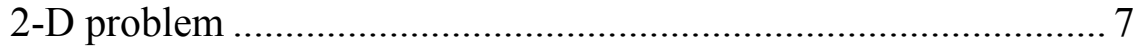

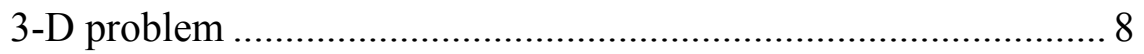

Conclusion............................................................................... 9

Nash Draw Bulk Volume Oil Prediction............................................................ 9

Regional Predicted Production Potential Map ....................................................... 10

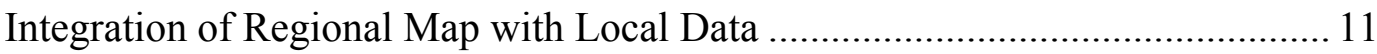

Expert System Rules and Development …………….................................. 12

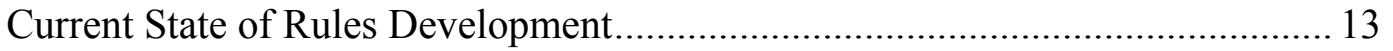

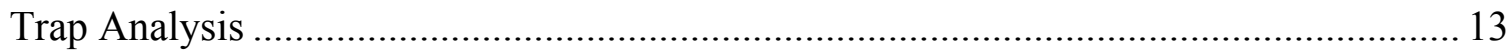

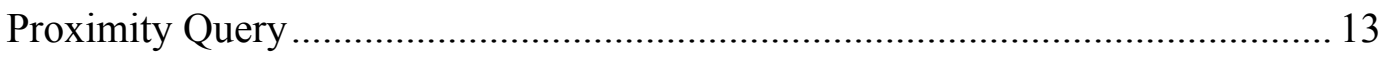

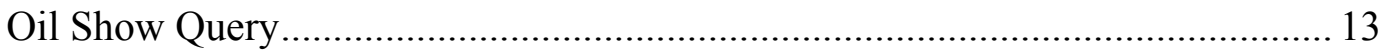

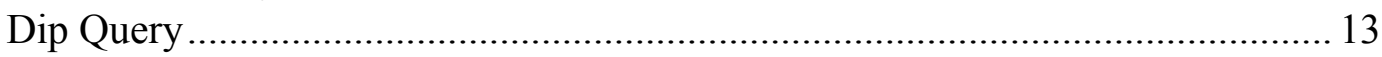

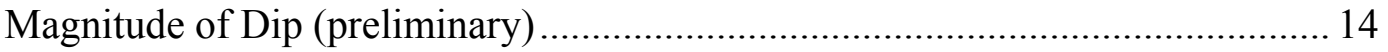

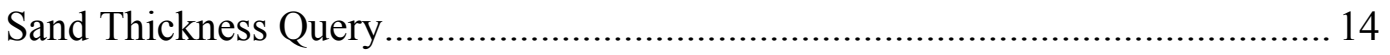

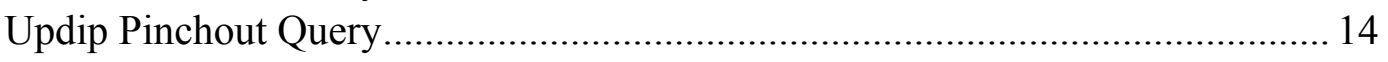

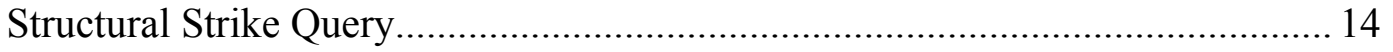

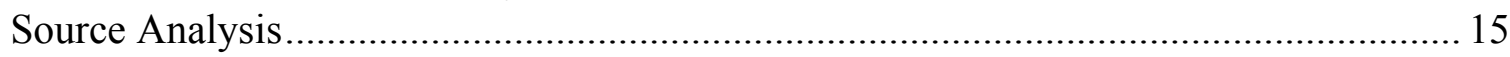

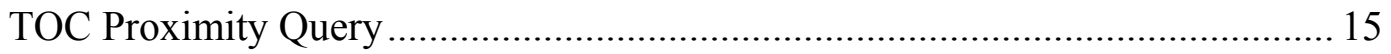

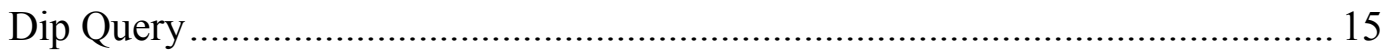

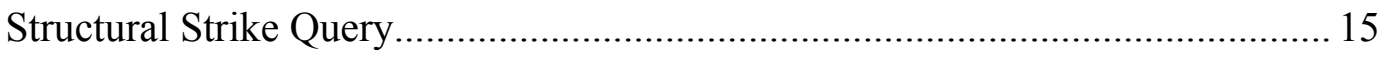

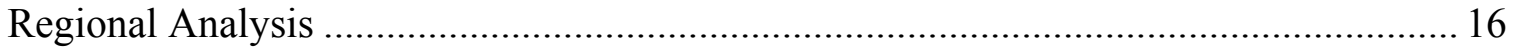

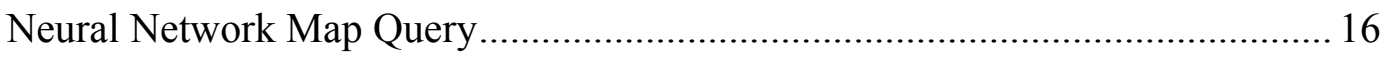

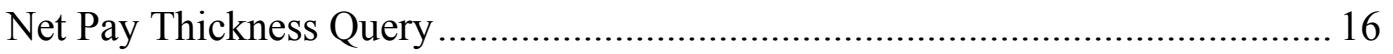

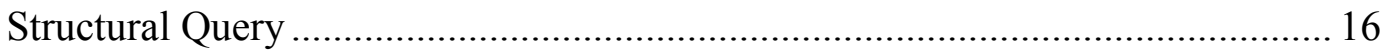

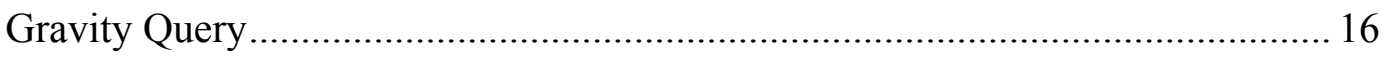

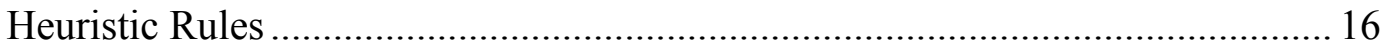

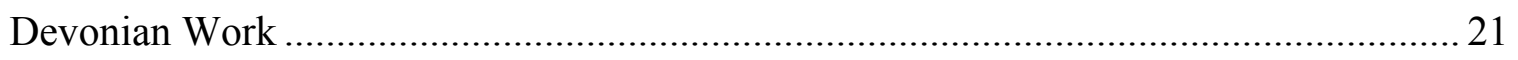

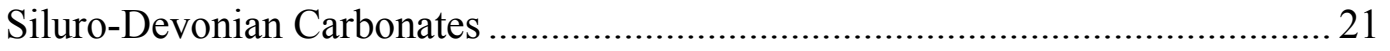




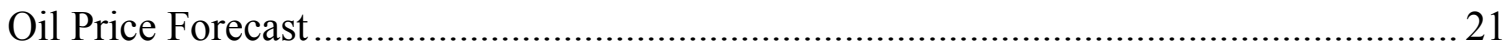

Current Objective ..................................................................................... 21

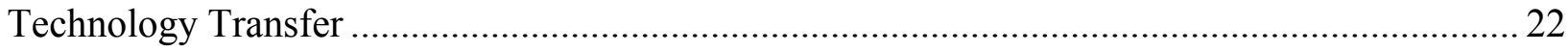

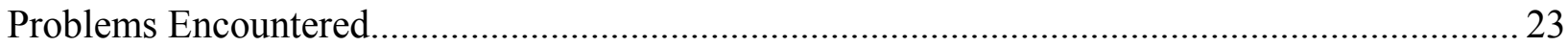

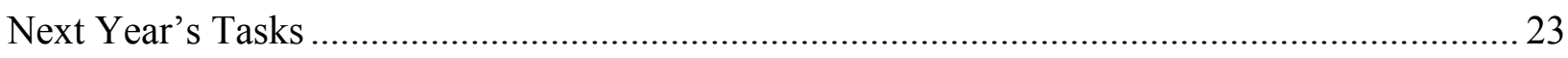

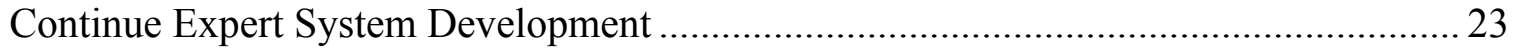

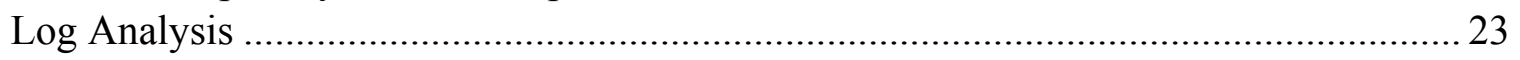

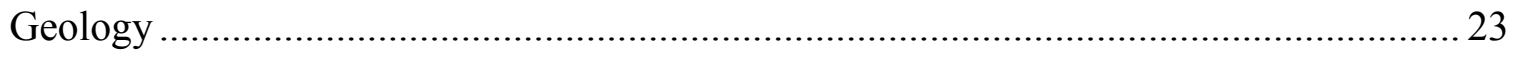

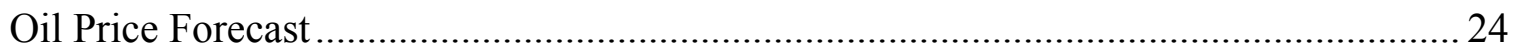

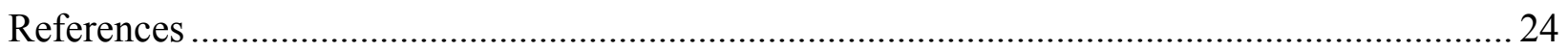

\section{List of Tables}

Table OT1. $x^{2}-1$ Function Results with Different $r / w$ Ratio .................................................... 8

Table OT2. $\operatorname{Sin}(\mathrm{x})+\cos (\mathrm{y})$ Function Results with Different $\mathrm{r} / \mathrm{w}$ Ratios .................................... 9

Table RL-I. First Year Initial Oil Producing Rate, bbl/mo ................................................... 11

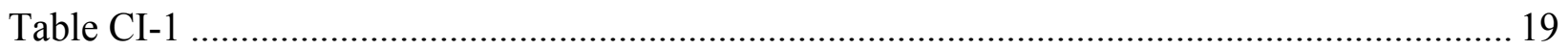




\section{List of Figures}

Fig. BC1. Location of project area in relation to Delaware Basin and other geologic elements, Permian Basin area southeast New Mexico and west Texas. Geologic elements modified from Hills (1984). .................................................................................................. 28

Fig. BC2. Stratigraphic chart of Delaware Mountain Group. Compiled from Payne (1976), Grauten (1979), Harms and Williamson (1988), and Montgomery et al. (1999). 28

Fig. BC3. Location of well data control points used in the Brushy Canyon part of this project. See Fig. BC1 for map location.

Fig. BC4. Three-dimensional view of structure on Bone Spring Formation and location of oil pools (in green) productive from the lower part of the Brushy Canyon Formation.

Fig. BC5. Three-dimensional view of structure on lower Brushy Canyon Formation and location of oil pools (in green) productive from the lower part of the Brushy Canyon Formation.

Fig. BC6. Isopach map of lower Brushy Canyon Formation. 30

Fig. BC7. Areas productive from lower Brushy Canyon, net thickness of lower Brushy Canyon sandstones with porosity $>15 \%$, and wells that unsuccessfully tested the lower Brushy Canyon.

Fig. BC8. Areas productive from lower Brushy Canyon and net thickness of lower Brushy Canyon sandstones with porosity $>10 \%$.

Fig. BC9. Net thickness of lower Brushy Canyon sandstones with porosity $>15 \%$ superimposed on 3-D diagram of Bone Spring structure.

Fig. BC10. Salinity of produced Brushy Canyon waters superimposed on 3-D diagram of Bone Spring structure.

Fig. BC11. Salinity of produced lower Brushy Canyon waters and areas productive from lower Brushy Canyon. 33

Fig. BC12. Total organic carbon content, in weight percent, of lower Brushy Canyon source rocks

Fig. BC13. Thermal maturity of lower Brushy Canyon source rocks as determined by Rock-eval TMAX values and areas productive from lower Brushy Canyon.

Fig. BC14. API gravity of lower Brushy Canyon oils. 
Fig. OT1. Real Overtraining Example (Poker Lake 89, perfect training). 35

Fig. OT2. Real Overtraining Example (Nash Draw 23, bad prediction). ...................................... 35

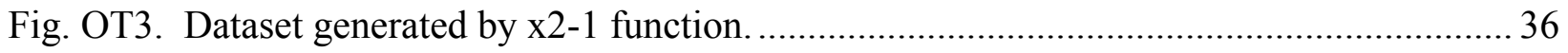

Fig. OT4. The 1-3-4-1 ANN results for x2-1 function................................................................. 36

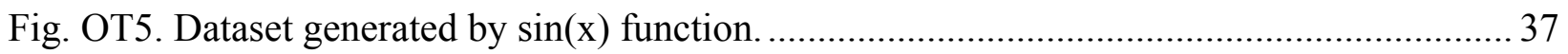

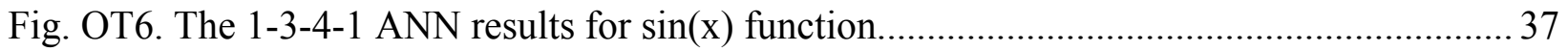

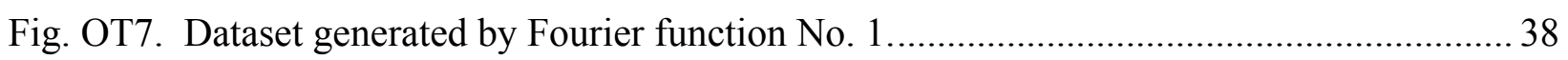

Fig. OT8. The 1-3-4-1 ANN results for Fourier function No.1 ........................................... 38

Fig. OT9. Dataset generated by Fourier Function No. 2 …........................................................ 39

Fig. OT10. The 1-3-4-1 ANN results for Fourier function No. 2 …………………….............. 39

Fig. OT11. Dataset generated by Fourier function No. 3 .................................................... 40

Fig. OT12. The 1-3-4-1 ANN results for Fourier function No. 3 ………………...................... 40

Fig. OT13. Dataset generated by $\sin (\mathrm{x})+\cos (\mathrm{y})$ function............................................................ 41

Fig. OT14. The 2-3-4-1 ANN results for $\sin (\mathrm{x})+\cos (\mathrm{x})$ function. ................................................... 41

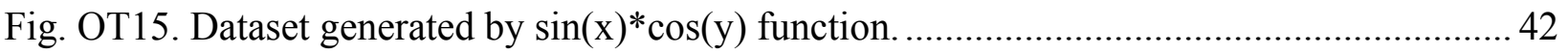

Fig. OT16. The 2-3-4-1 ANN results for $\sin (\mathrm{x}) * \cos (\mathrm{y})$ function.................................................. 42

Fig. BVO-1: Neural Network architecture used to correlate logs with core measured bulk

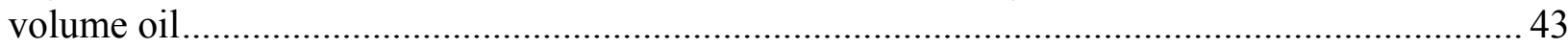

Fig. BVO-2: Architecture used to correlate bulk volume oil with average production ...............43

Fig. BVO-3: Training results for network used to correlate logs with core measured bulk

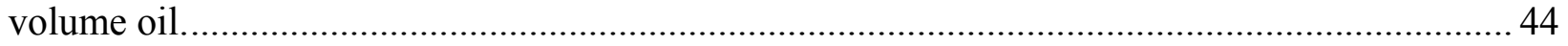

Fig. BVO-4: Training results for network used to correlate standard deviation, average

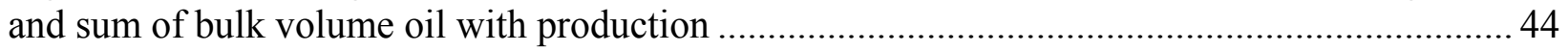

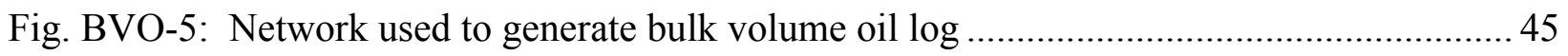


Fig. BVO-6: Blind testing with logs from a well 30 miles distant to training well.

Fig. BVO-7: Accuracy of 34-Well Training

Fig. RL-1: Map of predicted production potential based on the trained and tested neural network regression.

Fig. RL-2. NE Lea area zoom map.

Fig. CI-1 Crossplot of neural network training using the inputs identified via

FuzzyOnline. 48

Fig. CI-2. Crossplot of testing data for the trained neural network of Fig. CI-1. 48

Fig. CI-3.This figure demonstrates the benefits of neural network regressions for complex problems where forecasts need to be made. Assuming only the five points enclosed by diamonds are known to start, it is quite easy to fit a polynomial that exactly fits the training data but poorly fits the true data distribution. Neural networks can bypass this problem if a sufficient sample exists for training by creating a generalized solution.

Fig. CI-4. The original schematic for the fuzzy expert system shell.

Fig. CI-5. More complicated system, which breaks the analysis into several separate categories to simplify calculations and customization.

Fig CI-6. Distance weighted step function for proximity to established production. 50

Fig CI-7. Distance weighted step function for proximity to oil shows, used when production data is not available within 5 miles.

Fig CI-8. Illustration of the possible types of dip from one point to another considered by the expert system.

Fig CI-9. Distance weighted step function for proximity to source rocks with TOC $>5 \%$. 52

Fig CI-10. Step chart showing ranges for neural network predicted production potential. Three ranges are defined, High $(\mathrm{H})$, Medium (M), and Low (L)...... 52

Fig. D-1 Oil and gas fields producing from Siluro-Devonian carbonates reservoirs in southeast New Mexico.

Fig. D-2. Stratigraphic column of lower Paleozoic strata in southeast New Mexico. Production in the Siluro-Devonian section is obtained from several zones within the Thirtyone, Wristen, and Fusselman Formations. Modified from Hill (1986)......

Fig. D-3. Wells penetrating sub-Woodford Devonian strata in southeast New Mexico. 54 
Fig. D-4. Structure contour map of Siluro-Devonian carbonates.......................................... 54

Fig. D-5. Isopach map of Siluro-Devonian strata in southeastern New Mexico. ....................... 55 


\section{Disclaimer}

This report was prepared as an account of work sponsored by an agency of the United States Government. Neither the United States Government nor any agency thereof, nor any of their employees, makes any warranty, express or implied, or assumes any legal liability or responsibility for the accuracy, completeness, or usefulness of any information, apparatus, product, or process disclosed, or represents that its use would not infringe privately owned rights. Reference herein to any specific commercial product, process, or service by trade name, trademark, manufacturer, or otherwise does not necessarily constitute or imply its endorsement, recommendation, or favoring by the United States Government or any agency thereof. The views and opinions of authors expressed herein do not necessarily state or reflect those of the United States Government or any agency thereof. 


\section{Executive Summary and Objectives}

Incomplete or sparse information on types of data such as geologic or formation characteristics introduces a high level of risk for oil exploration and development projects. "Expert" systems developed and used in several disciplines and industries have demonstrated beneficial results. A state-of-the-art exploration "expert" tool, relying on a computerized database and computer maps generated by neural networks, is being developed through the use of "fuzzy" logic, a relatively new mathematical treatment of imprecise or non-explicit parameters and values. Oil prospecting risk can be reduced with the use of a properly developed and validated "Fuzzy Expert Exploration (FEE) Tool."

This FEE Tool can be beneficial in many regions of the U.S. by enabling risk reduction in oil and gas prospecting as well as decreased prospecting and development costs. In the 1998-1999 oil industry environment, many smaller exploration companies lacked the resources of a pool of expert exploration personnel. Downsizing, low oil prices, and scarcity of exploration funds have also affected larger companies, and will, with time, affect the end users of oil industry products in the U.S. as reserves are depleted. The pool of experts is much reduced today. The FEE Tool will benefit a diverse group in the U.S., leading to a more efficient use of scarce funds and lower product prices for consumers.

This seventh of ten semi-annual reports contains a summary of progress to date, problems encountered, plans for the next year, and an assessment of the prospects for future progress. The emphasis during the April 2002 through September 2002 period was directed toward development of rules for the fuzzy system.

\section{Introduction}

In the first three years of the Fee Tool Project, an immense amount of Delaware Basin data composed of regional geology, structure, production, gravity and aeromagnetic information, as well as local data such as well logs, has been accumulated. This data, organized and cataloged into several online databases, is available for the Expert System and users as needed and as appropriate in analyzing production potential. A preliminary map of production potential for the basin has been generated and stands ready to be modified by rules defined both by human experts in exploring the Delaware Basin, and by statistical rules defined by the database. A number of new and useful tools and technologies have been generated to support these efforts, including online useable interfaces for neural network analysis (PredictOnline), ranking of potential inputs using fuzzy logic (FuzzyOnline), a preliminary Expert System able to make rudimentary drilling decisions, and a web interface for accessing the databases and Expert System software.

In the next two years a finished Expert System will be provided that will run remotely from a browser on nearly any computer. The system will be able to aid in development and drilling decisions for both the Brushy Canyon and Devonian plays by providing readily accessible public information. An interactive and customizable questionnaire plus relevant analyses will produce an "Expert" opinion of a prospect in a short time to enhance the work of a human explorationist. 


\section{Progress and Discussion of Results}

\section{Brushy Canyon Review}

\section{Geology}

The Brushy Canyon Formation of the Delaware Mountain Group (Permian: Guadalupian) consists of 550 to $1650 \mathrm{ft}$ of interbedded fine-grained sandstones, siltstones, and minor detrital carbonates deposited in the deep-marine Delaware Basin (Fig. BC1). The Brushy Canyon Formation unconformably overlies the Bone Spring Formation (Permian: Leonardian) or erosional remnants of the Cutoff Formation (Permian: Guadalupian) throughout much of the Delaware Basin (Fig. BC2). The Brushy Canyon is overlain by basinal sandstones and siltstones of the Cherry Canyon Formation (Permian: Guadalupian). In New Mexico, depth to the Brushy Canyon ranges from 1950 $\mathrm{ft}$ near the northern and western margins of the basin to $8600 \mathrm{ft}$ in the deepest part of the basin in southwest Lea County.

The Brushy Canyon became a major exploration and development target in the middle to late 1980s. It had been drilled through and ignored for decades as producers concentrated on deeper targets, mainly gas-productive intervals in the Morrow and Atokan (Lower Pennsylvanian) and also on shallower oil-productive sandstones of the Bell Canyon Formation of the Delaware Mountain Group (Permian: Guadalupian). The Brushy Canyon sandstones were not considered a viable exploration target for four reasons (Montgomery et al., 1999). First, they are low-resistivity sandstones for which conventional log analysis indicates high water saturations. Second, they are less permeable than shallower oil-productive sandstones in the Bell Canyon. Third, the Brushy Canyon is a deeper target than the Bell Canyon, therefore making it seem not as economically viable. Fourth, little or no oil flows from Brushy Canyon sandstones on drill-stem tests. Since the mid-1980s, however, the Brushy Canyon has been recognized as a major, economically viable target. More than 110 fields currently produce oil and associated gas from the Brushy Canyon in southeast New Mexico. The predominant trapping mechanism is stratigraphic (Montgomery et al., 1999).

The Brushy Canyon has been subdivided into three informal stratigraphic units by most workers, an upper unit, a middle unit, and a lower unit (Fig. BC2; Montgomery et al., 1999). Boundaries between the units are not well defined and generally vary from worker to worker. The upper Brushy Canyon produces significant volumes of oil and the middle Brushy Canyon produces relatively little oil. The lower unit has produced most of the oil obtained from the Brushy Canyon. This part of the project concentrated on the lower Brushy Canyon.

Brushy Canyon fields have typically been discovered by reexamining and reentering old wells that have produced from deeper stratigraphic units such as the Morrow (Lower Pennsylvanian) and have been abandoned as the deeper production has declined to subeconomic levels. Recompletions are typically made in those wells that exhibited good mudlog shows in the Brushy Canyon but were never tested or were tested with water recovery on a drill-stem test. A few operators have drilled new wells updip of older wells that have exhibited shows in the Brushy Canyon. Generally, however, most discoveries have been made by reentering old wells. Most exploration, therefore, has been concentrated on wells that have been drilled to Lower Pennsylvanian targets. While 
this has proved to be a successful and economically viable strategy for many operators, it has limited exploration largely to areas where recently abandoned deep wells are available for reentry. Because many of the wells were originally drilled on structures that affect the Lower Pennsylvanian, most Brushy Canyon exploration has therefore been essentially structural in aspect and has largely ignored the stratigraphic component of trapping, which is dominant.

This portion of the project involved the acquisition, synthesis, and analysis of structural, stratigraphic, production, reservoir, and source-rock data. The data are collected from more than 720 wells basinwide (Fig. BC3). Wherever possible, data were collected so that data from productive wells in Brushy Canyon pools were offset by nonproductive wells adjacent to those pools. In this way, geologic contrasts between productive areas and immediately adjacent nonproductive areas are reflected in the dataset and its derivative maps. Data synthesis and analysis performed as this part of the project have been used to help devise and structure the neural network system.

The structure on top of the Bone Spring Formation (Fig. BC4) and lower Brushy Canyon Formation (Fig. BC5) indicate more than $7500 \mathrm{ft}$ of structural relief between the shallower parts of the basin to the north and the deepest part of the basin to the southeast. The structure on the top of the Brushy Canyon Formation (Fig. BC 5) is very similar with a relief of only $7200 \mathrm{ft}$, indicating a partial infilling of the basin during Brushy Canyon time. The structure on the top of the Bone Spring Formation includes numerous local closures and structural noses that are superimposed on the regional descent of the Bone Spring into the Delaware Basin. Also present are several structural lows that extend into the basin from adjacent areas on the Northwest shelf. As discussed below, many of these local structures controlled sand distribution in the lower Brushy Canyon and are therefore paleobathymetric elements that were in existence at the time of Brushy Canyon deposition. Many, but certainly not all, appear to be located over Pennsylvanian structures described by Montgomery et al. (1999). Pennsylvanian- and Permian-age structure has been overprinted by a southeast regional tilt of Laramide (Late Cretaceous Early Tertiary) age (Hills, 1963; Dickerson, 1985).

The lower part of the Brushy Canyon Formation is 60 to $500 \mathrm{ft}$ thick within the project area in southeast New Mexico (Fig. BC6). It consists of arkosic to subarkosic, fine-grained sandstones (reservoir facies), organic-rich siltstones (seal and source-rock facies), dolostones and limestones that are present mostly near the shelf margin, and black to dark-gray calcareous shales or marlstones (Montgomery et al., 1999).

Brushy Canyon sandstones are allochthonous sediments that originated on surrounding shelf areas and were transported into the deep-marine Delaware Basin prior to deposition. The mechanism of transport is enigmatic and has been ascribed more recently to various gravity-related flow processes including saline density currents (Harms, 1974; Harms and Williamson, 1988; Harms and Brady, 1996) and turbidity currents (Hull, 1957; Jacka et al., 1968). Whatever the mechanism of transport, the conveying currents apparently flowed downslope and deposited the sands in submarine channels and on submarine fan and channel complexes (e.g. May, 1996; Thomerson and Catalano, 1996; Basham, 1996; Broadhead et al., 1998). Most depositional models hypothesize that Brushy Canyon sands were initially transported across the Northwest shelf during lowstands of sea level when the shelf was exposed. The sands were then 
remobilized and transported into the basin through submarine canyons incised into the shelf-edge carbonates.

Thicker areas of the lower Brushy Canyon were deposited in structurally low depressions in the underlying Bone Spring Formation. Many of these depressions originate at the shelf edge and are elongate perpendicular to the shelf edge. This relationship between lower Brushy Canyon thickness patterns and underlying Bone Spring morphology indicates that the structural depressions were depressions that acted as conduits for the transport of Brushy Canyon sands into the deep basin and as ponding areas where submarine fans were formed.

Similar patterns of thickness distribution can be seen on isolith maps of reservoir quality sandstone within the lower Brushy Canyon. One map, derived from density porosity logs, show the net thickness of sandstone with at least $15 \%$ porosity (Fig. BC7). A map that shows thickness of sandstone with at least $10 \%$ porosity has similar patterns (Fig. BC8). Both of these maps indicate the distribution of reservoir quality sandstones that are capable of sustained, economic levels of oil production, although the sandstones with a minimum of $10 \%$ porosity may be marginally productive. Reservoir quality sandstones in the Brushy Canyon that are oil productive typically have porosity in the 12 to 22\% range (see Asquith et al., 1996; Gawloski, 1995; Hoose and Dillman, 1995; LeMar, 1995; May, 1996; Mitchell, 1995; Tittl, 1995; White, 1995; Worrall, 1995). It is possible that some sandstones with more than $15 \%$ porosity will not be productive because of the dominance of micropores that that inhibit the migration and production of oil (see Asquith et al., 1996).

Thicker areas of reservoir quality sandstones are located along the northern and western margins of the basin and are distributed along linear to lobate trends that extend from the basin margin into the deeper parts of the basin. Primary sources of reservoir quality sand were mostly located to the northwest and the west. The eastern part of the Northwest shelf contributed lesser, but still significant, volumes of sand. Only minor amounts of reservoir quality sand were derived from the Central basin platform to the east. An overlay of the $15 \%$ porosity isolith map on the Bone Spring structure map indicates that the reservoir sandstones are confined mostly to the structural depressions in the underlying Bone Spring or are present as lobe-shaped deposits (submarine fans) downslope of where the depressions terminate (Fig. BC9). Deflection of transporting currents around structural closures and noses in the basin is evident in the map patterns.

Depositional sandstone units are separated by $5 \mathrm{ft}$ to $20 \mathrm{ft}$ thick layers of organicrich siltstones. These siltstones are represented on logs as radioactive beds. Most exhibit much greater lateral continuity than the interbedded sandstones. Several of the siltstone beds can be correlated throughout the basin. They are thought to represent periods of basin starvation (Garber et al., 1989; Gardner, 1997). The siltstones are use to internally subdivide the Brushy Canyon into its upper, middle, and lower units.

When areas of established, discovered oil production from the lower Brushy Canyon are compared with the structural configuration of the lower Brushy Canyon (Fig. BC5), it is evident that oil accumulations are not coincident with the larger scale structural closures and noses. Productive areas are mostly coincident with structurally low areas in the Brushy Canyon. These low areas are inherited from paleobathymetric and paleostructural lows that characterize the upper surface of the underlying Bone Spring Formation. Areas of lower Brushy Canyon production are coincident with 
reservoir fairways where net thickness of lower Brushy Canyon sandstones with at least $15 \%$ porosity is $15 \mathrm{ft}$ or more (Fig. BC7). The map of net thickness of sandstones with porosity greater than $10 \%$ exhibits a somewhat less explicit correlation with production (Fig. BC8). Therefore, the fuzzy logic system probably should not emphasize structure in the conventional manner. Instead of focusing target areas on structural closures and noses, the fuzzy logic system will focus on paleostructural lows that acted as conduits for sediment transport. Structural closures may be significant where they are located downslope and affect pond sediment flows, causing accumulation of thick reservoir quality sands, or where the structural configuration postdates sediment deposition and therefore had no affect on sediment transport routes.

A major question is raised by the maps that overlay productive areas on the reservoir sandstone trends. Why is production largely absent from areas in the westernmost and northwestern most parts of the research area where reservoir sandstones occur in abundance? These areas typically have more than $100 \mathrm{ft}$ of lower Brushy Canyon sandstone with at least $15 \%$ porosity, yet these areas lack production. Although this may be partially due to incomplete testing and evaluation, it is likely that geological factors also play a role and that some parts of these sandstone-rich areas are truly barren of commercial hydrocarbons. Can this be explained by a paucity of seals? It may be that oil and gas have migrated updip out of the basin and have not been trapped in the Brushy Canyon for lack of adequate barriers to migration. Figure BC7 shows that the larger oil accumulations within the Brushy Canyon coincide with areas of thick reservoir sandstones that thin or pinchout in an updip (northerly, northwesterly, or westerly) direction. The thin sands in the northernmost and westernmost parts of the basin appear to be continuously connected with the outcrop and therefore have not provided updip seals, at least along major sand trends.

Alternatively, eastward tilting during the Laramide may have led to flushing of the Brushy Canyon in this region by influent groundwaters (Lindsay, 2001). Influent waters may have moved downdip in an easterly direction until they encountered seals that also acted to trap hydrocarbons in stratigraphic traps to the east. Maps that show salinity of produced lower Brushy Canyon waters (Fig. BC10, BC11) were constructed for this project and indicates that salinity decreases toward the northern and western margins of the basin indicating recharge of fresh water along the lower Brushy Canyon outcrop, and therefore supporting Lindsay's hypothesis.

Another possibility that may explain the sparse distribution of hydrocarbons in these areas is an absence or paucity of source rocks. It has been reasonably well established that, at least in places, oil accumulations within the Brushy Canyon are sourced by organic-rich siltstones within the Brushy Canyon (Hays and Tieh, 1992; Robinson, 1993). The sandstone reservoirs are interbedded with their source rocks and the source strata also act as seals for the accumulations. Robinson (1993) concluded that the low permeabilities of Brushy Canyon reservoirs are indicative of short migration distances. If this is the case, then oil accumulations should be preferentially concentrated in areas where source rocks are mature, thick, and have relatively high contents of organic carbon. Data and maps relating to these hypotheses were collected and created as part of this project in order to provide the fuzzy expert tool information with which to evaluate the importance of source rocks. A map of total organic carbon (TOC) content of lower Brushy canyon source rocks (Fig. BC12) indicates that sufficient organic material 
is present within the lower Brushy Canyon to form adequate source facies throughout the Delaware Basin. Thermal maturity of Brushy Canyon source rocks, although adequate for oil generation throughout the research area, increases to the south in the deeper parts of the basin and also to the west with increasing proximity to the Rio Grande rift (Figure BC13). Oil gravity data collected and mapped for this project indicate a bimodal distribution of lower Brushy Canyon oils (Fig. BC14). Oils with higher API gravities (API $>40$ degrees), which are lighter and presumably more thermally mature, have been trapped along major sandstone fairways whereas somewhat heavier oils (API $<40$ degrees) are present where sand bodies do not occur along major sandstone fairways. This distribution of oils suggests that lighter, more mature Brushy Canyon oils may have been generated in deeper, more mature parts of the Delaware basin and migrated updip along sandstone fairways until they were trapped. The somewhat heavier oils had their origin in source beds close to the reservoirs in the shallower parts of the basin; the limited extent of sandstone bodies in these areas caused local hydrocarbon entrapment and prevented the oil from migrating longer distances. Thus, proximity to sandstone fairways plays a significant role in oil gravity and quality within the lower Brushy Canyon.

\section{Computational Intelligence}

\section{Overtraining Problem}

The pitfalls of neural network "overtraining" were discussed in the Third Annual

report $^{1}$ when the problem was encountered with the Poker Lake 89 dataset. The density and neutron porosity logs along with the deep and shallow resistivity logs were used as input to train a 4-2-1 neural network with the limited domain dataset (19 available BVO measurements). The training was almost perfect, as shown in Fig. OT1. The Poker Lake 89 neural network was used to predict the Nash Draw 23 BVO log shown in Fig. OT2. Notice that the predicted high BVO values are in areas where the core values (truth) are low. Experience to date suggests that the ratio of samples to neural network weights (node tie lines) should exceed 2 to minimize this over-training problem. The ratio is 1.9:1 in the Poker Lake 89 example. During this reporting period, synthetic datasets were used to investigate the empirical 2:1 rule.

\section{Overtraining investigated with synthetic datasets}

Correctly training neural networks is a notoriously difficult problem. In training neural networks, one of the major pitfalls is overtraining. Overtraining occurs when a network has learned not only the basic mapping associated with input and output data, but also the subtle nuances and even the errors specific to the training set. If too much training occurs, the network may only memorize the training set and lose its ability to generalize new data which results in a network that performs well on the training set, but poorly on out-of-sample test data and produces poor predictions. To assure accurate predictions overtraining should be avoided.

Experience applying neural networks to correlate logs with core measured BVO suggests that the records/weights (or core measurements/NN tie lines) must be larger than two to minimize overtraining. The following numerical studies use 2D and 3D synthetic datasets to confirm this rule of thumb. 


\section{Methodology Outline}

\section{2-D problem}

Generate synthetic datasets using $x^{2}-1, \sin (x)$, and three different Fourier equations, named Fourier No. 1, No. 2, and No. 3 respectively. Random(x), which generates random numbers in a given range, is taken as the noise (error) of the output of these functions. By suitable control and normalization of the input and output, we make the output values of these functions in the range from -1 to 1 and those of $\operatorname{random}(\mathrm{x})$ range from -0.1 to 0.1 , thus with a relative error 0.1 for the output. Here relative error means the range of random(x) divided by the range of the functions' output. The number of total records is $600,300,150,100,75,60,40,30,20$, and 15 respectively. Eighty percent of the total records were taken randomly as training data, the remaining $20 \%$ as the testing set for the network. These records were used to model ANNs with a constant 1-3-4-1 architecture, in other words, one input layer with one node, two hidden layers with three and four nodes respectively and one node in output layer.

These functions are shown in Eq.(1) to Eq.(5) and the training data are shown in Figure OT3, OT5, OT7, OT9, and OT11.

Polynomial Function:

$y=x^{2}-1$.

Where $\mathrm{x}$ ranges from 0 to 1.414

Trigonometric Function:

$y=\sin (x)$.

Where $\mathrm{x}$ ranges from 0 to 6.28 .

Fourier No.1 function:

$$
y_{1}=\left\{\begin{array}{l}
-l-x,-l \leq x \leq-\frac{l}{2} \\
x,-\frac{l}{2} \leq x \leq \frac{l}{2} \quad \text { where. } l=1 \\
l-x, \frac{l}{2} \leq x \leq l \\
\mathrm{y}=2 \mathrm{y}_{1}
\end{array}\right.
$$

Fourier No.2 function:

$$
\begin{aligned}
y_{1}=\left\{\begin{array}{l}
\left(\pi-\theta_{1}\right) x, 0 \leq x \leq \theta_{1}-\theta_{2} \\
\frac{\pi}{2}\left(x+\theta_{1}-\theta_{2}\right)-\theta_{1} x, \theta_{1}-\theta_{2} \leq x \leq \theta_{1}+\theta_{2} . .(4) \text { Where } \quad 0<\theta_{2}<\theta_{1}<\frac{\pi}{2}, \\
\theta_{1}(\pi-x), \theta_{1}+\theta_{2} \leq x \leq \pi
\end{array}\right. \\
\mathrm{y}=\mathrm{y} 1 / 1.64
\end{aligned}
$$

Here we choose $\theta_{1}=1$ and $\theta_{2}=0.5$. 
Fourier No.3 function:

$y_{1}=\left\{\begin{array}{l}x(\pi+x),-\pi \leq x \leq 0 \\ x(\pi-x), 0 \leq x \leq \pi\end{array}\right.$.

$\mathrm{y}=\mathrm{y}_{1} / 2.46$

The neural network (Predict Online) used to train and test the synthetic data, generates a $r^{2}$ value that is used to analyze the training/testing cycles. The $r^{2}$ is defined as:

$r^{2}=1-\frac{\sum_{i}\left(x_{i}-y_{i}\right)^{2}}{\sum_{i}\left(x_{i}-\bar{Y}\right)^{2}}$

$\bar{Y}=\sum_{i} y_{i} / n$

$\mathrm{r}^{2}$ indicates the performance of ANNs.

Table OT1 shows the 1-3-4-1 ANN results for $\mathrm{x}^{2}-1$ function with different $\mathrm{r} / \mathrm{w}$, when $\mathrm{r} / \mathrm{w}=1.68$, the network performs well for both training and testing, but when $\mathrm{r} / \mathrm{w}=1.26$, the $\mathrm{r}_{\text {train }}{ }^{2}=1, \mathrm{r}_{\text {test }}{ }^{2}$ rapidly decreases to only about 0.72 . The $\mathrm{ANN}$ is overtrained. All the results are shown in Figs. OT4, OT6, OT8, OT10, and OT12.

\begin{tabular}{|c|c|c|c|c|c|}
\hline \multicolumn{7}{|c|}{ Table OT1 } \\
\hline $\begin{array}{c}\text { No. of train } \\
\text { records }\end{array}$ & $\mathrm{r}_{\mathrm{w}} \mathrm{w}^{*}$-1 Function Results with Different r/w Ratio \\
\cline { 3 - 6 } & Cycles & $\mathrm{r}_{\text {train }}{ }^{2}$ & test & sum \\
\hline 480 & 25.26 & 600 & 0.99175 & 0.99017 & 1.98192 \\
\hline 240 & 12.63 & 800 & 0.98957 & 0.98989 & 1.97946 \\
\hline 120 & 6.32 & 1000 & 0.99167 & 0.98303 & 1.9747 \\
\hline 80 & 4.21 & 1400 & 0.99692 & 0.98123 & 1.97815 \\
\hline 60 & 3.16 & 800 & 0.99335 & 0.98926 & 1.98261 \\
\hline 48 & 2.53 & 1000 & 0.99666 & 0.9707 & 1.96736 \\
\hline 32 & 1.68 & 800 & 1.00000 & 0.98143 & 1.98143 \\
\hline 24 & 1.26 & 600 & 1.00000 & 0.71851 & 1.71851 \\
\hline 16 & 0.84 & 800 & 1.00000 & 0.45852 & 1.45852 \\
\hline 12 & 0.63 & 400 & 1.00000 & -0.00016 & 0.99984 \\
\hline
\end{tabular}

Remarks: ${ }^{*} \mathrm{r} / \mathrm{w}$ is the number of records divided by the number of weights

\section{3-D problem}

The previous methodology was applied to a 2-3-4-1 architecture ANN to study 3D functions. In other words, Predict Online (ANN) with one input layer with two nodes, two hidden layers with three and four nodes respectively and one node in output layer was used to analyze function $\mathrm{z}=\sin (\mathrm{x})+\cos (\mathrm{y})+\operatorname{random}(\mathrm{x})$ and function 
$\mathrm{z}=\sin (\mathrm{x}) * \cos (\mathrm{y})+\operatorname{random}(\mathrm{x})$. The inputs are $\mathrm{x}$ and $\mathrm{y}$ and $\mathrm{z}$ is the output. The training data are shown in Figure OT13 and OT15. Table OT2 shows the 2-3-4-1 ANN results for $\sin (\mathrm{x})+\cos (\mathrm{x})$ function with different $\mathrm{r} / \mathrm{w}$. When $\mathrm{r} / \mathrm{w}=1.45$, the network performs well for both training and testing, but when $\mathrm{r} / \mathrm{w}=0.73$, the $\mathrm{r}_{\text {train }}{ }^{2}=0.999, \mathrm{r}_{\text {test }}{ }^{2}$ decreases to 0.90 and the ANN is overtrained. All the results are shown in Figure OT14 and OT16.

\begin{tabular}{|c|c|c|c|c|c|}
\hline \multicolumn{7}{|c|}{$\operatorname{Sin}(\mathrm{x})+\cos (\mathrm{y})$ Function Results with Different r/w Ratios } \\
\hline \multirow{2}{*}{$\begin{array}{c}\text { No. Of Training } \\
\text { Records }\end{array}$} & $\mathrm{r} / \mathrm{w}^{*}$ & Cycles & $\mathrm{r}_{\text {train }}{ }^{2}$ & Test & Sum \\
\hline 961 & 34.94 & 1600 & 0.99384 & 0.99228 & 1.98612 \\
\hline 320 & 11.64 & 1400 & 0.99429 & 0.99758 & 1.99187 \\
\hline 160 & 5.82 & 600 & 0.98726 & 0.98399 & 1.97125 \\
\hline 80 & 2.91 & 1200 & 0.99539 & 0.99802 & 1.99341 \\
\hline 40 & 1.45 & 1200 & 0.99852 & 0.99237 & 1.99089 \\
\hline 20 & 0.73 & 1200 & 0.99935 & 0.90423 & 1.90358 \\
\hline 10 & 0.36 & 800 & 0.99989 & 0.00000 & 0.99989 \\
\hline
\end{tabular}

Remarks: * r/w is the number of records divided by the number of weights

\section{Conclusion}

Using PredictOnline, more than ten different functions were evaluated to find the minimum $\mathrm{r} / \mathrm{w}$. The numerical experiments with well-defined synthetic datasets demonstrate that to minimize overtraining of 1-3-4-1 neural network, $r / w$ should exceed 2.0 for all tested functions. The implication is that 2.0 is the lower $\mathrm{r} / \mathrm{w}$ limit to minimize overtraining for these $2 \mathrm{D}$ problems. The limited $3 \mathrm{D}$ dataset suggests that $\mathrm{r} / \mathrm{w}>1.0$ maybe necessary to minimize overtraining for the 3D synthetic dataset.

\section{Nash Draw Bulk Volume Oil Predictions}

This procedure is built on the idea that the inclusion of core oil saturation values in log analyses improves the interpretation. It also assumes that statistical parameters can be correlated to production. This poses an inverse problem of correlating between the various logs, the core measured bulk oil and production. The problem can be solved by developing multivariate equations such as those resulting from neural networks.

The correlations were achieved using two sequential networks. The first network was used to correlate the log data with the bulk volume oil and the second to correlate statistical data based on the estimated bulk volume oil with the average monthly production for the first year of production. A destructive design methodology was used to obtain the optimum network architectures. The ratio of the input records to the number of network tie lines was kept above 2:1 to avoid overtraining of the networks.

The two porosity logs and density logs served as inputs to the first network. The reason being a typical suite of logs include the porosity and density logs plus the shallow and deep resistivity logs. The neutron $\log$ is affected by the presence of hydrocarbon; the density log gives a good estimate of the porosity while the shallow and deep resistivity logs provide information on saturations within the formation. A total of 214 output data 
(obtained from cores), averaged over 2-ft intervals, was used to train and test the neural network. Correlations were developed between the four log inputs and the core measured bulk volume oil defined as:

$$
(\mathrm{BVO})_{\text {core }}=\phi \times \mathrm{S}_{\mathrm{o}}
$$

This neural network was highly complex. It had an input layer consisting of 4 nodes, an output layer consisting of a single node and four hidden layers with $6,4,5,2$ nodes respectively. This network trained to a correlation coefficient of $85 \%$ with $100 \%$ of the available data. The finished network was subjected to a validation testing process with $80 \%$ of the available data (Weiss et al., 2001)

The second network was trained and tested using the sum, average and standard deviation of the bulk volume oil from 34 wells. This network was less complex consisting of an input layer with three nodes, an output layer with one node and one hidden layer with four nodes and trained to $86 \%$. The architectures are shown in Fig. BVO-1 and Fig. BVO-2. The training results of the two networks are shown graphically in Fig. BVO-3 and Fig. BVO-4.

The correlations developed were applied to 16 Brushy Canyon wells in the Nash Draw field to estimate the bulk volume oil. The main goal of this process was to validate the efficiency of the trained network to make predictions on other wells. These wells also had sidewall core information that was used to judge the accuracy of the predictions. Some of the results are shown in Fig. BVO-5 and Fig. BVO-6. The goodness of the BVO log prediction in Fig. BVO-6 is especially gratifying since the well is located 30 -miles from the training dataset.

Having validated the network, it was used to estimate the bulk volume oil in 34 Brushy Canyon wells. The statistical properties average, sum and standard deviation of the BVO-log from the 34 wells were used to train the second network. The accuracy of the trained 3-4-1 network (Weiss et al., 2001) can be judged with Fig. BVO-7.

Summarizing, these correlations were achieved using two sequential neural networks. The first network was trained and tested using four inputs, the density and neutron porosity along with the shallow and deep resistivity logs, to correlate with the bulk volume oil $\left(\Phi^{*}\right.$ So $)$ obtained from core analyses. The resulting network was used to estimate BVO for 34 Brushy Canyon wells that were not a part of the training data set. The second network was trained and tested using statistical data; sum, average and standard deviation of the estimated bulk volume oil, to correlate with the average monthly production for the first year the well produced. A cross plot of the estimated production versus the actual production of these wells was then used to evaluate the commercial viability of new wells or reentry completions in the Brushy Canyon.

\section{Regional Predicted Production Potential Map}

In last year's work we accomplished a neural network regression for predicted production potential using regional data. The average of barrels of oil per month (BOPM) in the first year was calculated for each 40-ac bin in the New Mexico portion of the Delaware basin, Brushy Canyon formation. These data were used to generate a map (Fig. RL-1) to highlight potential areas of exploration. This was a major step in the project, however. Neural network analysis necessarily results in a non-crisp solution; examination of the cross-plots in Figs. CI-1 and CI-2 demonstrate that there are potential sources of 
error in the maps, though in general the high cross-correlation means the overall fit is good. Therefore it would be inappropriate to expect that any given drilling locations would produce exactly as mapped, as there are simply too many variables and the algorithm is designed to form generalized solutions, as seen in Fig. CI-3. Our goal is to use this potential oil rate map as the basis for the expert system that will then quantify the risk associated with each prospect by answering questions often posed by human experts exploring in the Brushy Canyon, as well as questions posed by statistical analyses of the data itself. The map and associated database also provide a rich source of valuable heuristic rules for the expert system. A complete summary of the development of this map may be found in the last semiannual report.

\section{Integration of Regional Map with Local Data}

The regional Predicted Potential Map seen in Fig. RL-1 was generated with a neural network trained with derivatives of the regional gravity, thickness, and structure maps as input to a 4-10-10-10-1 neural network, with the initial producing rate of 520 wells as output. The ratio of sample to weights is about $2.1: 1$. The network trained to a $90 \%$ correlation coefficient and tested to $81 \%$. A consortium member operates nine wells in the NE Lea field that produce from an interval about $2500 \mathrm{ft}$ above the Lower Brushy Canyon zone. The production from the upper zone is declining, thus the need to estimate potential production from the LBC zone. The density and neutron porosity logs and the shallow and deep resistivity logs through the LBC zone are available.

The potential for behind-pipe LBC zone production was first evaluated with the Predicted Potential Map. An area zoom of the NE Lea field and the wells of interest is shown in Fig. RL-2. The regional map predicts potential initial production varying from 500-5500 barrels of oil per month.

The density and neutron porosity logs and the shallow and deep resistivity logs through the $\mathrm{LBC}$ zone provide a local dataset to evaluate and compare to the regional map predictions. The Nash Draw 23 bulk volume oil neural network (Weiss et al., 2001) was used to generate pseudo BVO logs through the LBC zone in the NE Lea wells. The statistics of the resulting BVO logs were used as input to the 34-well initial production neural network to predict oil production. The initial production predictions based on the Regional Map are compared to the log based predictions in Table RL-I.

\begin{tabular}{|l|c|c|}
\hline \multicolumn{3}{|c|}{ Table RL-I. First Year Initial Oil Producing Rate, bbl/mo } \\
\hline Well & Regional Map Predictions & Log Predictions \\
\hline Mark Federal \#1 & 3000 & 4486 \\
\hline Union Federal \#1 & 2500 & 4017 \\
\hline Laurie D. Federal \#1 & 500 & 3463 \\
\hline North Lea Federal \#1-Y & 3000 & 1693 \\
\hline North Lea Federal \#2 & 4000 & 1507 \\
\hline North Lea Federal \#3 & 5500 & 1242 \\
\hline Unocal Federal 8 \#1 & 5500 & 1209 \\
\hline Union A Federal\#2 & 3500 & 193 \\
\hline Union Federal A \#1 & 3500 & 0 \\
\hline
\end{tabular}


The predictions are considered to be in reasonable agreement, except for the two Union Federal wells.

\section{Expert System Rules and Development}

Basic design changes. The original design entailed the use of a single massive expert system to make decisions about a prospect's potential as a well site, Fig. CI-4. As we have investigated the process of designing and running expert systems, it has become apparent that a multitiered system, with components running in parallel, would be both more efficient and more versatile in actual usage. Figure CI-5 shows the current design structure for implementing and accessing the various expert systems needed to evaluate production potential. The new design is more efficient for several reasons. First, it will be faster to code the rules and the resulting code will run faster. Second, parallel expert systems will allow the user to consider only the data types they feel are most influential, and ease customization to their personal philosophies. Third, database entry, IO, from the system, will occur in numerous small packets instead of large chunks and extraneous data transfers will be reduced.

Implementation. Figure CI-5 shows the basic layout of the FEE Tool project. Tier 1 is a user interface that allows selection of an area or prospect of interest. Users can select the types of data they are interested in, and can review that data online with their browsers. Tier 2 in Fig. CI-5 represents the access of the user's browser with our online database. Advanced users can manipulate the transferred data for personal use. This data will reside on the user's computer and will not be generally available or affect the permanent database in any way. This allows the use of proprietary information with the system. Once the data is accepted or modified, the next step is to run the appropriate expert systems using the available data to answer heuristic questions and accepting user input to answer other questions that "experts" tend to ask when evaluating Brushy Canyon prospects. In Tier 3, there are five expert systems that can be applied based on user wishes. These address Regional Indications, Trap Assessment, Formation Assessment, Improved Recovery, and Oil Price. Specifics and starting rules for these five systems are discussed below. Some users may elect to not factor in certain aspects, or to hardwire their own values for future oil price.

Types of rules. Two main types of rules are implemented. Heuristic rules are derived directly from our analysis of regional and local data. These rules are interpreted from the data using algorithms, such as distance relationships, and are based on publicly available data. Heuristic rules include elements like proximity of mature source rocks, structural pinchouts, nearest producing well, and formation thickness. We have made progress on developing these rules (Table 1) as they apply to the basic Expert System given.

Expert rules come from interviews with Delaware explorationists and mimic questions they ask when evaluating prospects. Expert rules may include information about position on structure, porosity or permeability ranges, and production at analogous sites. In addition, heuristic rules can be replaced if the user has more detailed knowledge than is publicly available. Both types of rules may be fuzzy, as appropriate. Generally, for sites 
with less information heuristic rules will be more important and will provide a first estimate of production potential. For sites with sufficient specific or proprietary information, expert rules will be dominant. Two new explorationists have volunteered to be interviewed as a result of our recent annual meeting.

\section{Current State of Rules Development}

Broken down by subsection, the following paragraphs outline the initial rules already coded into the Expert System and the methods for evaluating each prospect based on database and user supplied information.

\section{$\underline{\text { Trap Analysis }}$}

\section{Proximity Query}

Question: Is the prospect located within five miles of established production in the Brushy Canyon?

Answer supplied by the Database and is the basis for a "first guess"

This "first guess" is distance weighted using a normalized step function (Fig CI-6)

Two possible results from this query

RULE: No, the prospect is not within five miles, resulting in a zero starting estimate

Passes to Oil Show Query

RULE: Yes, it is within five miles, resulting in 1.0, 0.8, 0.4, or 0.2 starting estimate

Passes to Dip Query

\section{Oil Show Query}

Is the prospect within two miles of a verified oil show?

Answer is from user input.

Possible results are yes, or no.

RULE: Yes results yields a starting guess based on the step function (Fig CI-7)

RULE: No, results in initial starting guess of 0.05

Both pass to Dip Query

\section{Dip Query}

Question: Is the established production downdip from the prospect?

Engine searches the database to determine if the prospect is at lower, or higher structural elevation, further queries if there is structural highs or lows between the two points (see Fig CI-8)

Three cases are analyzed, updip, downdip, unrelated structure RULE: Updip-Prospect is enhanced by taking $\sqrt{ }$ (initial closeness value) RULE: Downdip - Prospect is reduced by taking (initial closeness value) ${ }^{2}$ Passes to Magnitude of Dip Query 
RULE: Unrelated structure -- prospect is neither upgraded or downgraded

Passes to Sand Thickness Updip Query

\section{Magnitude of Dip (preliminary)}

Question: What is the magnitude of the dip?

Answer supplied by database using simple rise/run relationship (maximum dip)

Six possible fuzzy rules available

RULE: High updip, enhance by taking cube root

RULE: Moderate updip, enhance by taking square root

RULE: Low updip, no change

RULE: High downdip, reduce by cubing

RULE: Moderate downdip, reduce by squaring

RULE: Low downdip, no change

All pass to Sand Thickness Query

\section{Sand Thickness Query}

Question: What is the thickness of pay sand (phi > 15\%) at the prospect?

Answer supplied by database

Several answers possible (fuzzy ranges)

RULE: Thick, $>75 \mathrm{ft}$ net porous sand thickness, enhance by taking cube root

Passes to Updip Pinchout Query

RULE: Mod. thick, 50 to $75 \mathrm{ft}$ net porous sand, enhance by taking square root

Passes to Updip Pinchout Query

RULE: Average, 25 to $50 \mathrm{ft}$ net porous sand, do not enhance

Passes to Updip Pinchout Query

RULE: Low, $<25 \mathrm{ft}$ net porous sand, reduce prospect by squaring.

\section{Updip Pinchout Query}

Question: Within 1 mile updip does the sand thin to $15 \mathrm{ft}$ or less?

Database supplied answer. Along maximum dip azimuth from the prospect.

Three results possible:

RULE: Yes, enhance prospect by square root

RULE: No, thickness increases, decrease prospect by squaring

RULE: No, no change, prospect unaffected

All pass to Structural Strike Query

\section{Structural Strike Query}

Question: Is the prospect on a structural strike? 
User-supplied result (pop-up map of structure)

Two possible results

Rule: Yes, enhance prospect by square root

Rule: No, decrease prospect by square

Ends TRAP ASSESSMENT

\section{Source Analysis}

\section{TOC Proximity Query}

Question: Are there TOC $>5 \%$ rocks present within 5 miles of the prospect?

Two possible results from database search and values assigned based on the chart shown in Fig CI-10.

RULE: Source value set to 0.25, move to END SOURCE ANALYSIS

RULE: Yes, advance to Dip Query after assigning values from chart.

\section{Dip Query}

Question: Is the prospect updip of the heightened TOC?

Engine searches the database to determine if the prospect is at lower, or higher structural elevation, further queries if there is structural highs or lows between the two points 3 cases are analyzed, updip, downdip, unrelated structure RULE: Updip - Prospect is enhanced by taking $\sqrt{ }$ (initial closeness value) Passses to Structural Strike Query RULE: Downdip_-Prospect is reduced by taking (initial closeness value) ${ }^{2}$ Passes to END SOURCE ANALYSIS

RULE: Unrelated structure -- prospect is neither upgraded or downgraded Passes to Structural Strike Query

\section{Structural Strike Query}

Question: Is the prospect on a structural strike?

User-supplied result (pop-up map of structure)

Two possible results

RULE: Yes, enhance prospect by square root

RULE: No, prospect is unaffected

Ends TRAP ASSESSMENT 


\section{$\underline{\text { Regional Analysis }}$}

\section{Neural Network Map Query}

Question: What is the estimated potential production at the location based on the neural network-generated production potential map?

Database provided answer, following stepchart Fig C-10:

RULE: High, production potential at site is assigned a value of 0.8

RULE: Medium, production potential is assigned a value of 0.5

RULE: Low, production potential is assigned a value of 0.2

All pass to Net Pay Thickness Query

\section{Net Pay Thickness Query}

Question: What is the estimated net pay thickness (sandstone $>15 \%$ porosity) at the prospect?

Database provided answer, 4 possible results:

RULE: 0-50ft, prospect is reduced by squaring

RULE: $50-100 \mathrm{ft}$, prospect is neither enhanced or degraded

RULE: $100-150 \mathrm{ft}$, prospect enhanced by square root

RULE: $>150 \mathrm{ft}$, prospect enhanced by cube root

All pass to Structural Query

\section{Structural Query}

Question: Is the prospect on a local structural anomaly?

User-provided, pop-up map shows residual structure (regional structure less regional structural trend). Three possible results:

RULE: Prospect is near top of local structure, enhance by square root

Pass To Gravity Query

RULE: Prospect is on local structure, do not enhance

Pass To Gravity Query

RULE: Prospect is not on local structure, degrade by squaring

\section{Gravity Query}

Question: Does gravity support the structural query?

User-provided, pop-up map shows regional gravity anomaly and residual maps, two possible results

RULE: Yes, enhance prospect by square root

RULE: No, do not enhance 


\section{END REGIONAL ANALYSIS}

Scoring of rules. Each of the subexpert systems will assign a numerical score based on the answers to individual questions as outlined in the previous section. These will be tuned as the expert system is tested on wells outside the database. As each subprocess in figure $\mathrm{X}$ results in a numerical value for Risk, an overall evaluation is required, at this stage the user's value for oil price, or our projection is also factored in using a weighted sum of the individual risk components:

Risk $=[\mathrm{r}(\mathrm{R})(\mathrm{W})+\mathrm{r}(\mathrm{T})(\mathrm{X})+\mathrm{r}(\mathrm{F})(\mathrm{Y})+\mathrm{r}(\mathrm{E})(\mathrm{Z})] * \mathrm{r}(\mathrm{O})$ Where $\mathrm{W}+\mathrm{X}+\mathrm{Y}+\mathrm{Z}=100 \%$, and where $\mathrm{r}(\mathrm{O})$ is a scaling factor based on oil price

\section{Heuristic Rules}

One source of rules for the Fuzzy Expert Exploration Tool is the statistical analyses of gridded data in our databases. Currently the regional database has four basic data types for the Brushy Canyon: gravity, aeromagnetic, structure, and thickness. An additional eight attributes for each of those four basic types has been calculated: DX, DY, DX2, DY2, dip azimuth, dip magnitude, curvature azimuth, and curvature magnitude. Additional data include location information in latitude/longitude, oilfield X-Y coordinate systems, and a numeric grid number that also functions as a database key. Additionally, in grids that contain a Brushy Canyon well, there is relevant production information for oil, water, and gas. One factor that complicates working with the databases is the fact that the grid is not square: rather, it runs linearly from north to south increasing by integer amounts from the top of the study area to the bottom. The grid then steps over to the next "column." Each gridpoint is separated by a physical distance of $1320 \mathrm{ft}$ that corresponds to an area of 40 acres contained by four adjacent (squared) gridpoints. The gridding system looks something like this:

081318

0409141923

01051015202427

02061116212528

03071217222629

The primary use of the regional database thus far has been to organize the regional data, determine which bins contain production information, and then to calculate a "first guess" map of production potential using the data with the highest fuzzy rank to predict production. With this "first guess" map we enter a new phase, where we want to evaluate the risk associated with these predictions. To do this we are using an expert system programmed in Jess and designed to ask the same sort of questions a human explorationist would, when looking at a prospect. "Is it high on structure? Where is it in the basin? Are there stratigraphic traps; is it close to other producing wells?" A lot of these questions can be answered directly from the database itself, and indeed have been built into a separate table that speeds the process of examining a prospect. This work has been completed for the trap assessment phase and a summary of the additional tabulated heuristic rules can be found in subsequent paragraphs and are summarized in Table CI-1 
The trap assessment portion of the fuzzy expert system is designed to assign a value representing potential to each point in a database of locations in the New Mexico Delaware basin. The database consists of 60,478 grid points, coordinates in UTM feet and Lat-Lon, and geological data measured at each of the points. Other information available about the region included a listing of all of the producing wells in the region through 1999 and a subset of that list with wells that were known to produce out of the Brushy Canyon formation. The end result of the trap assessment phase of the fuzzy expert system is a number (fuzzy membership function) calculated from a combination of user supplied inputs and data from the database. The values of the output range from zero to one, with numbers close to one indicating a spot with a high potential for producing oil.

\section{Distance to nearest producing well}

The distance to the nearest producing well provides the initial value for the potential estimate. The distance to each well and the minimum were computed using Matlab and Excel. For each grid point, this minimum distance was noted, along with the location of the closest producing well. A step function was used to assign a value for the initial potential estimate. Values of $\mu=0.8$ to $\mu=0.05$ were used with a higher value representing a grid point within 1320 feet of a producing well, and the lowest value representing a grid point over five miles from the nearest producing well. Once the initial value was obtained for all 60,478 data points, it is ready to be enhanced or reduced based on various Expert Knowledge such as dip direction and magnitude, thickness of the producing sand and up-dip sand pinchout.

\section{Dip}

For each grid point and its closest neighboring producer, the dip was calculated using the values for subsea elevation found in the database of geological data. The values computed can be used to modify the starting estimate by either enhancing, reducing or leaving the starting estimate unchanged. For instance, if the grid point was up dip from the producing well, the prospect is enhanced. The grid points are then flagged with a $2,1,0,-1$ or -2 , indicating a strong enhancement, a moderate enhancement, no change, a moderate reduction, or a strong reduction. This flag can then be used to modify the starting estimate that came from the distance computations in the previous section. An example of how this modification is currently done is to take a root to enhance a number and using a power to reduce a number. Since the initial estimates are between 0 and 1, taking a square root or cube root will result in a larger number that remains between 0 and 1 , while raising the number to the $2^{\text {nd }}$ or $3^{\text {rd }}$ power will result in a smaller estimate that also remains between 0 and 1 . Other possible methods of enhancing or reducing the estimate are under consideration, such as adding or subtracting a constant. This is an area where expert input is extremely valuable, to help judge the significance of concepts like dip in predicting the potential of a prospect.

\section{Sand Thickness}

Further modification to the estimate is done by looking at the thickness of the Brushy Canyon sands at the grid point. This is data that is provided in the database, and four 
flags are currently being used here, $2,1,0$, and -1 , with the same meanings as above. The cutoff values in feet for the different flags were based on the mean and standard deviation of the sand thickness provided in the database.

\section{Sand Pinchout}

Software has been developed to look at each point and find the coordinates in UTMfeet for its eight neighboring points. The dip between the point and all of its neighbors was computed, unless the point was located on a boundary of the study area, in which case there was no change made to the estimate. Once the eight dips had been computed, the neighboring point with maximum dip from the original grid point was examined for sand pinchout. If the thickness at this particular point was found to be less than 15 feet, a flag of 1 was added to the database for this point, suggesting that a sand pinchout and thus, an enhanced potential was found. If the thickness at this particular neighboring point was actually greater than the thickness at the grid point in question, the potential was flagged with $\mathrm{a}-1$, suggesting a reduction in potential. If neither case was true, the value was left unchanged at this step. As before, the suggested method for enhancing or reducing the estimate is to use roots or powers, however, other methods may also be applied.

5. User-Supplied Data

At various points in this process, the user of the fuzzy expert system can supply data of their own, or data obtained by looking at a pop-up map of the region. For instance, in developing the starting estimate, the user can consider oil shows as well as the known producers that were used to develop the initial values. A step function similar to that for distance to producing wells has been developed for distance to oil shows, and can be used to find a slightly higher starting estimate when the grid point is more than five miles from any producing oil well.

Table CI-1

\begin{tabular}{|l|l|l|}
\hline & Data returned & Procedure \\
\hline Distance & $\begin{array}{l}\text { Initial value of } \\
\text { membership } \\
\text { function } \mu, \\
(0<\mu<1)\end{array}$ & $\begin{array}{l}\text { Compute distance from each gridpoint to nearest } \\
\text { producing well, using 2257 known producing wells with } \\
\text { coordinates in UTM feet using the standard distance } \\
\text { function. Use minimum distance in a step function to } \\
\text { return a value from between 0.8 to 0.05, with 0.8 } \\
\text { representing a gridpoint within 1320 feet from a } \\
\text { producing well. }\end{array}$ \\
\hline Dip & $\left.\begin{array}{l}\text { Enhancement } \\
(\text { flag:-2, }\end{array}-1,0,1,2\right)$ & $\begin{array}{l}\text { Determine which of the wells in the previous computation } \\
\text { was the closest well to the gridpoint. Use subsea elevation } \\
\text { at the closest well and the gridpoint to determine the dip. } \\
\text { If the gridpoint is updip, enhance the value and flag with a } \\
\text { 2 a 1 depending on the magnitude of the dip. If } \\
\text { downdip, degrade the value. Methods to enhance or } \\
\text { degrade the value might involve taking a square root or a } \\
\text { cube root to enhance, or squaring or cubing the value to } \\
\text { reduce it. A flag is returned instead of a new value in } \\
\text { order to explore other possibilities of enhancing/reducing }\end{array}$ \\
\hline
\end{tabular}




\begin{tabular}{|l|l|l|}
\hline Thickness & $\begin{array}{l}\text { Enhancement } \\
\text { (flag: }-1,0,1,2)\end{array}$ & $\begin{array}{l}\text { the value. } \\
\text { The thickness is computed using the thickness of the } \\
\text { Brushy Canyon sand values found in the database. To find } \\
\text { cutoff values, the mean and standard deviation of the } \\
\text { thickness were used as a basis with a thickness of over } \\
200 \mathrm{ft} \text { resulting in a flag of 2. Similar methods for } \\
\text { enhancing or reducing may be used here. }\end{array}$ \\
\hline $\begin{array}{l}\text { Sand } \\
\text { Pinchout }\end{array}$ & $\begin{array}{l}\text { Enhancement } \\
\text { flag: }-1,0,1)\end{array}$ & $\begin{array}{l}\text { For each gridpoint, the coordinates of its eight } \\
\text { neighboring points were computed. If a gridpoint had all } \\
\text { eight neighbors, i.e., it was not on the boundary, then the } \\
\text { neighbor with maximum updip from the original point } \\
\text { was found. If the thickness at this point was less than 15 } \\
\text { feet, a sand pinchout is suggested resulting in an enhanced } \\
\text { potential and a flag of 1. If the thickness at this point is } \\
\text { greater than the thickness of the original gridpoint, a } \\
\text { reduction in potential is suggested, resulting in a flag of }- \\
\text { 1. If neither case is true, the value remains unchanged. }\end{array}$ \\
\hline
\end{tabular}

An example prospect:

- 3900 feet to nearest producing well (initial value 0.4 from Fig CI-7)

- Prospect is moderately updip of producer

- Sands are moderately thick (63 ft)

- No updip pinchout

- Is on structural strike

yields the following result:

$$
R(T)=\sqrt{ }(\sqrt{ }(\sqrt{ }(0.4)))=89 \%
$$

A decent risk assuming predicted production supports.

A second example prospect:

- $1300 \mathrm{ft}$ from oil show (initial value of 0.5 from Figure CI-8)

- Prospect is moderately downdip

- Sand thickness is low (20 feet)

- No Updip Pinchout exists

- On structural strike

yields the following result:

$$
R(T)=\sqrt{ }(((0.5) 2) 2)=25 \%
$$

A poor risk even if predicted production supports the prospect.

Progress on a Graphical user interface for the system is progressing. 


\section{$\underline{\text { Devonian Work }}$}

\section{Siluro-Devonian Carbonates}

Devonian and Siluro-Devonian carbonates produce from numerous oil and gas fields in southeastern New Mexico (Fig. D-1). The 122 Siluro-Devonian fields in southeast New Mexico had produced a cumulative 443 MMBO by 1995 (Broadhead and Speer, 1995) 10\% of the oil produced from southeast New Mexico. Production is from a number of zones within the Silurian and Devonian sections (Fig. D-2). A variety of mechanisms form traps, most notably anticlines, faulted anticlines, and subunconformity pinchouts (Speer, 1993).

Geologic data acquisition continued on the Siluro-Devonian carbonates during the reporting period. During the previous reporting period, 1600 wells in southeast New Mexico that have penetrated the Devonian (Fig. D-3) were identified and entered into a database; longitude and latitude have been calculated for these wells. During the present reporting period, a regional network of cross sections was constructed in order to establish correlation control and to provide quality assurance of data. Logs from a total of 220 wells were correlated throughout southeast New Mexico. Correlated wells were selected from all productive Siluro-Devonian fields and non-productive areas as well, in order to provide a dataset that fully contrasts productive areas with non-productive areas. In each well, the top of the Siluro-Devonian carbonate section was correlated in addition to the top of the Fusselman Formation and the top of the Montoya Formation. Several prominent marker beds within the Siluro-Devonian section were correlated as well.

Similar to our earlier work on the Brushy Canyon Formation, we used our correlated data to produce geologic structure maps (Fig. D-4), and isopach (thickness) maps (Fig. D-5) of Siluro-Devonian carbonate strata. We will relate these to production/nonproduction in both visual and artificial intelligence settings. The goal is to use our artificial intelligence system to predict trap configurations in Devonian strata.

\section{$\underline{\text { Oil Price Forecast }}$}

\section{Current Objective}

Earlier work with small datasets suggested that correlations between the future price of commodities and oil price might exist. An investigation is in progress to determine if traders in commodities other than oil might actually be excellent forecasters of oil price. About 69 commodities had their 90-day futures prices fuzzy-ranked to investigate their relationship of the price of oil to the commodity strike date. If the future commodity price varied regularly with the real oil price on the strike date a correlation should be evident. The dataset broke down into 14 groups, each with a large number of commodities; because there was considerable overlap, many commodities ended up in more than one group.

The 90-day commodity future price data begin and end at different dates, but it is necessary to place the commodities with the same start and end dates in the same group and fuzzy-rank them together. This is unlike the conventional correlation, where one-onone tests for correlation were conducted between the future closing price of the 
commodity in question and that of west Texas intermediate-grade crude oil. As a result, all the data underwent conventional correlation, but not all commodities could be fuzzyranked. The top fuzzy-ranked commodity in each group was determined.

The top three 90-day commodities, which were silver (Comex), heating oil (Nymex), and silver (1000 Ounce-Cbot) selected from one of the most promising fuzzyranked groups, had their future closing prices used as input to PredictOnline, with the real oil price on the strike date as the output. The training results were poor, indicating no strong correlations existed. The top three commodities from the conventional correlation list, taken together, had too little data to develop correlations using PredictOnline.

It was necessary to select three other commodities with sufficient data to use in PredictOnline. The accuracy of the conventional correlations (x-y plot) of the future closing prices of unleaded gasoline (Nymex), GSCI (IOM), and heating oil (Nymex) to the price of the west Texas intermediate grade crude oil three months in the future, was $74 \%, 72 \%$ and $67 \%$ respectively, as defined by $\mathrm{R}^{2}$. These three 90 -day commodities prices served as neural network input with the price of the west Texas intermediate grade crude oil on the strike date as the output. The network trained to an $\mathrm{R}^{2}$ of 0.91906 . The result is interesting (but not overly), because of the obvious relationship of two of the commodities namely, gasoline and heating oil, to crude oil.

The future closing prices of the top conventionally ranked commodities with no clear connection to crude oil served as input for the neural network. The $\mathrm{R}^{2}$ of the Dow Jones (E)(CBOT), E-Mini S\&P (IOM), and pound/yen (Finex) were $86 \%, 79 \%$ and $73 \%$ respectively. These were put through the PredictOnline software, which correlated them to crude oil with an $\mathrm{R}^{2}$ of $99 \%$. The neural network developed with these three commodities is appropriate for blind testing with data not used in the development of the 3-1-1 network architecture. It is necessary to download additional data from www.barchart.com to use for blind testing. Since the commodity datasets are small, blind testing will be very important.

\section{Technology Transfer}

During this six-month period (April 20021-September 2002) the following six papers or presentations were made to disseminate the results of the project:

1. Weiss, W. W., Balch, R.S., and Stubbs, B.A.: "How Artificial Intelligence Methods Can Forecast Oil Production," paper SPE 75143 presented at the 2002 Symposium on Improved Oil Recovery, Tulsa, April 13-17.

2. Balch, R.S., Hart, D.M. and Weiss, W. W.: "Regional Data Analysis to Better Predict Drilling Success: Brushy Canyon Formation, Delaware Basin New Mexico," paper SPE 75145 presented at the 2002 Symposium on Improved Oil Recovery, Tulsa, April 13-17.

3. Balch, R.S., Hart, D.M., Weiss, W.W., Broadhead, R.F.: "Using Artificial Intelligence to Predict Drilling Success Using Regional Data, Brushy Canyon Formation, Delaware Basin, New Mexico," Transactions, Southwest Section A.A.P.G Convention, Ruidoso, NM June 6-8, 2002.

4. Subramaniam V., and Weiss, W.W.: "Evaluation of Well Completion Opportunities in the Lower Brushy Canyon Using Neural Networks," Transactions, Southwest Section A.A.P.G Convention, Ruidoso, NM June 6-8, 2002. 
5. Weiss, W.W.: "Reducing the Risk of Installing a Waterflood," Presented at the Annual Petroleum Engineering Summer School, Workshop No. 11 Risk Minimization and Probabilistic Application in the Petroleum Industry, Dubrovnik, Croatia, 10-14 June, 2002.

6. Weiss, W. W., Gottumukkala, V., and Balch, R.S.: “A New Method of Calibrating Wireline Logs With Carbonate Core Measurements to Recognize Pay Zones," Paper 77330 presented at the SPE Annual Technical Conference, San Antonio, TX Sept 29, 2002.

Additionally, five companies have asked specifically for information on areas of the Predicted Potential map. Zooms of these areas were generated for Strata Production Company, Bass Enterprise Production Company, Reed and Stevens Inc., Speerex Ltd., and Lynx Petroleum Consultants Inc.

\section{Problems Encountered}

The acquisition of regional seismic lines continues to be a problem due to the value of the data. Local datasets are available such as those from the DOE-funded Nash Draw project. The processed data from this $3 \mathrm{D}$ data set was used to develop new methods of interpreting the distribution of thickness, porosity, water saturation and depth throughout the survey area. The methodology can be applied throughout the Delaware Basin.

Coding of the required web interface algorithms has been an ongoing problem. New graduate students in place six months ago at the time of the semi-annual have departed. Currently, REACT group professionals are educating themselves in JAVA and are continuing development in what should be a more sustainable fashion.

\section{Next Year's Tasks}

\section{Continue Expert System Development}

Currently the Expert System has been programmed to use some basic rules in several different categories. About 100 rules are in the current version; this preliminary system can be run on a laptop computer and will be of great assistance in giving human explorationists a feel for the system. Work is ongoing in numerically grading questions.

\section{$\underline{\text { Log Analysis }}$}

As Devonian log information becomes available it will be correlated with core data to develop pseudo-logs. Production will then be correlated with the pseudo-log statistics.

\section{Geology}

Regional maps of source rocks will be constructed. The chief source rock unit is the Devonian Woodford shale, which directly overlies the Devonian carbonates (Fig. D2). The Silurian Simpson shales are source rocks that underlie the Siluro-Devonian 
carbonate section. The Woodford is thought to be the chief source unit for lower Paleozoic reservoirs in the Permian Basin and the Simpson is a secondary but still important source unit. ${ }^{7,8}$ As with the Brushy Canyon, we will map regional distributions of source rock maturity and quality and relate these to oil and gas distribution. With the depth of the Woodford varying from less than $7000 \mathrm{ft}$ in the northern part of the basin in Chaves County to more than 15,000 ft in the southern part in Lea and Eddy Counties, we expect to encounter thermal maturity variations across the oil window/gas window boundary that will relate to the distribution of oil reservoirs and gas reservoirs. The map of Siluro-Devonian oil and gas fields (Fig. D-1) indicates that most gas fields are located in the more deeply buried southern parts of the basin where thermal maturity of source rocks should be higher. These relationships will be quantified for use in the artificial intelligence system. Thermal maturity variations may also help in the prediction of gasoil ratios and therefore relate to aspects of recovery efficiency.

\section{Oil Price Forecast}

Additional data from www.barchart.com will be purchased for blind testing. Since the commodity datasets are small, blind testing will be an important step in predicting oil price from commodity futures.

\section{References}

Asquith, G.B., M.D. Thomerson, and M.D. Arnold, 1996, Recognition of possible oil and water wettability changes in the Permian Delaware Mountain Group sandstones from petrophysical well logs, , in W.D. DeMis and A.G. Cole, eds., The Brushy Canyon play in outcrop and subsurface: concepts and examples: Permian Basin Section SEPM, Publication 96-38, pp. 153-171.

Basham, W.L., 1996, Delaware Mountain Group sandstone channel orientations: implications for sediment source and deposition, in W.D. DeMis, and A.G. Cole, eds., The Brushy Canyon play in outcrop and subsurface: concepts and examples: Permian Basin Section SEPM, Publication 96-38, pp. 91-102.

Broadhead, R.F., F. Luo, and S.W. Speer, 1998, Oil and gas resources at the Waste Isolation Pilot Plant (WIPP) site, Eddy County, New Mexico: New Mexico Bureau of Mines and Mineral Resources, Circular 206, pp. 3-72.

Broadhead, R.F., and Speer, S.W., 1995, Oil and gas fields in the New Mexico part of the Permian Basin, in: A symposium of the oil and gas fields of Southeastern New Mexico, (1995 supplement): Roswell Geological Society, 32-49.

Dickerson, P.W., 1985, Evidence for Late Cretaceous - Early Tertiary transpression in Trans-Pecos Texas and adjacent Mexico, in P.W. Dickerson, and W.R. Muehlberger, eds., Structure and tectonics of Trans-Pecos Texas: West Texas Geological Society, Publication 85-81, pp. 185-194. 
Dow, W.D., Talukdar, S.C., and Harmon, L., 1990, Exploration applications of geochemistry in the Midland Basin, Texas (abstract): American Association of Petroleum Geologists, Bulletin+, v. 74, pp. 644-645.

Garber, R.A., G.A. Grover, and P.M. Harris, 1989, Geology of the Capitan shelf margin subsurface data from the northern Delaware Basin, in P.M. Harris, and G.A. Grover, eds., Subsurface and outcrop examination of the Capitan shelf margin, northern Delaware Basin: SEPM Core Workshop no. 13, pp. 3-269.

Gardner, M.H., 1997, Sequence stratigraphy and hydrocarbon habitat of the Permian (Guadalupian) Delaware Mountain Group, Delaware Basin, west Texas, in R.P. Major, ed., Oil and gas on Texas state lands: an assessment of the resource and characterization of type reservoirs: Bureau of Economic Geology, University of Texas at Austin, Report of Investigations No. 241, pp. 147-157.

Gawloski, T., 1995, Geronimo Delaware, in Oil and gas fields of southeastern New Mexico, 1995 supplement: Roswell Geological Society, pp. 225-226.

Grauten, W.F., 1979, Fluid relationships in Delaware Mountain sandstone, in N.M. Sullivan, ed., Guadalupian Delaware Mountain Group of west Texas and southeast New Mexico, 1979 symposium and field conference guidebook: Permian Basin Section Society of Economic Paleontologists and Mineralogists, Publication 79-18, pp. 191-204.

Harms, J.C., 1974, Brushy Canyon Formation, Texas: a deep-water density current deposit: Geological Society of America, Bulletin, v. 85, pp. 1763-1784.

Harms, J.C., and C.R. Williamson, 1988, Deep-water density current deposits of Delaware Mountain Group (Permian), Delaware Basin, Texas and New Mexico: American Association of Petroleum Geologists, Bulletin, v. 72, pp. 299-317.

Harms, J.C., and M.J. Brady, 1996, Deposition of the Brushy Canyon Formation: 30 years of conflicting hypotheses, in W.D. DeMis, and A.G. Cole, eds., The Brushy Canyon play in outcrop and subsurface: concepts and examples: Permian Basin Section SEPM, Publication 96-38, pp. 51-59.

Hays, P.D., and T.T. Tieh, 1992, Organic geochemistry and diagenesis of the Delaware Mountain Group west Texas and southeast New Mexico, in D.W. Cromwell, M.T. Moussa, and L.J. Mazzullo, eds., Transactions Southwest Section American Association of Petroleum Geologists, 1992 convention: Southwest Section American Association of Petroleum Geologists, publication SWS 92-90, pp. 155-175.

Hills, J.M., 1963, Late Paleozoic tectonics and mountain ranges, western Texas to southern Colorado: American Association of Petroleum Geologists, Bulletin, v. 47, pp. 1709-1725. 
Hills, J.M., 1984, Sedimentation, tectonism, and hydrocarbon generation in Delaware Basin, west Texas and southeastern New Mexico: American Association of Petroleum Geologists, Bulletin, v. 68, pp. 250-267.

Hoose, G., and G. Dillman, 1995, Sand Dunes Delaware, W: Sand Dunes Delaware, S, in Oil and gas fields of southeastern New Mexico, 1995 supplement: Roswell Geological Society, pp. 325-328.

Hull, J.P., 1957, Petrogenesis of Permian Delaware Mountain sandstone, Texas and New Mexico: American Association of Petroleum Geologists, Bulletin, v. 41, pp. 278-307.

Jacka, A.D., R.H. Beck, L.C. St. Germain, and S.C. Harrison, 1968, Permian deep-sea fans of the Delaware Mountain Group (Guadalupian), Delaware Basin, in B. Silver, ed., Guadalupian facies, Apache Mountain area, west Texas: Permian Basin Section SEPM, Publication 68-11, pp. 49-90.

Katz, B.J., Dawson, W.C., Robison, V.D., and Elrod, L.W., 1994, Petroleum system of the Central Basin Platform, West Texas, U.S.A., in: Magoon, L.B., and Dow, W.G., eds., The petroleum system from source to trap: American Association of Petroleum Geologists, Memoir, v. 60, pp. 453-461.

LeMar, D., 1995, Loving Brushy Canyon, East, in Oil and gas fields of southeastern New Mexico, 1995 supplement: Roswell Geological Society, pp. 283-286.

Lindsay, R.F., 2001, Meteoric recharge, displacement of oil columns and development of residual oil intervals in the Permian Basin (abstract); American Association of Petroleum Geologists, Official program book for 2001 annual convention, p. A118.

May, B., 1996, Geology and development history of the Livingston Ridge and Lost Tank Delaware pools, southeastern New Mexico, in W.D. DeMis, and A.G. Cole, eds., The Brushy Canyon play in outcrop and subsurface: concepts and examples: Permian Basin Section SEPM, Publication 96-38, pp. 113-118.

Mitchell, S.T., 1995, Nash Draw Brushy Canyon, in Oil and gas fields of southeastern New Mexico, 1995 supplement: Roswell Geological Society, pp. 297-300.

Montgomery, S.L., J. Worrall, and D. Hamilton, 1999, Delaware Mountain Group, west Texas and southeastern New Mexico, a case of refound opportunity: Part 1 - Brushy Canyon: American Association of Petroleum Geologists, Bulletin, v. 83, pp. 1901-1926.

Payne, M.W., 1976, Basinal sandstone facies, Delaware Basin, west Texas and southeast New Mexico: American Association of Petroleum Geologists, Bulletin, v. 60, pp. 517527. 
Read, A., Broadhead, R., Lopez, A., Fleming, E., and Watrous, J., 2000, New Mexico oil and gas pool maps: New Mexico Bureau of Mines and Mineral Resources, Circular 209.

Robinson, K., 1993, -- Region 5, west Texas and eastern New Mexico, in R.B. Powers, ed., Petroleum exploration plays and resource estimates, 1989, onshore United States: U.S. Geological Survey, Open-file report 93-522, pp. 11-12.

Spain, D.R., 1992, Petrophysical evaluation of a slope fan/basin-floor fan complex:

Cherry Canyon Formation, Ward County, Texas: American Association of Petroleum Geologists, Bulletin, v. 76, pp. 805-827.

Speer, S.W., 1993, PP-6; Siluro-Devonian, in: Atlas of major Rocky Mountain gas reservoirs: New Mexico Bureau of Mines and Mineral Resources, 163.

Thomerson, M.D., and L.E. Catalano, 1996, Depositional regimes and reservoir characteristics of the Brushy Canyon sandstones, east Livingston Ridge Delaware field, Lea County, New Mexico; in W.D. DeMis, and A.G. Cole, eds., The Brushy Canyon play in outcrop and subsurface: concepts and examples: Permian Basin Section SEPM, Publication 96-38, pp. 103-111.

Tittl, J.S., 1995, Herradura Bend Delaware East, in Oil and gas fields of southeastern New Mexico, 1995 supplement: Roswell Geological Society, pp. 235-238.

Weiss, W.W. and Broadhead, R.F., 2002, Risk reduction with a fuzzy expert exploration tool, third annual technical progress report: U.S. Department of Energy ,Contract No. DE-AC-26-99BC15218.

Weiss, W.W. and Broadhead, R.F., 2001, Risk reduction with a fuzzy expert exploration tool, second annual technical progress report: U.S. Department of Energy, Contract No. DE-AC-26-99BC15218.

White, D., 1995, Los Medanos Delaware, in Oil and gas fields of southeastern New Mexico, 1995 supplement: Roswell Geological Society, pp. 275-278.

Worrall, J., 1995, Hat Mesa Delaware, in Oil and gas fields of southeastern New Mexico, 1995 supplement: Roswell Geological Society, pp. 275-278. 


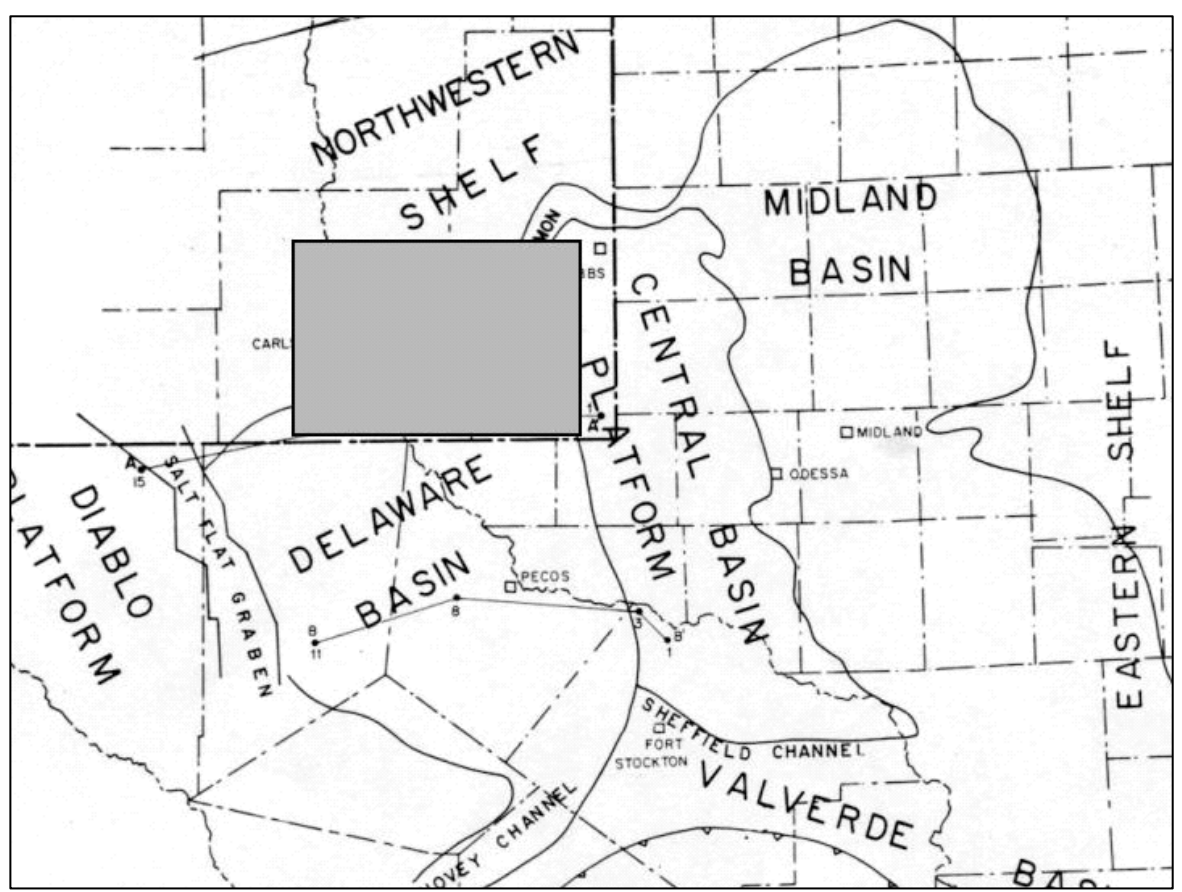

Fig. BC1. Location of project area in relation to Delaware Basin and other geologic elements, Permian Basin area southeast New Mexico and west Texas. Geologic elements modified from Hills (1984).

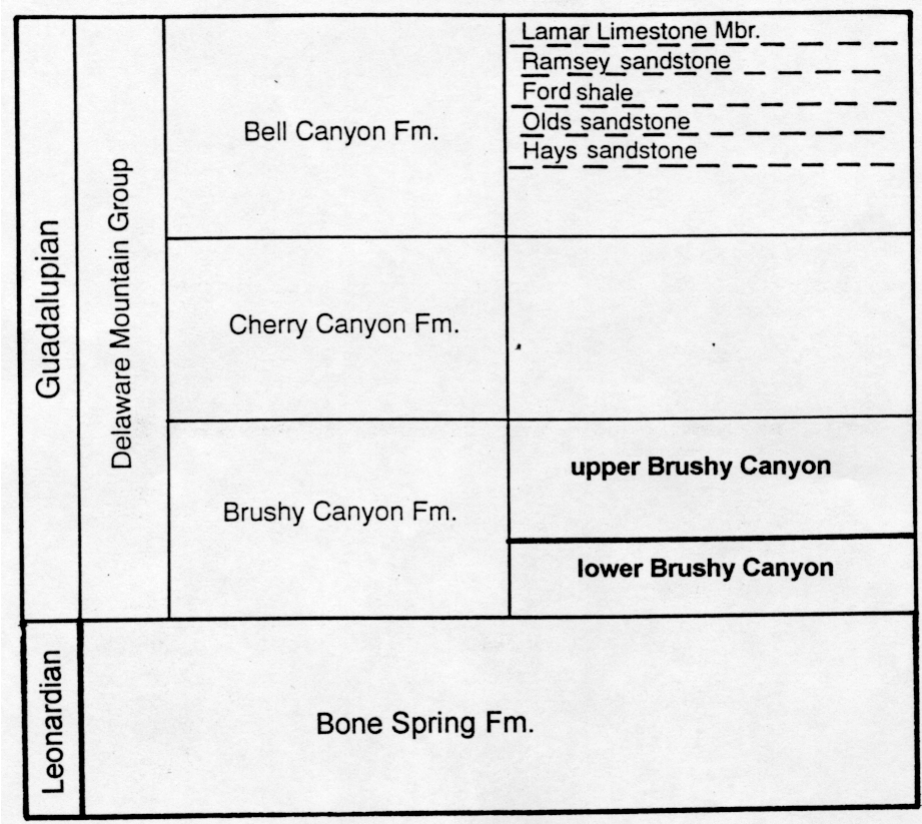

Fig. BC2. Stratigraphic chart of Delaware Mountain Group. Compiled from Payne (1976), Grauten (1979), Harms and Williamson (1988), and Montgomery et al. (1999). 


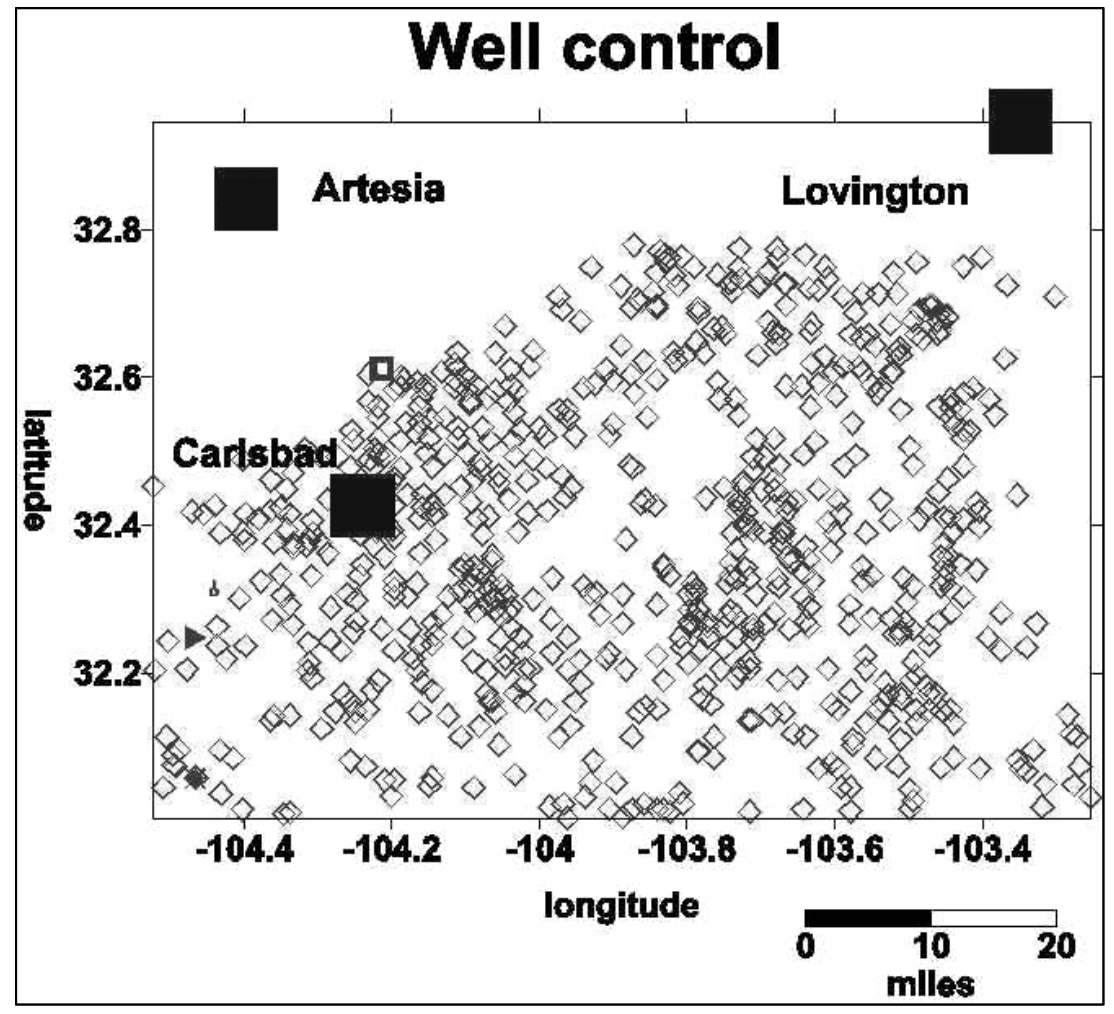

Fig. BC3. Location of well data control points used in the Brushy Canyon part of this project. See Fig. BC1 for map location.

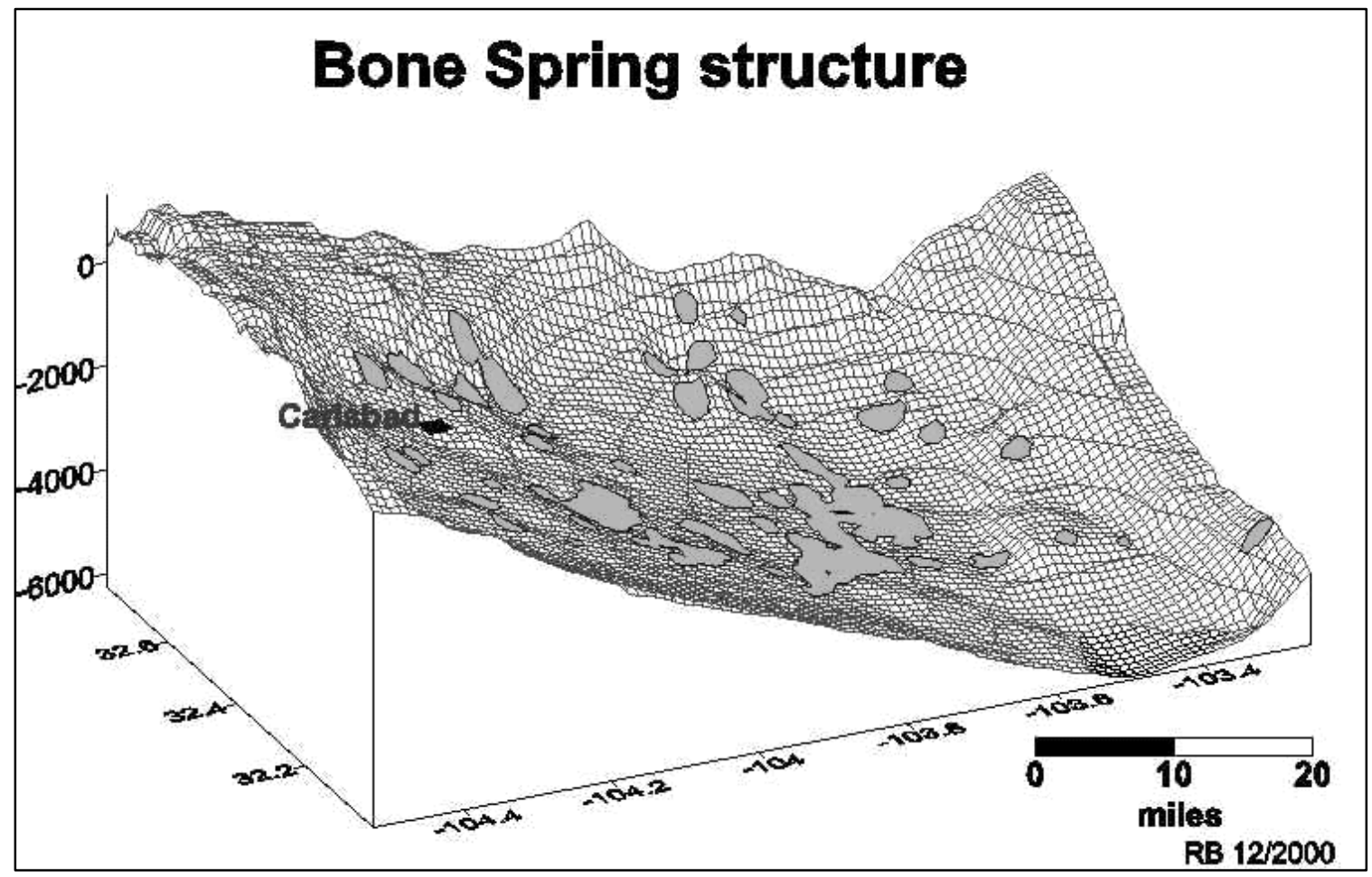

Fig. BC4. Three-dimensional view of structure on Bone Spring Formation and location of oil pools (in green) productive from the lower part of the Brushy Canyon Formation. 


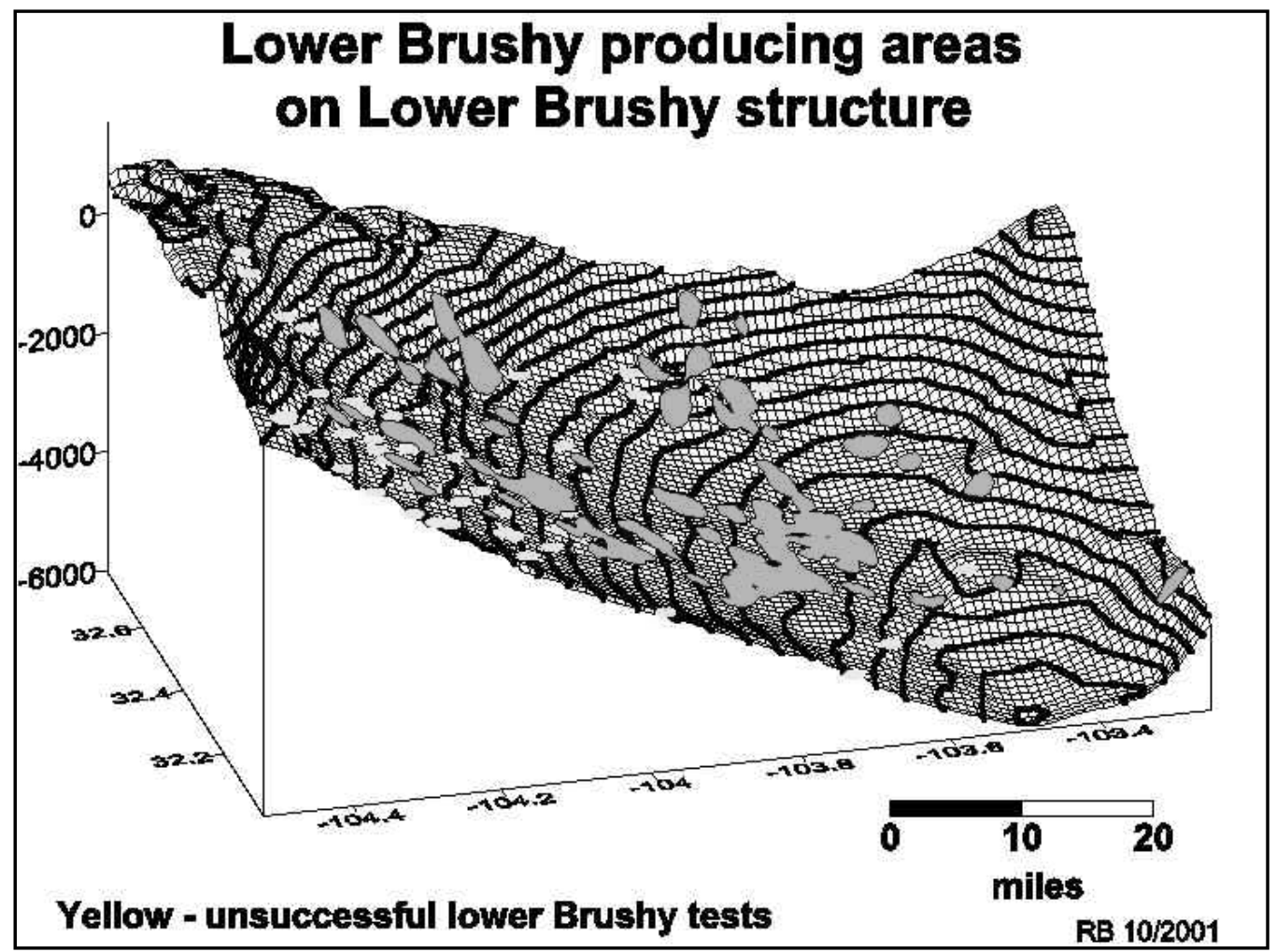

Fig. BC5. Three-dimensional view of structure on lower Brushy Canyon Formation and location of oil pools (in green) productive from the lower part of the Brushy Canyon Formation.

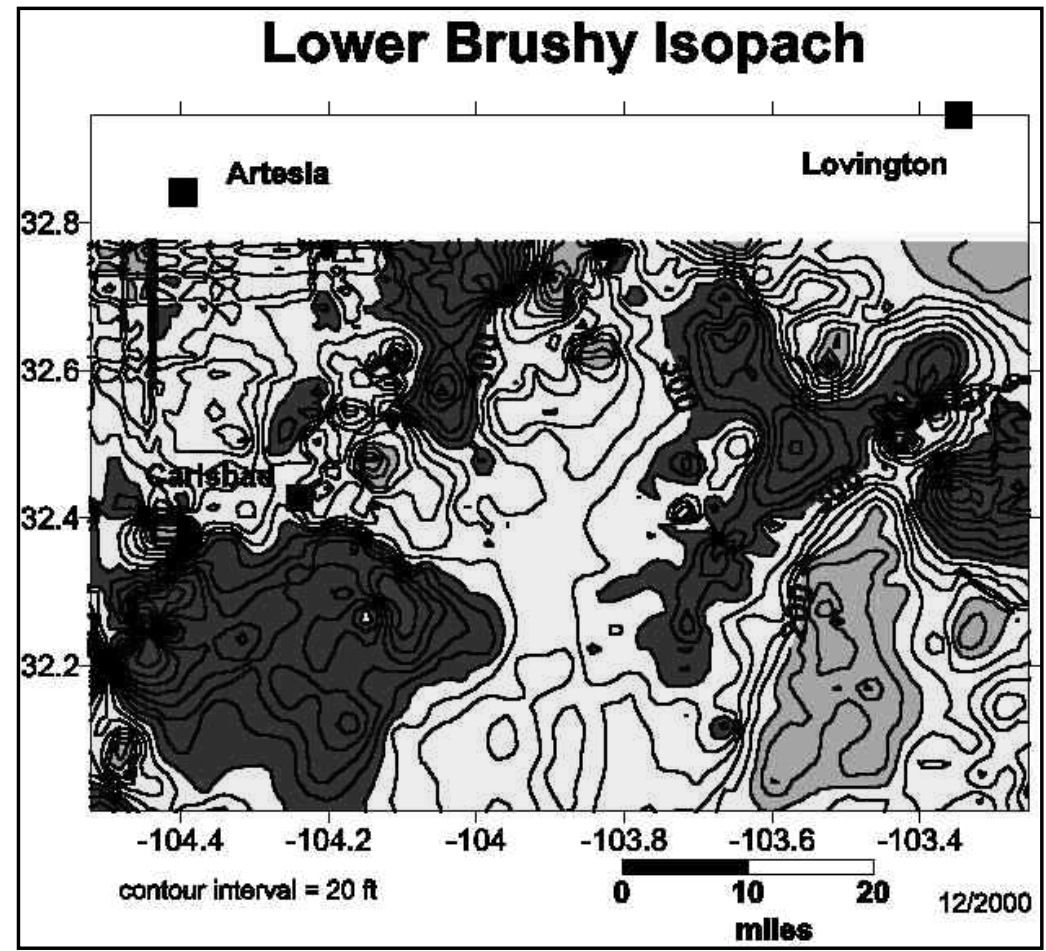

Fig. BC6. Isopach map of lower Brushy Canyon Formation. 


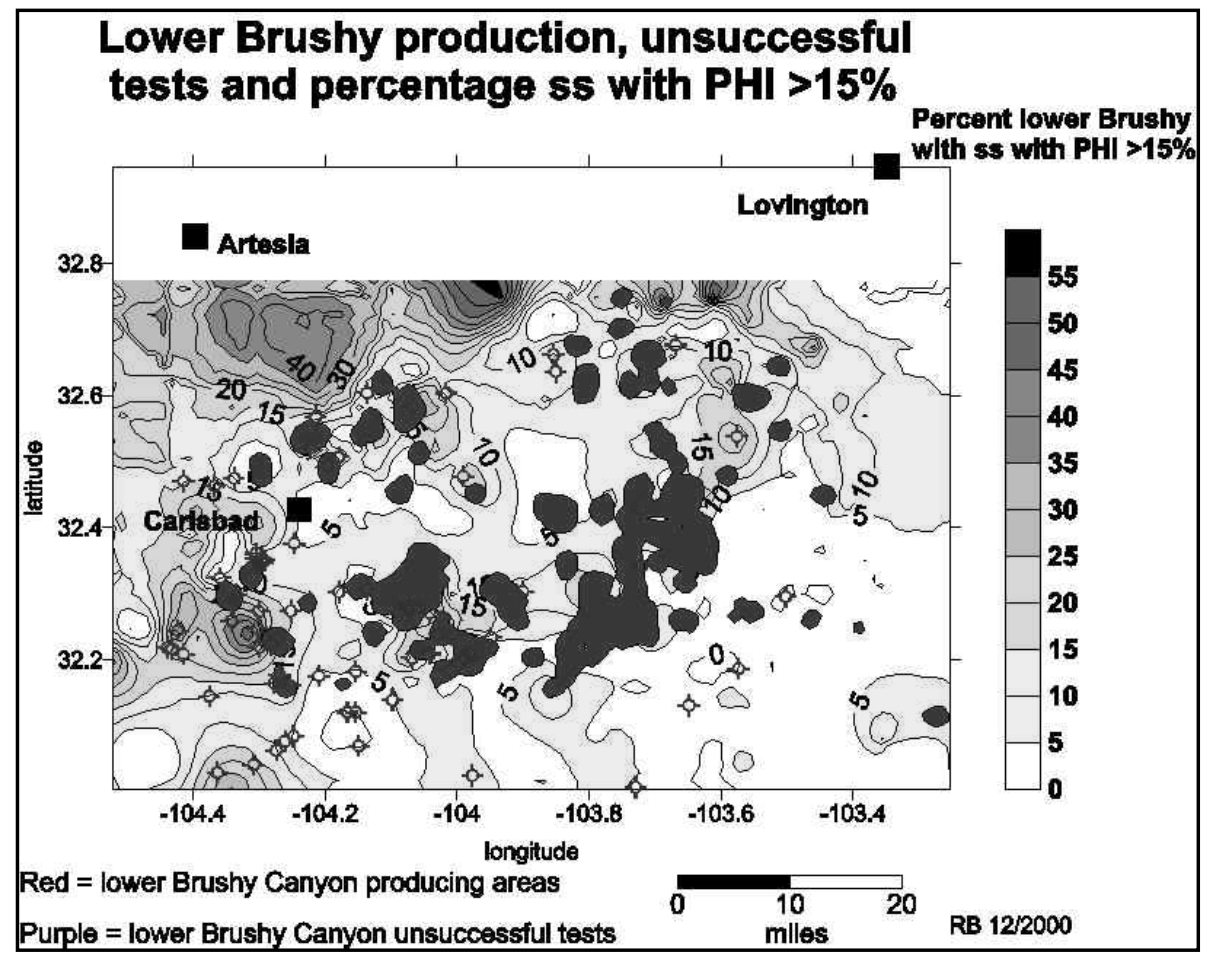

Fig. BC7. Areas productive from lower Brushy Canyon, net thickness of lower Brushy Canyon sandstones with porosity $>15 \%$, and wells that unsuccessfully tested the lower Brushy Canyon.

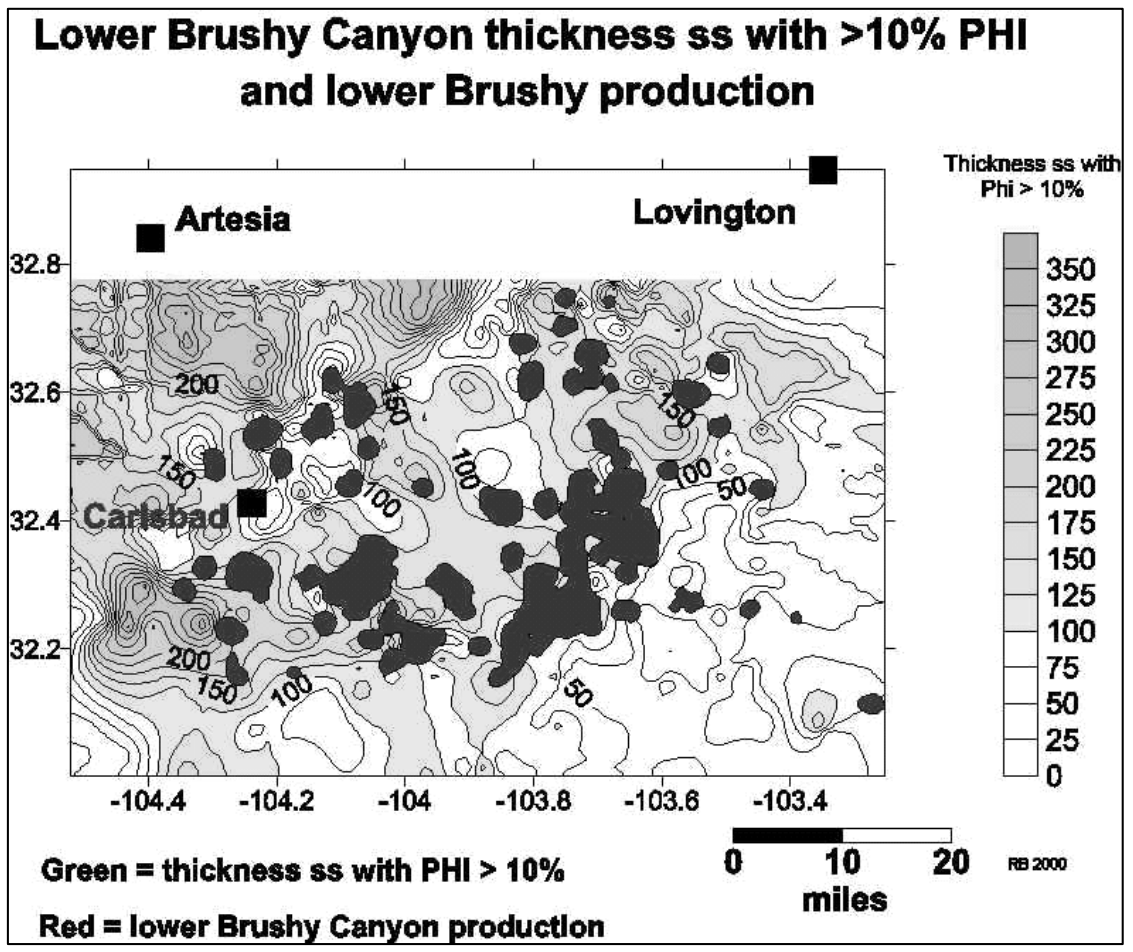

Fig. BC8. Areas productive from lower Brushy Canyon and net thickness of lower Brushy Canyon sandstones with porosity $>10 \%$. 


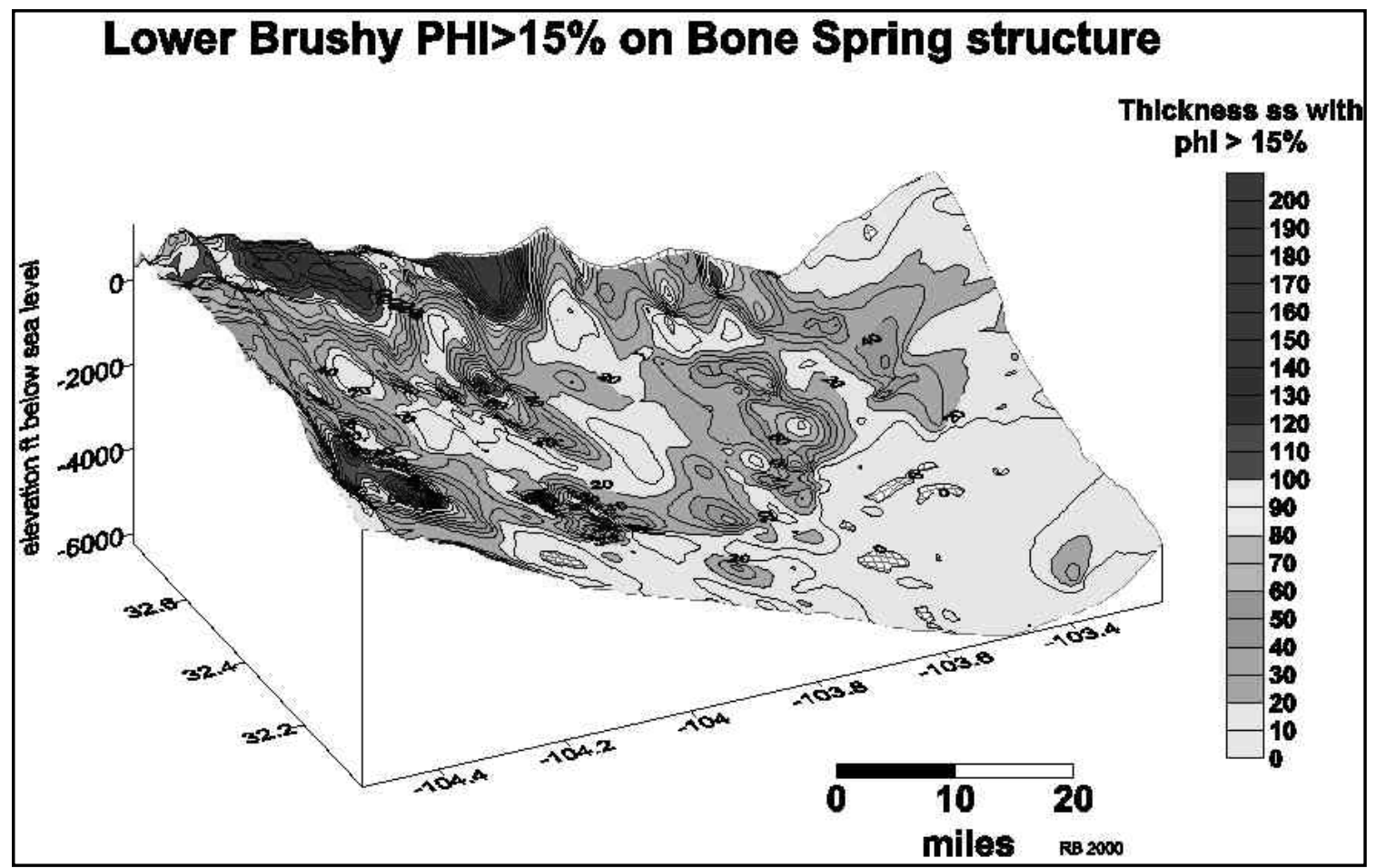

Fig. BC9. Net thickness of lower Brushy Canyon sandstones with porosity $>15 \%$ superimposed on 3-D diagram of Bone Spring structure.

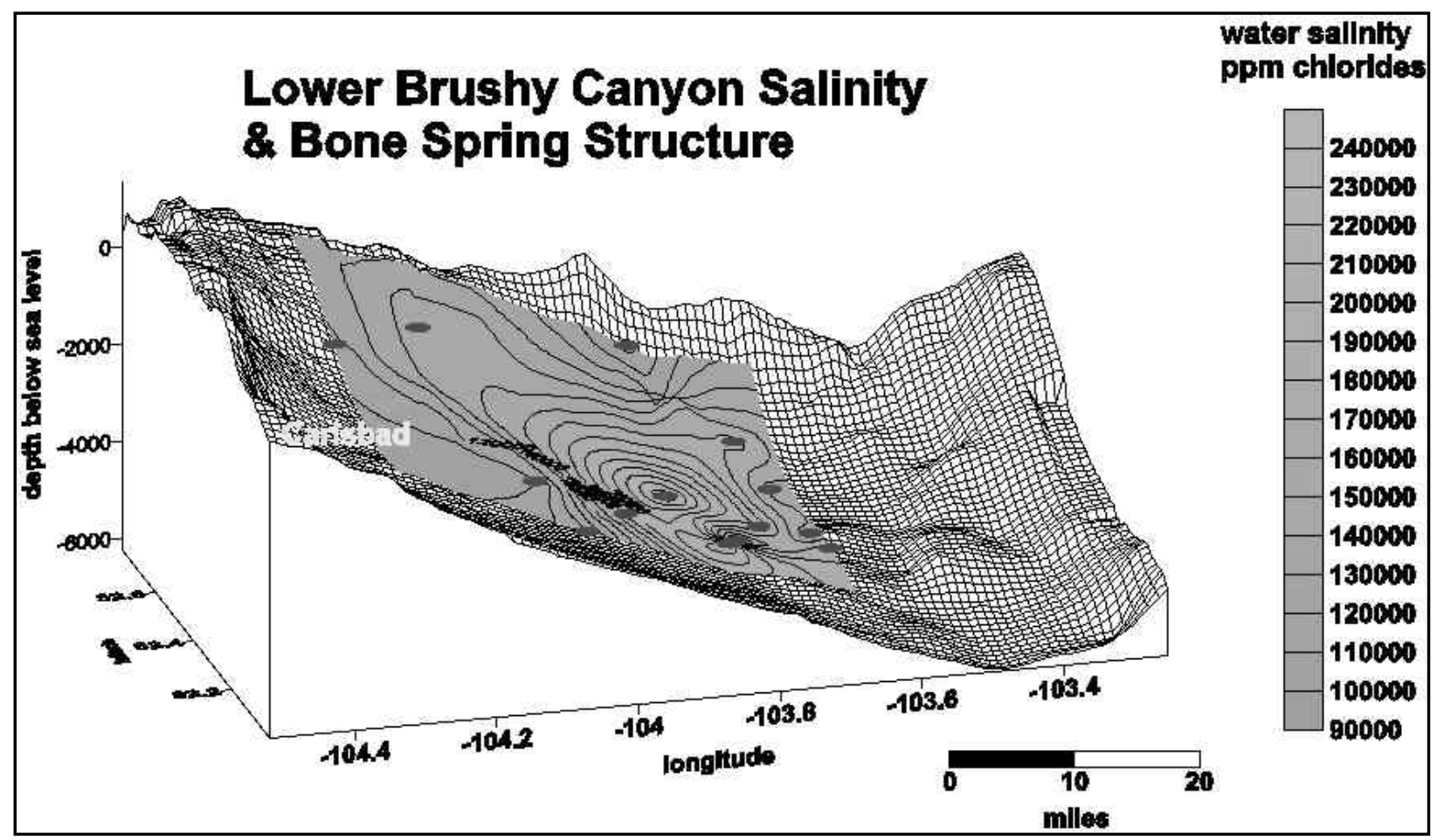

Fig. BC10. Salinity of produced Brushy Canyon waters superimposed on 3-D diagram of Bone Spring structure. 


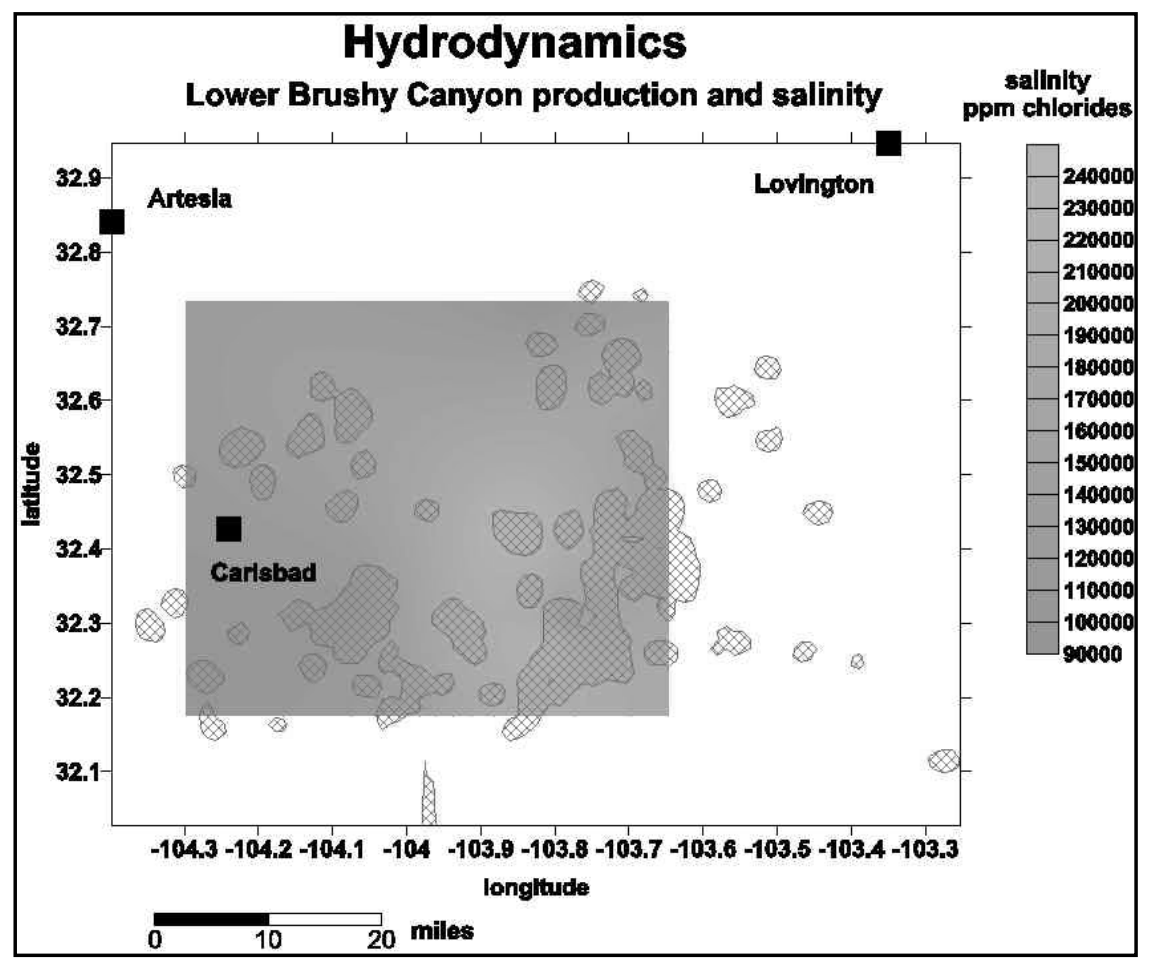

BC11. Salinity of produced lower Brushy Canyon waters and areas productive from lower Brushy Canyon.

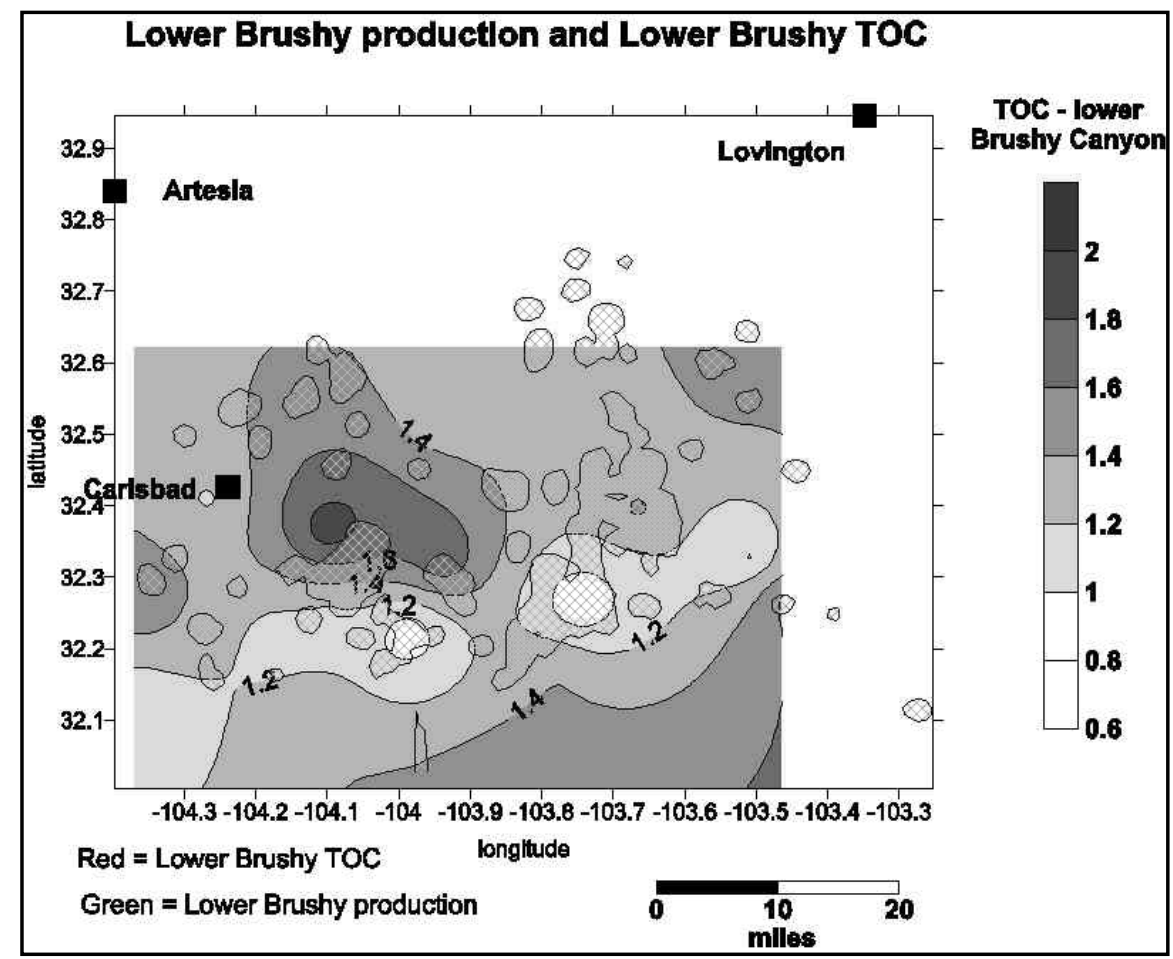

Fig. BC12. Total organic carbon content, in weight percent, of lower Brushy Canyon source rocks 


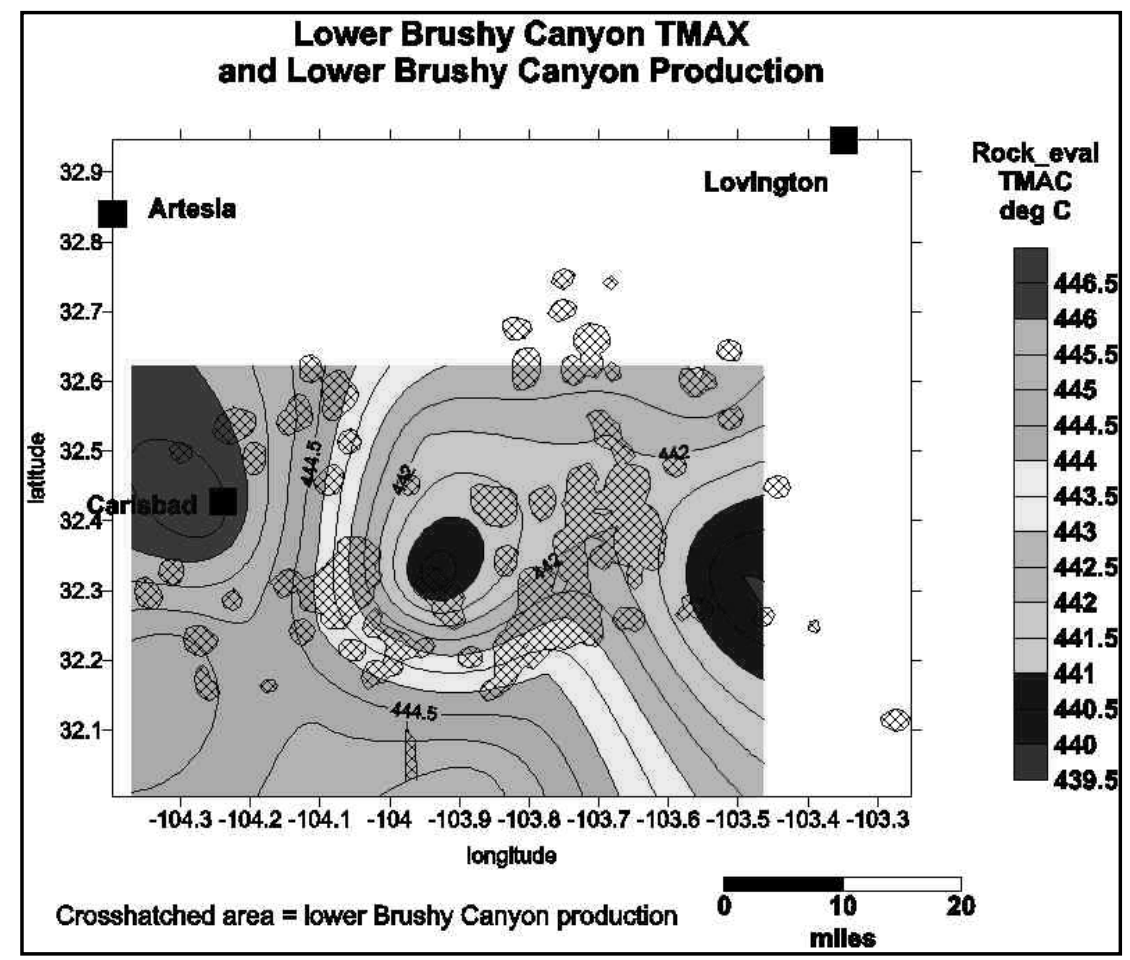

Fig. BC13. Thermal maturity of lower Brushy Canyon source rocks as determined by Rock-eval TMAX values and areas productive from lower Brushy Canyon.

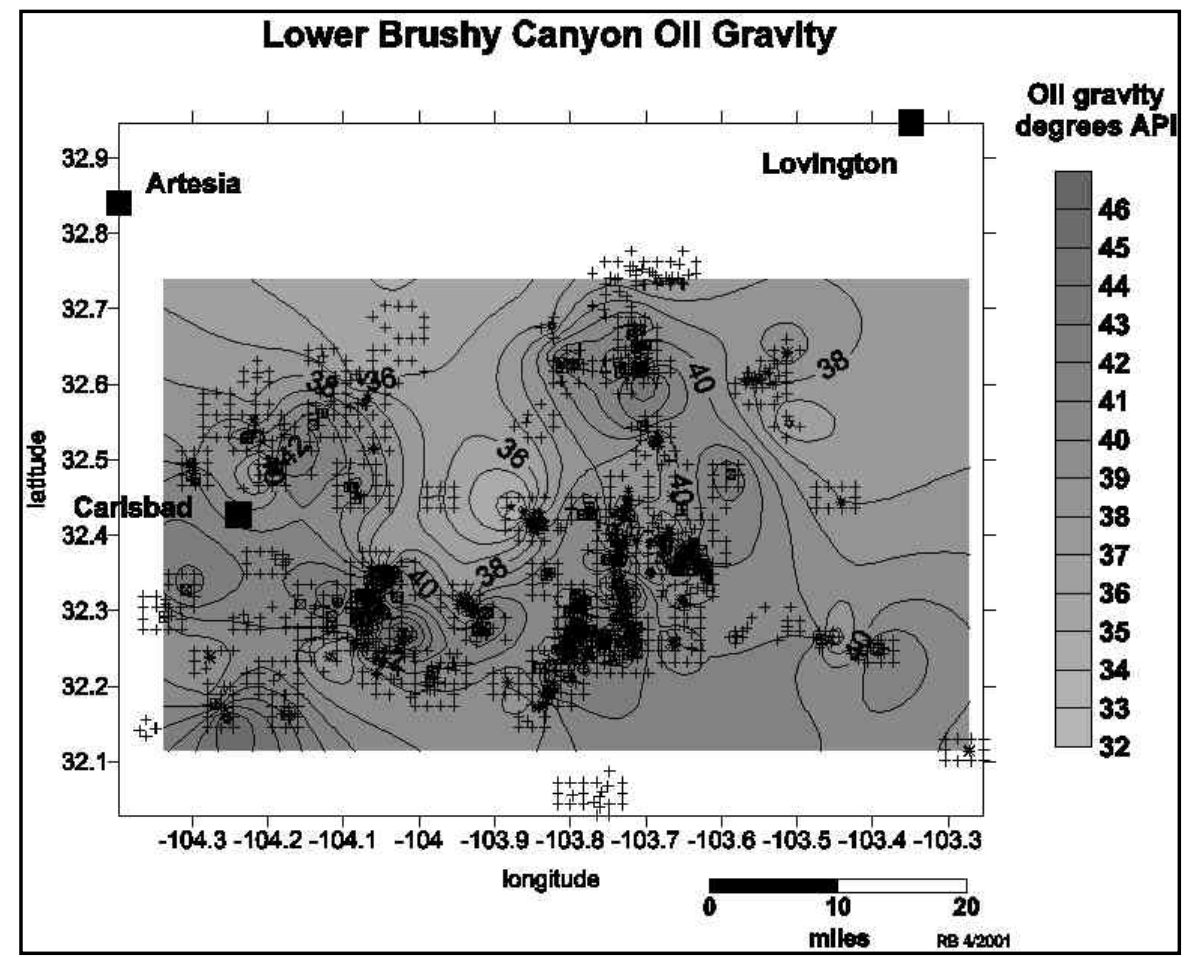

Fig. BC14. API gravity of lower Brushy Canyon oils. 


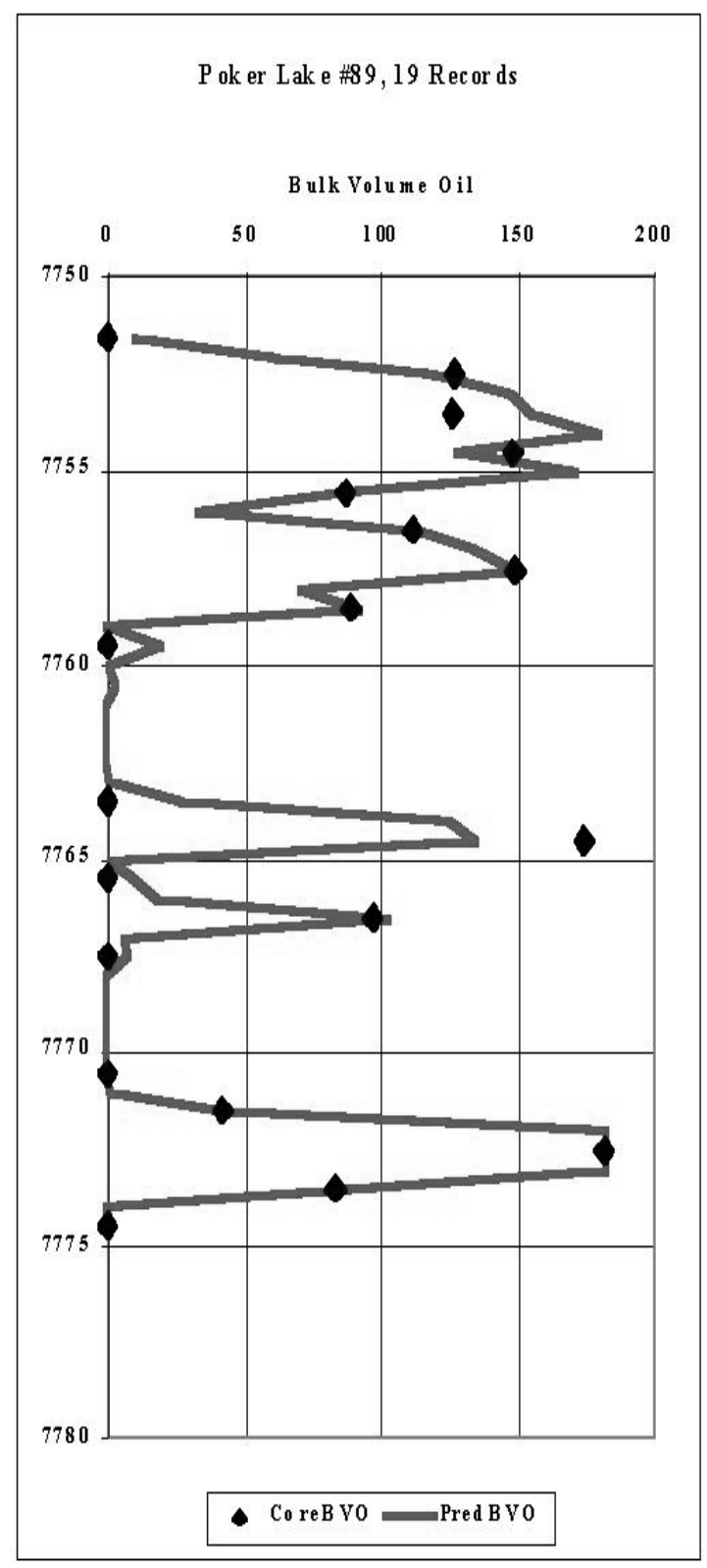

Fig. OT1. Real overtraining example (Poker Lake 89, perfect training).

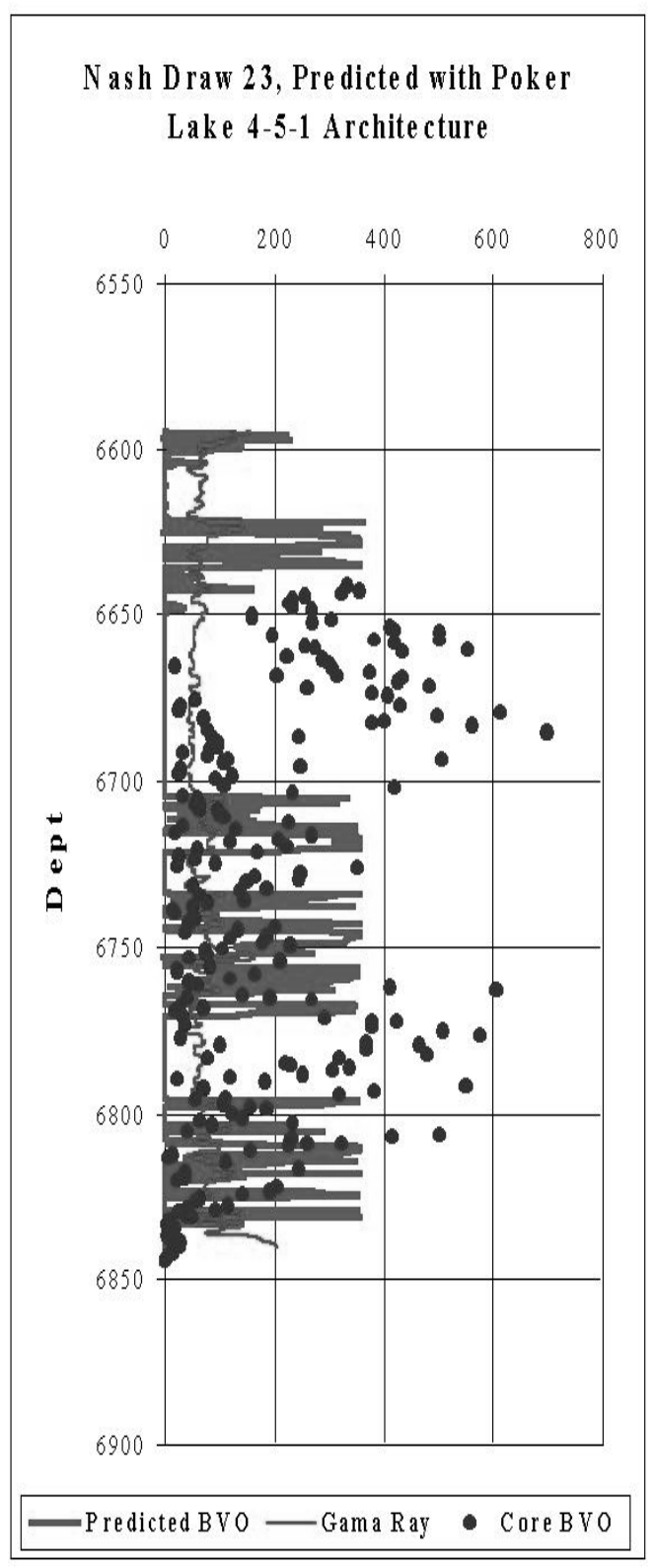

Fig. OT2. Real overtraining example (Nash Draw 23, bad prediction). 


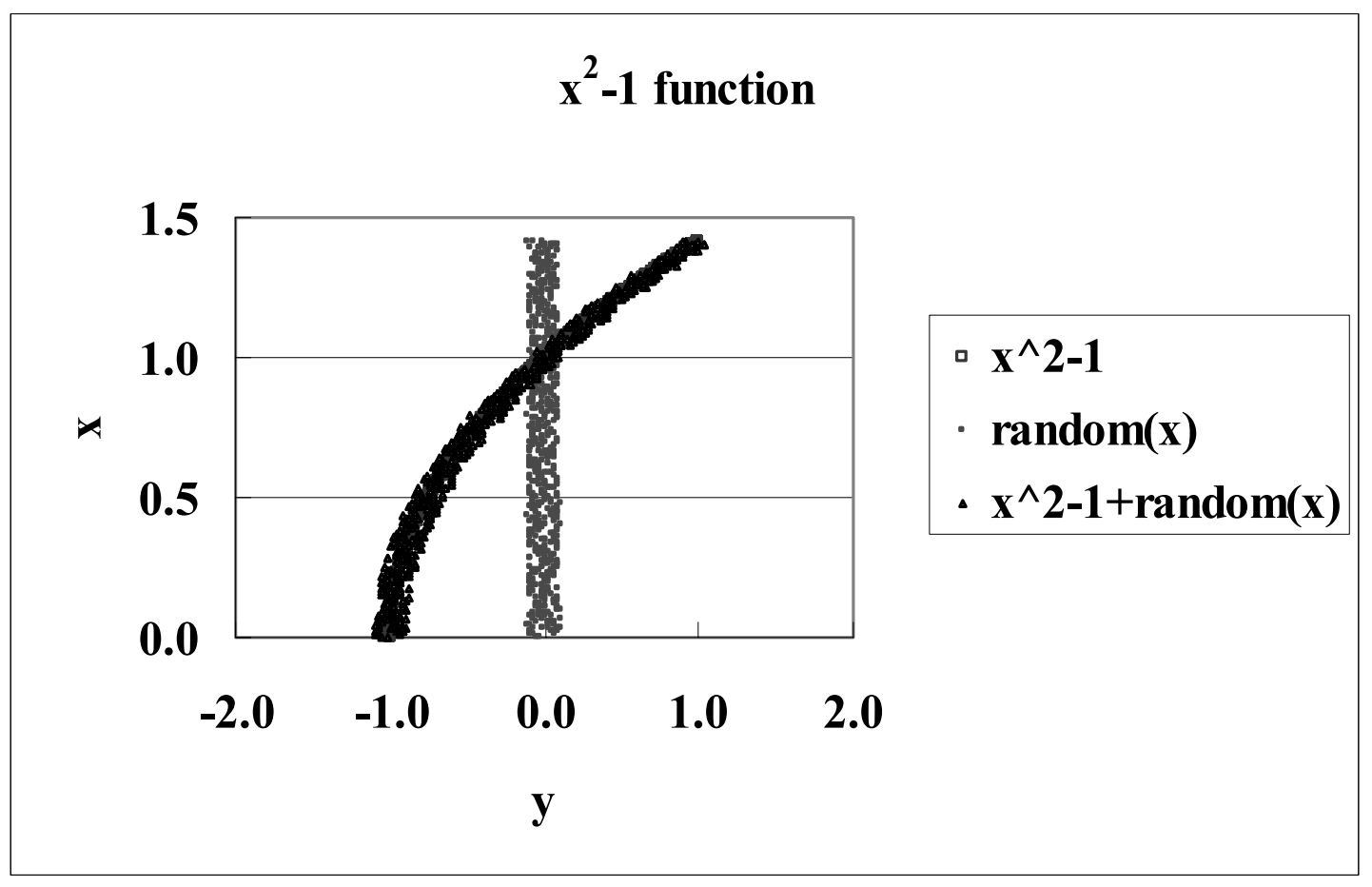

Fig. OT3. Dataset generated by x2-1 function.

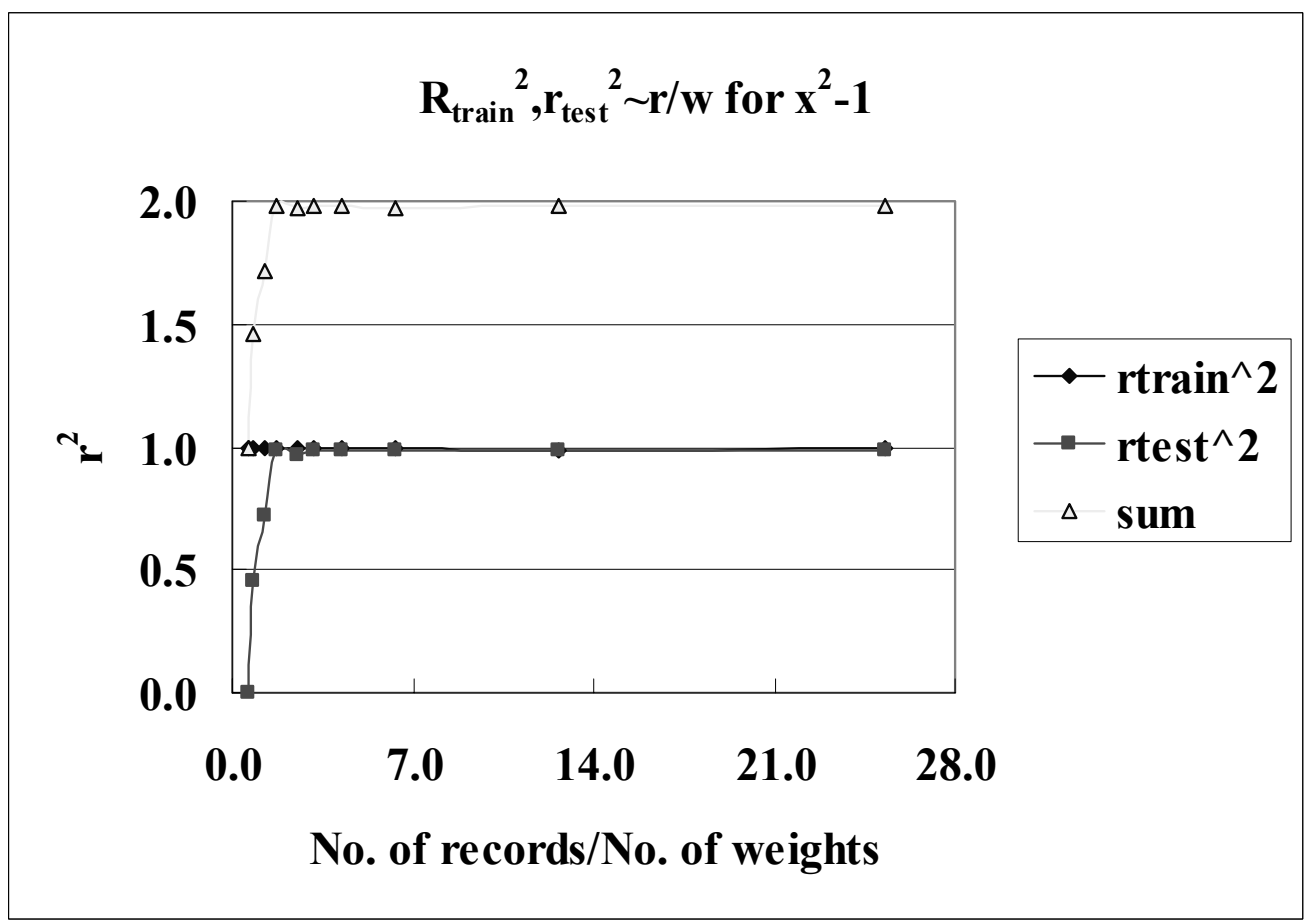

Fig. OT4. The 1-3-4-1 ANN results for x2-1 function. 


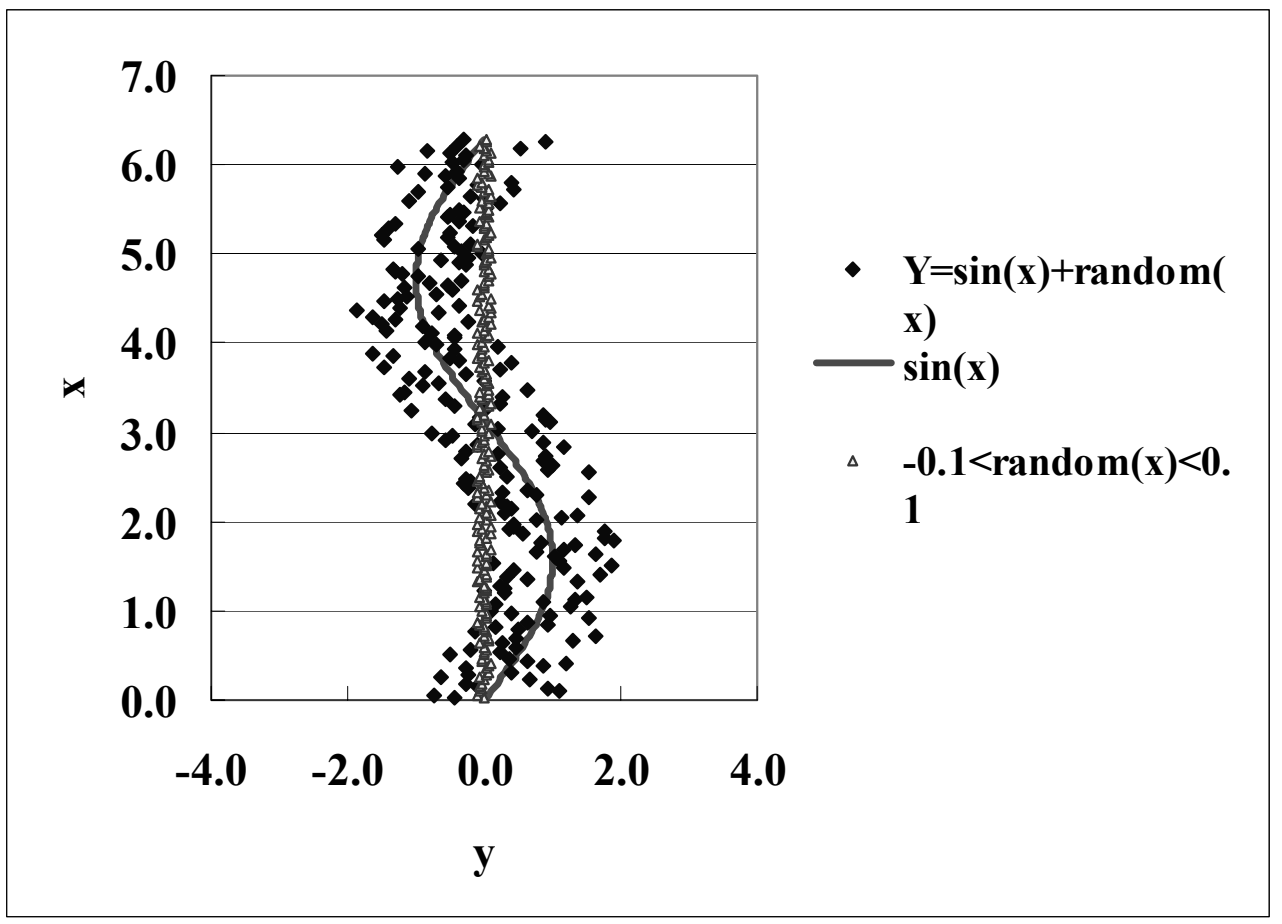

Fig. OT5. Dataset generated by $\sin (\mathrm{x})$ function.

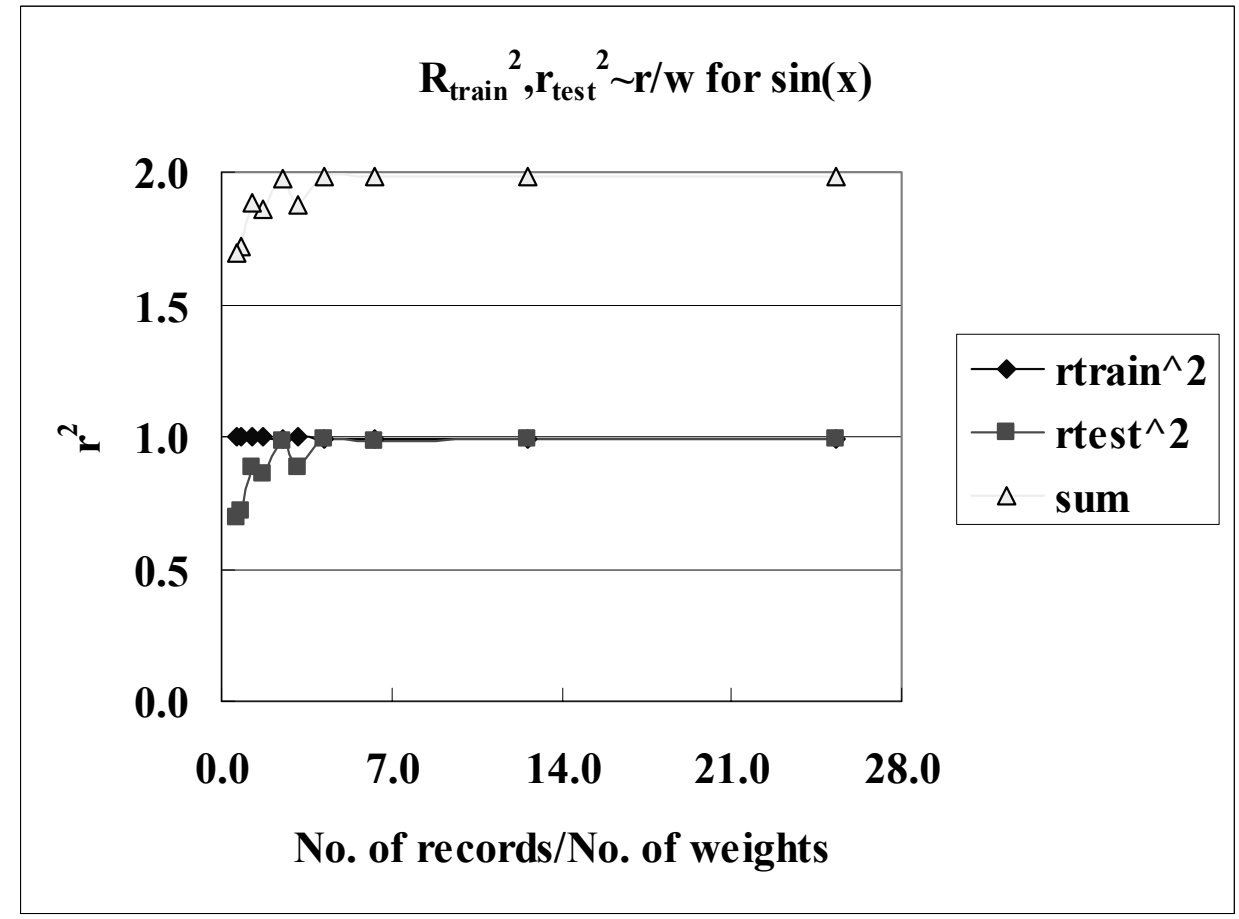

Fig. OT6. The 1-3-4-1 ANN results for $\sin (\mathrm{x})$ function. 


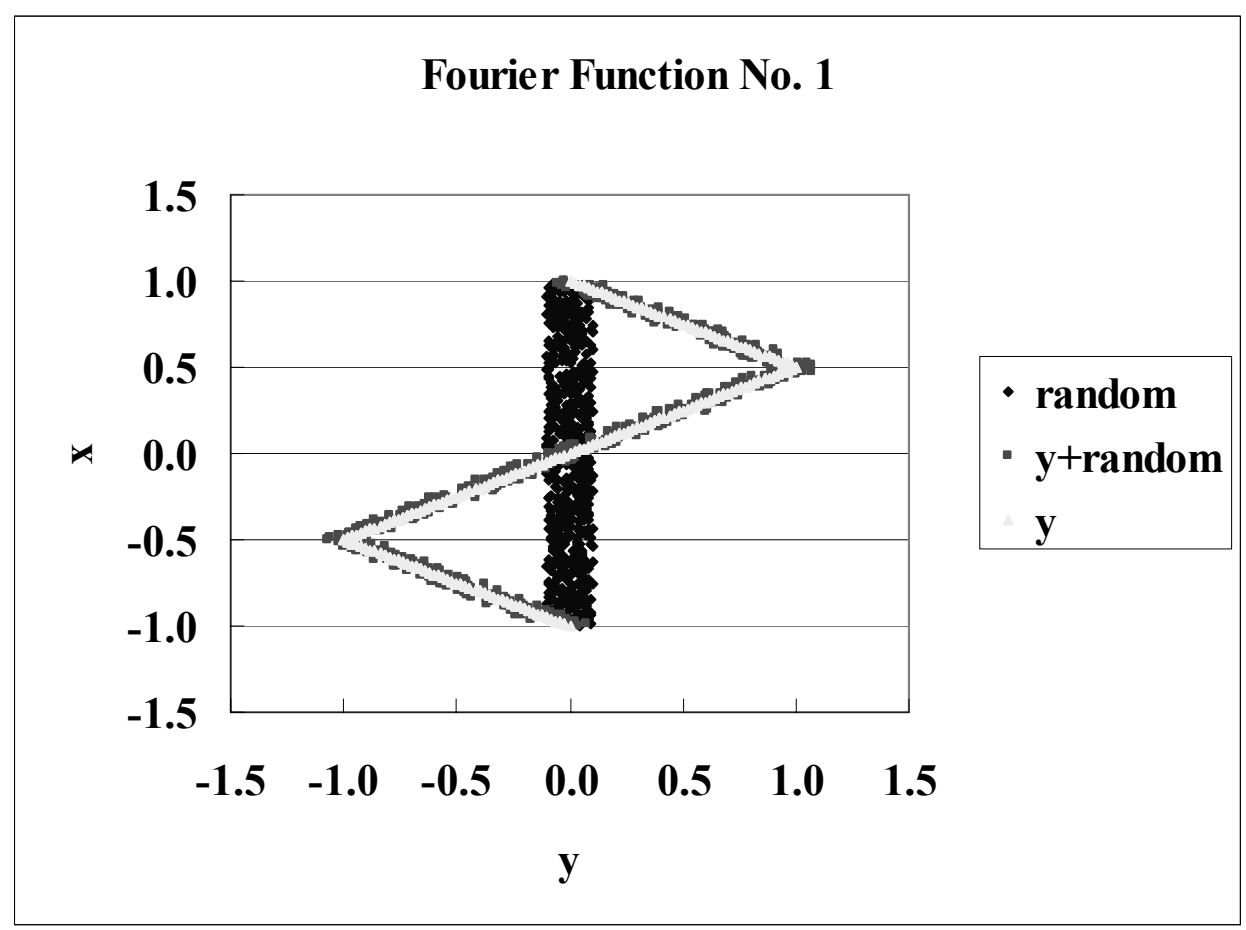

Fig. OT7. Dataset generated by Fourier function No. 1.

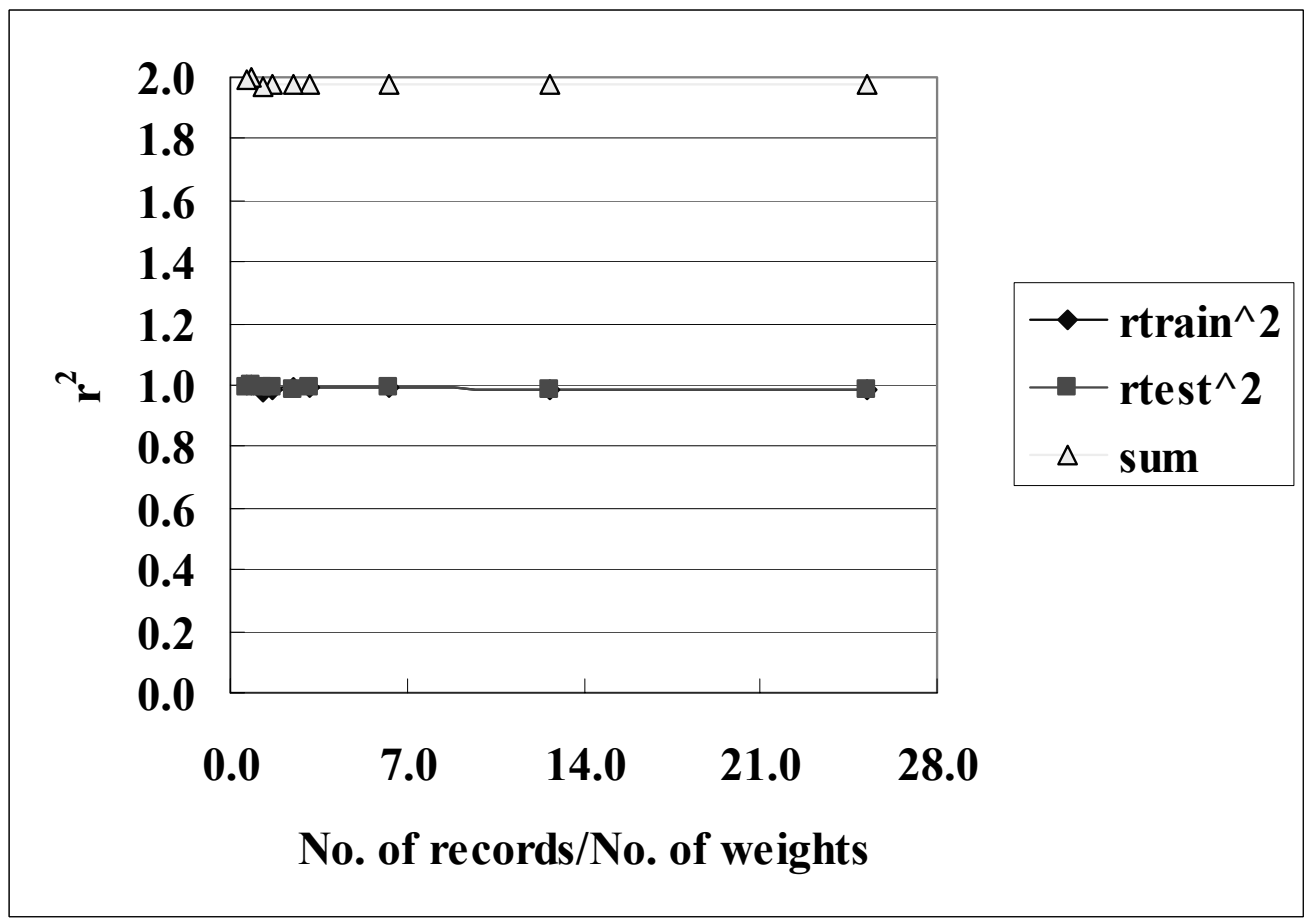

Fig. OT8. The 1-3-4-1 ANN results for Fourier function No.1 


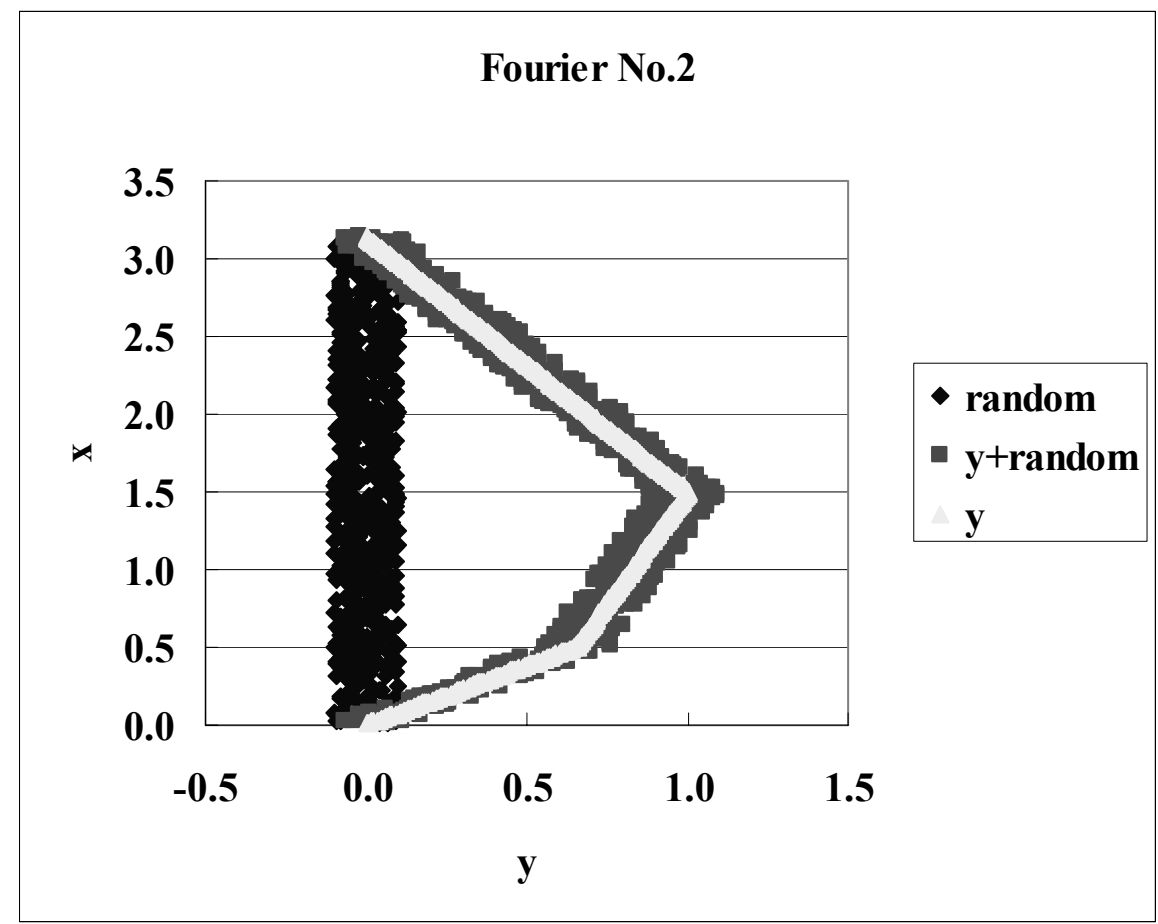

Fig. OT9. Dataset generated by Fourier Function No.2.

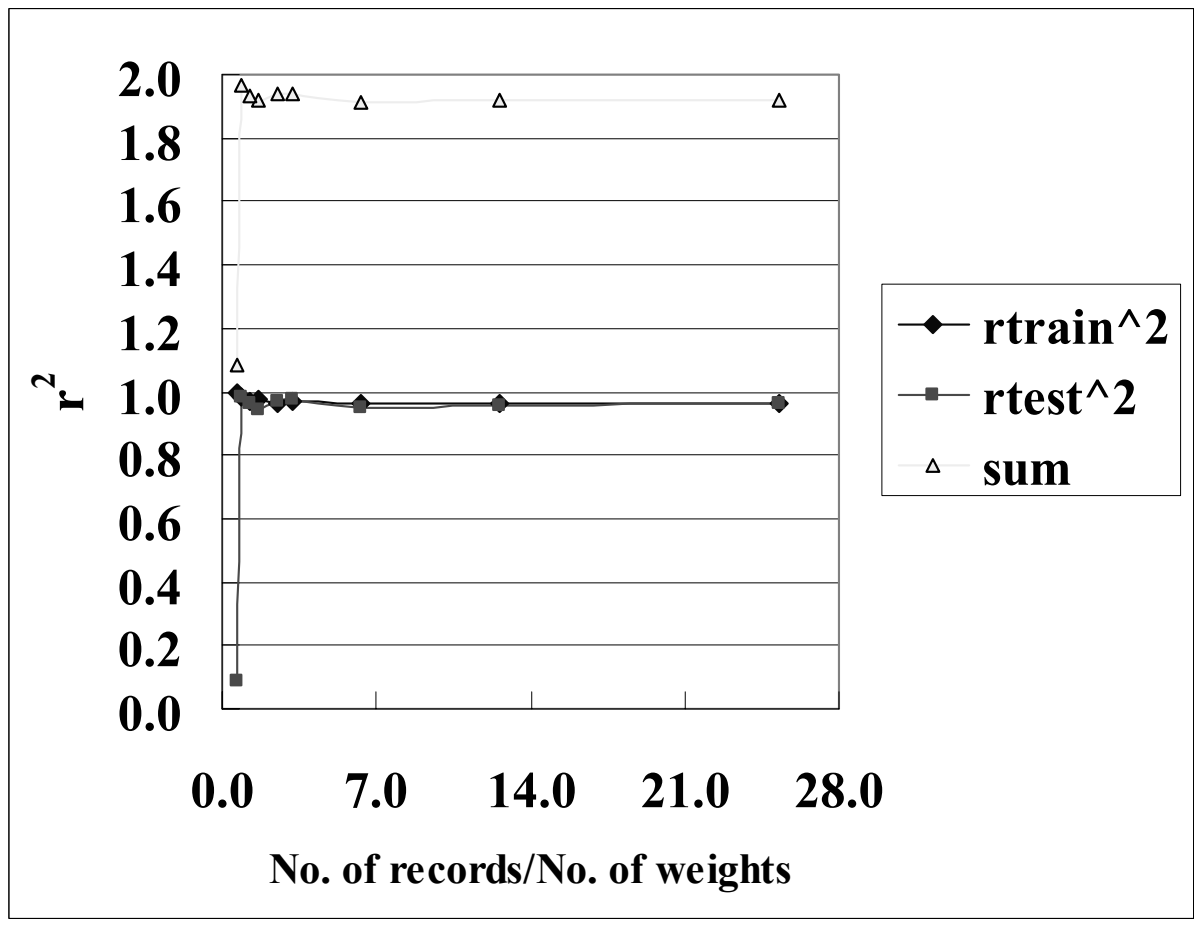

Fig. OT10. The 1-3-4-1 ANN results for Fourier function No. 2. 


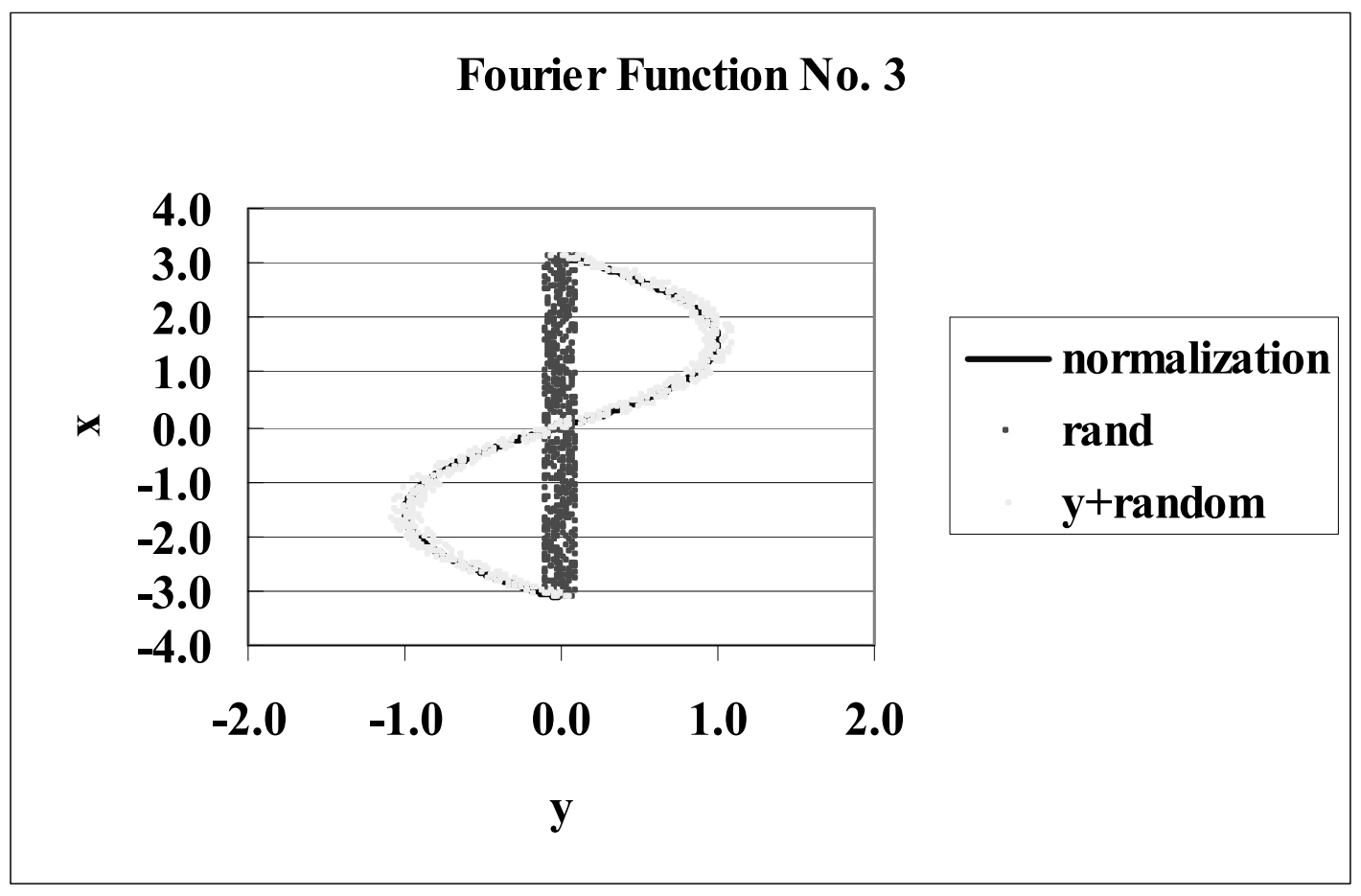

Fig. OT11. Dataset generated by Fourier function No. 3.

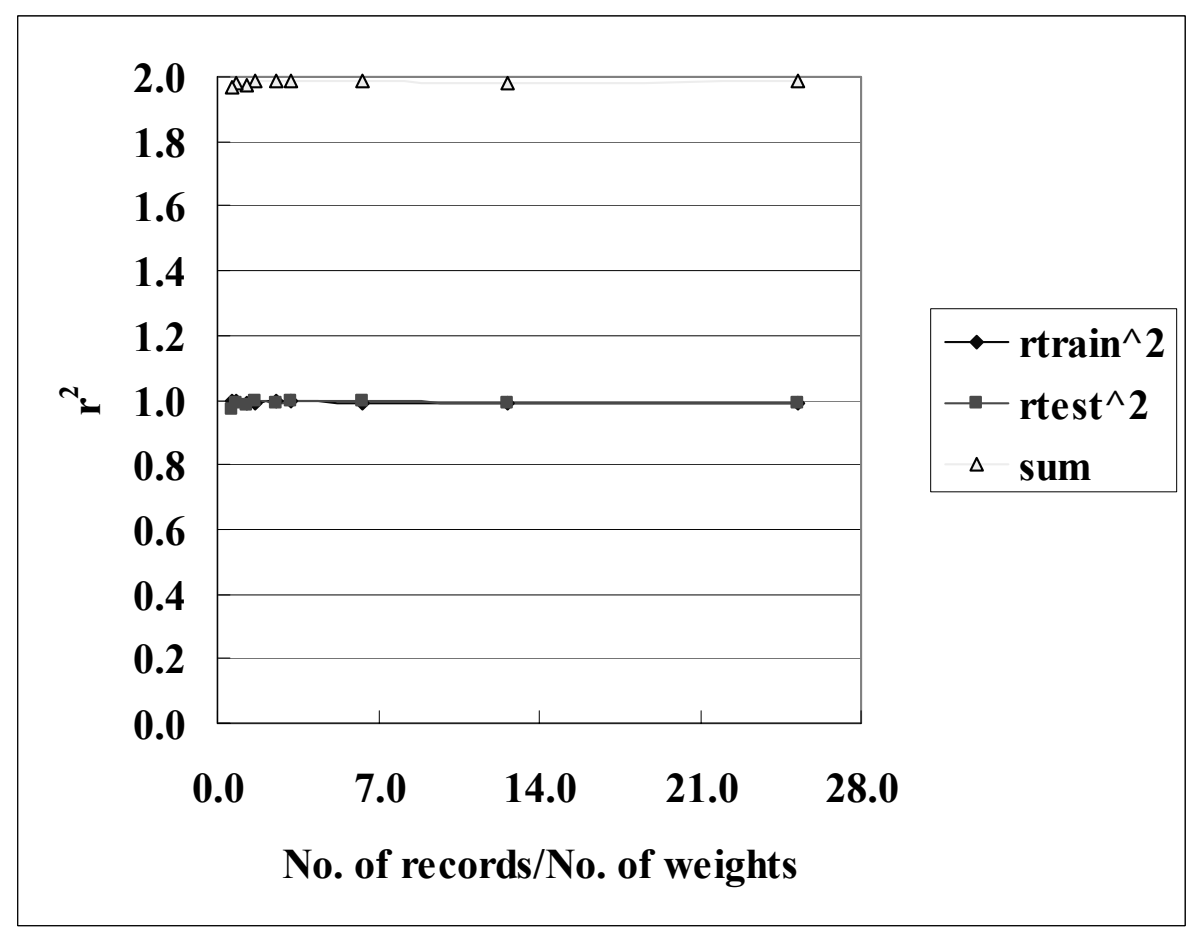

Fig. OT12. The 1-3-4-1 ANN results for Fourier function No. 3. 


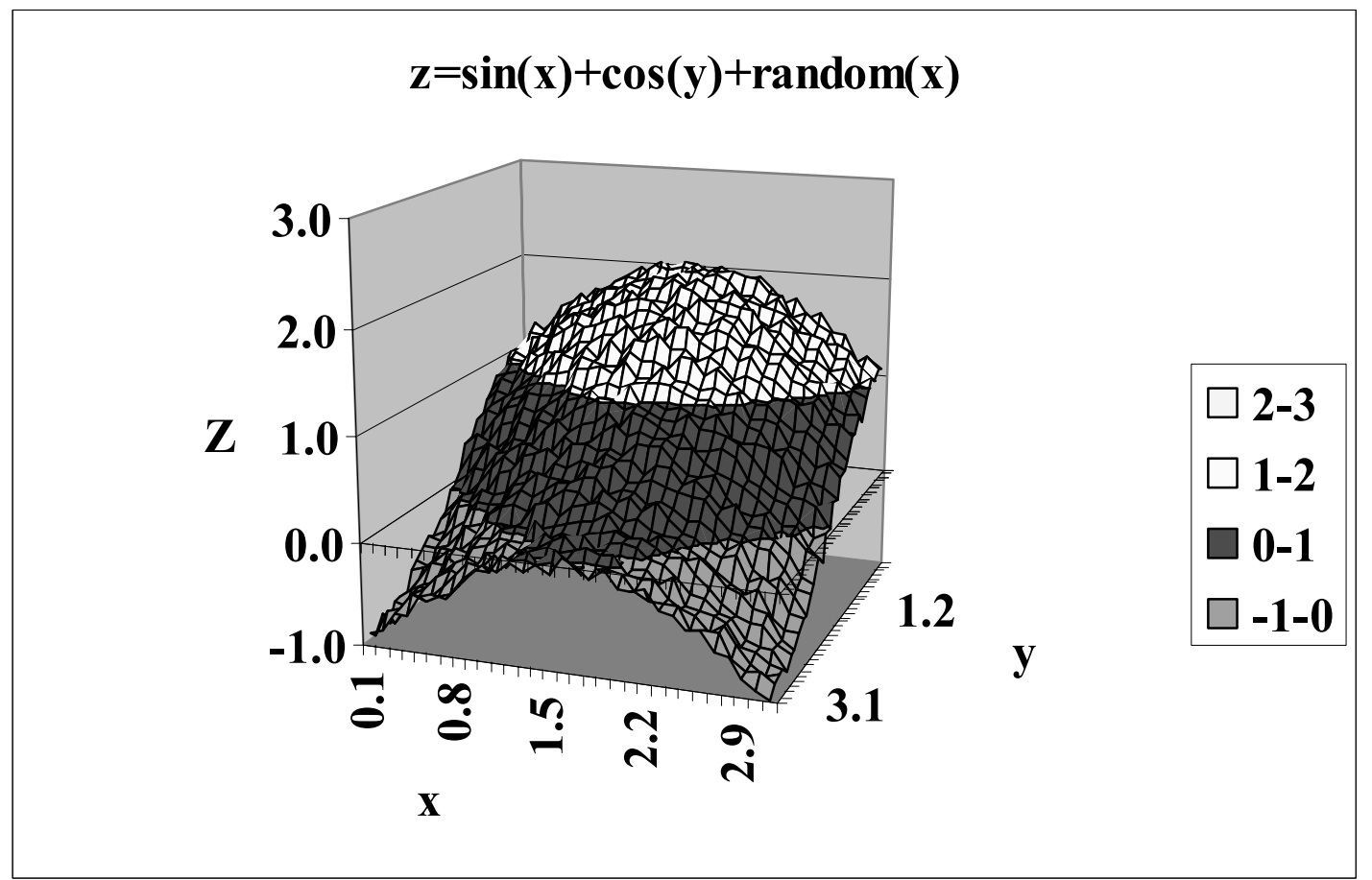

Fig. OT13. Dataset generated by $\sin (\mathrm{x})+\cos (\mathrm{y})$ function.

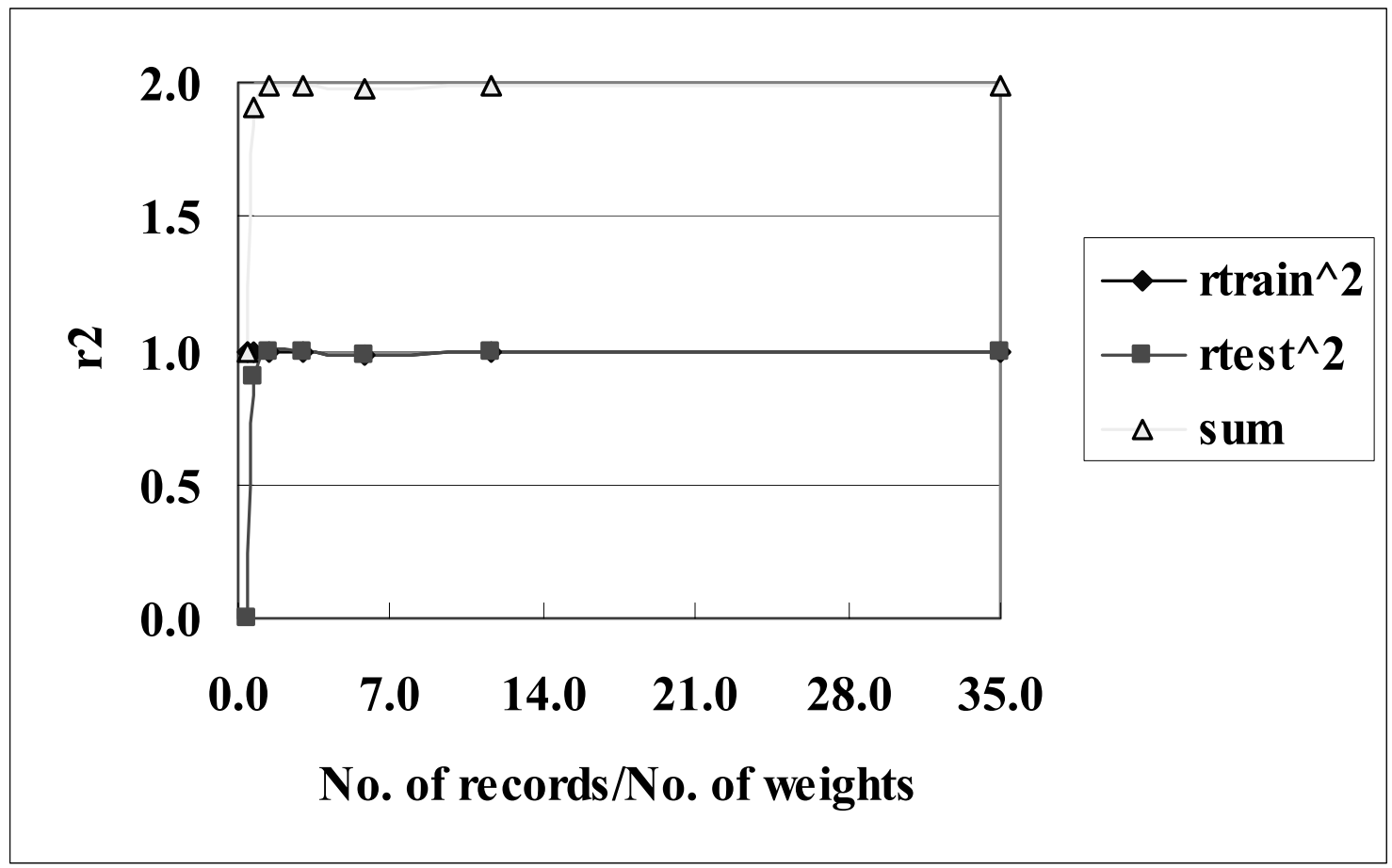

Fig. OT14. The 2-3-4-1 ANN results for $\sin (\mathrm{x})+\cos (\mathrm{x})$ function. 


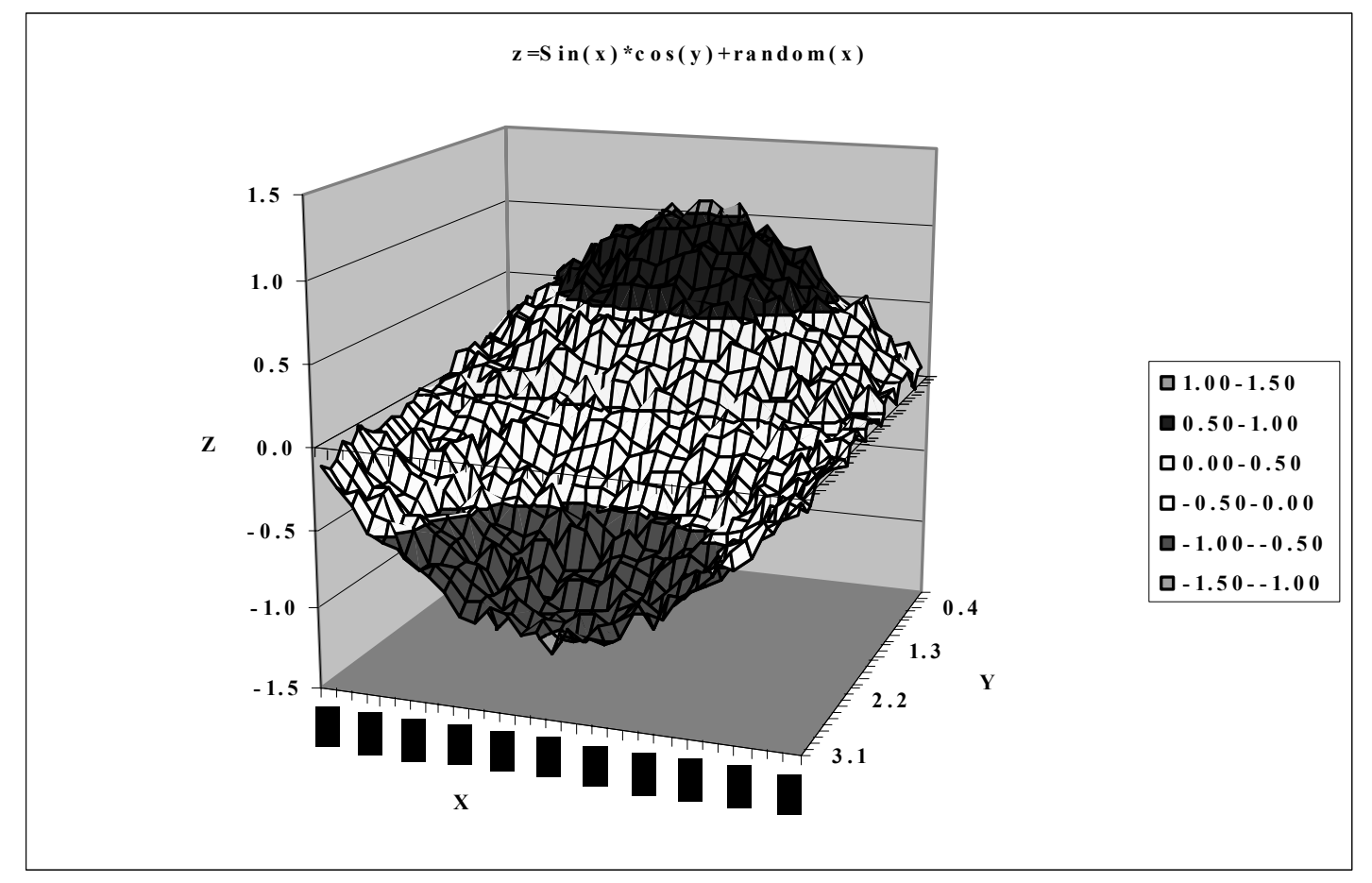

Fig. OT15. Dataset generated by $\sin (\mathrm{x}) * \cos (\mathrm{y})$ function.

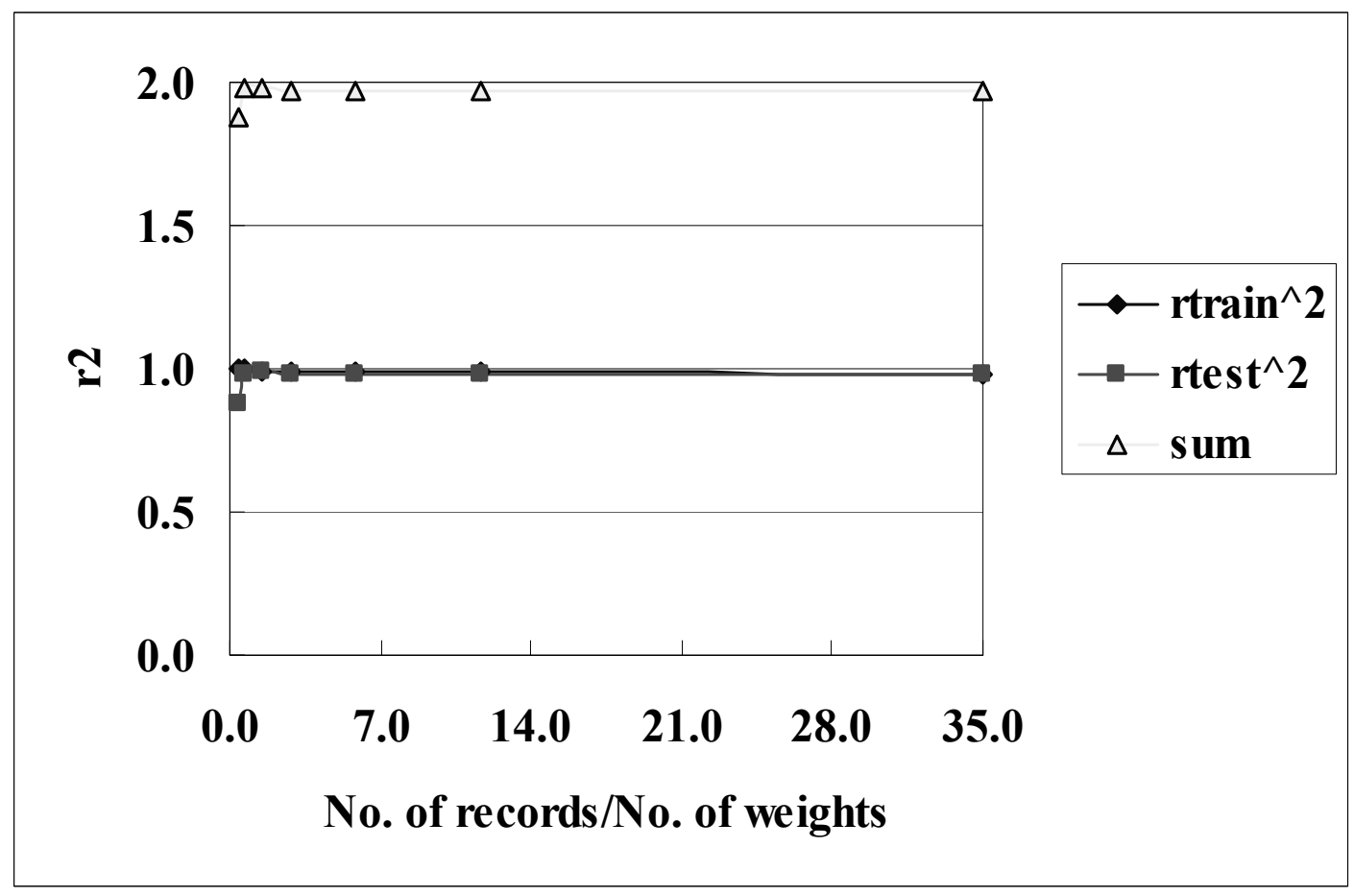

Fig. OT16. The 2-3-4-1 ANN results for $\sin (\mathrm{x})^{*} \cos (\mathrm{y})$ function. 


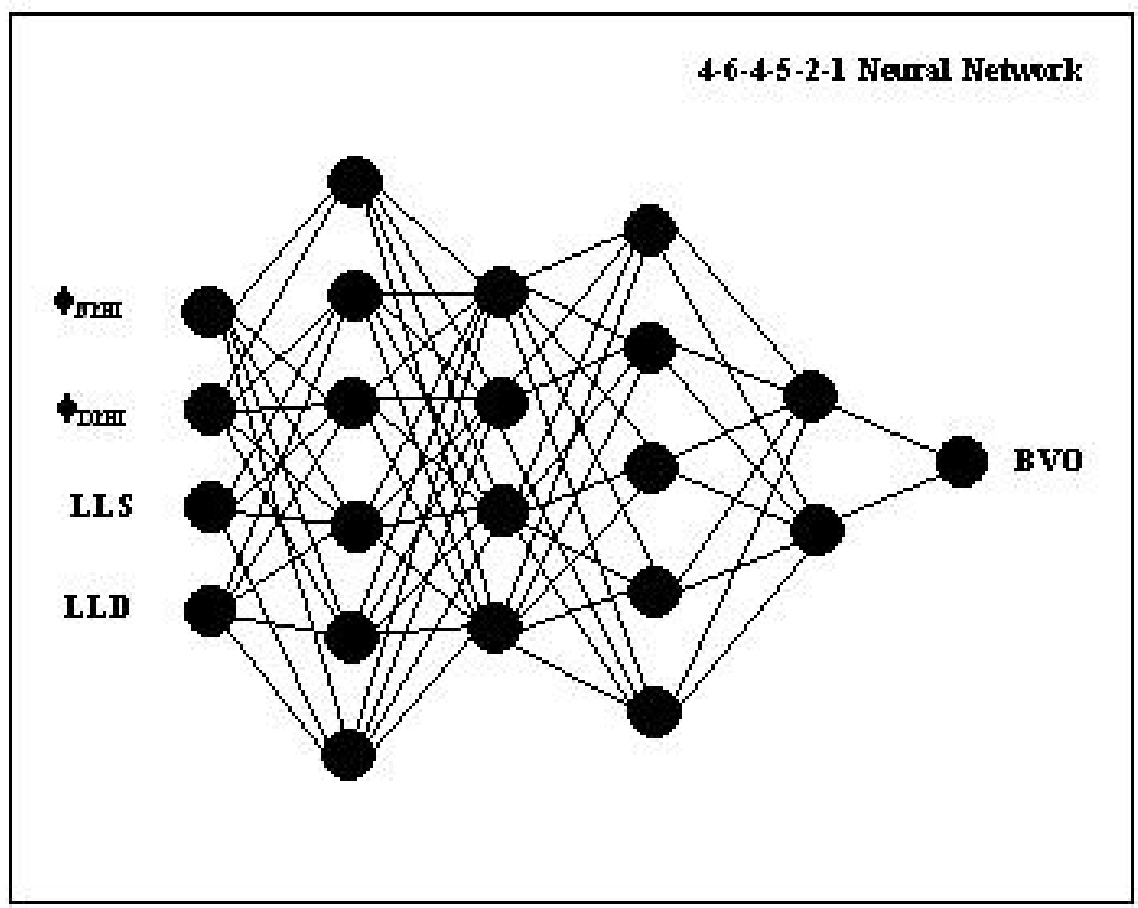

Fig. BVO-1. Neural network architecture used to correlate logs with core measured bulk volume oil.

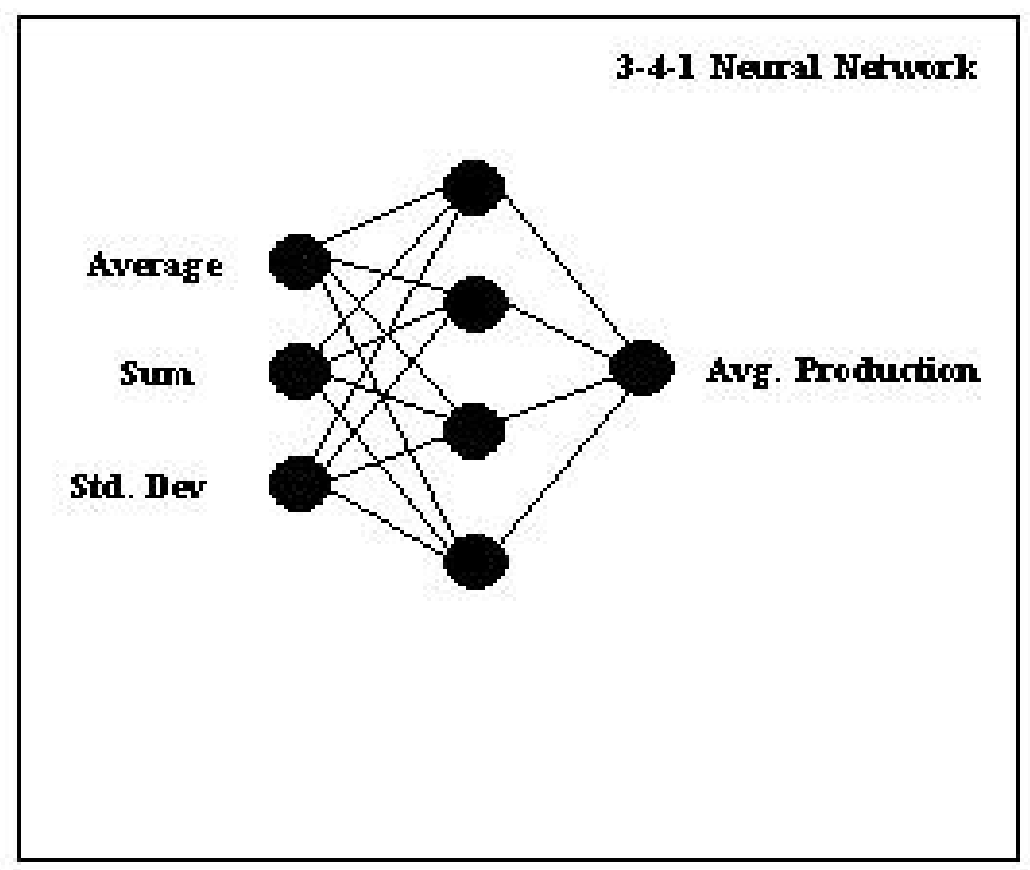

Fig. BVO-2. Architecture used to correlate bulk volume oil with average production. 


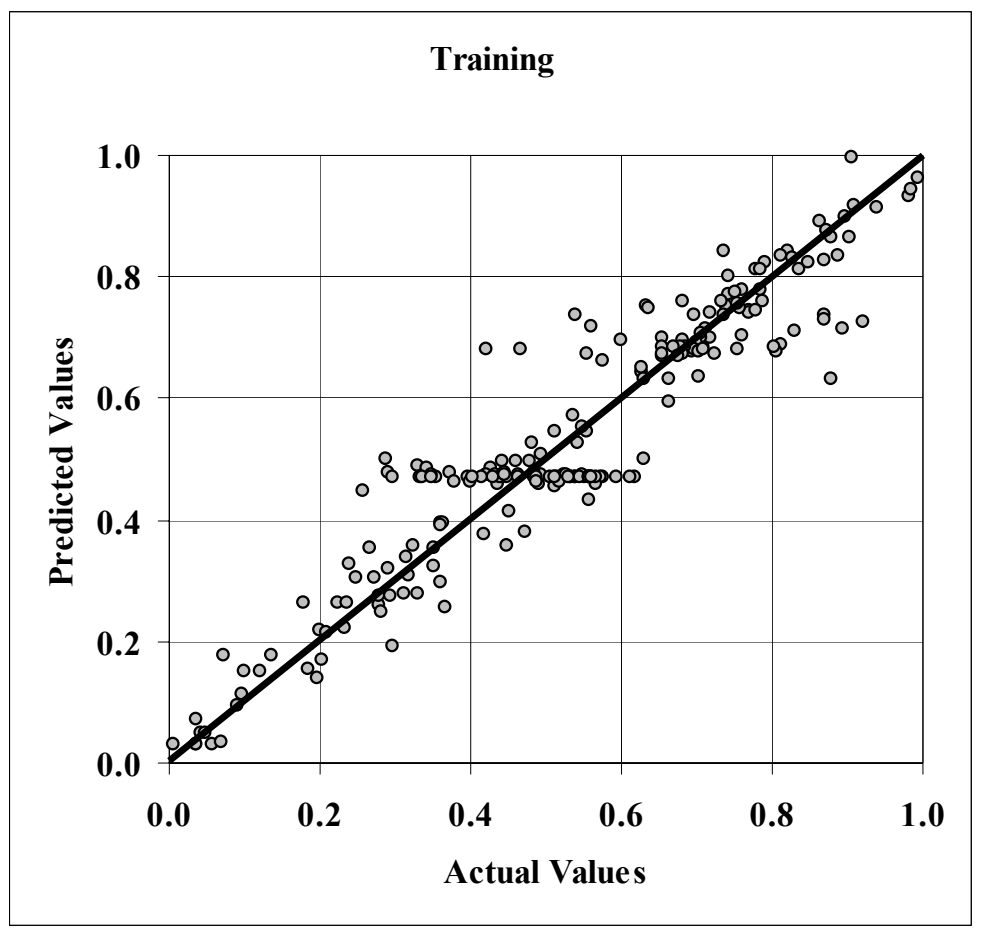

Fig. BVO-3.Training results for network used to correlate logs with core measured bulk volume oil.

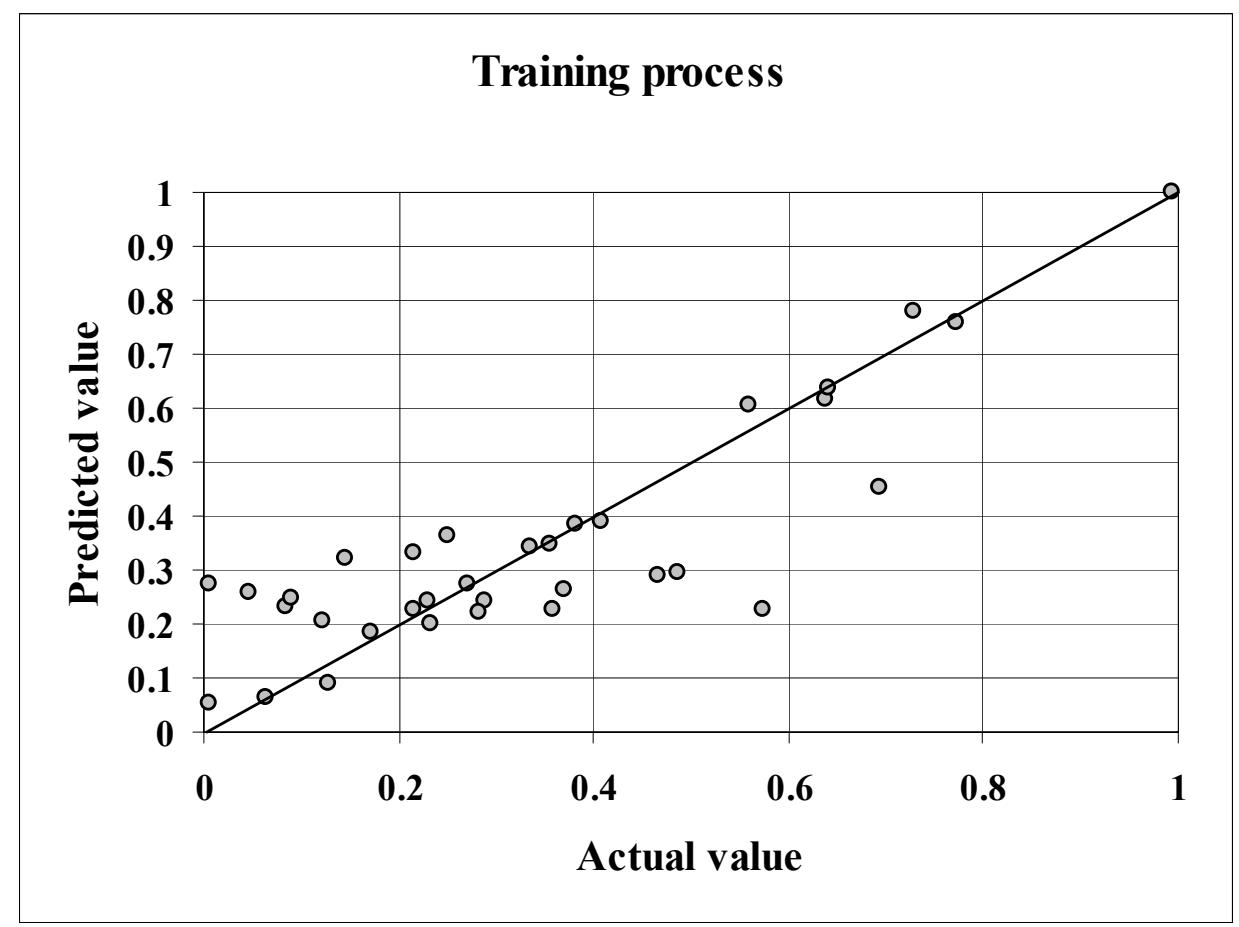

Fig. BVO-4. Training results for network used to correlate standard deviation, average and sum of bulk volume oil with production. 


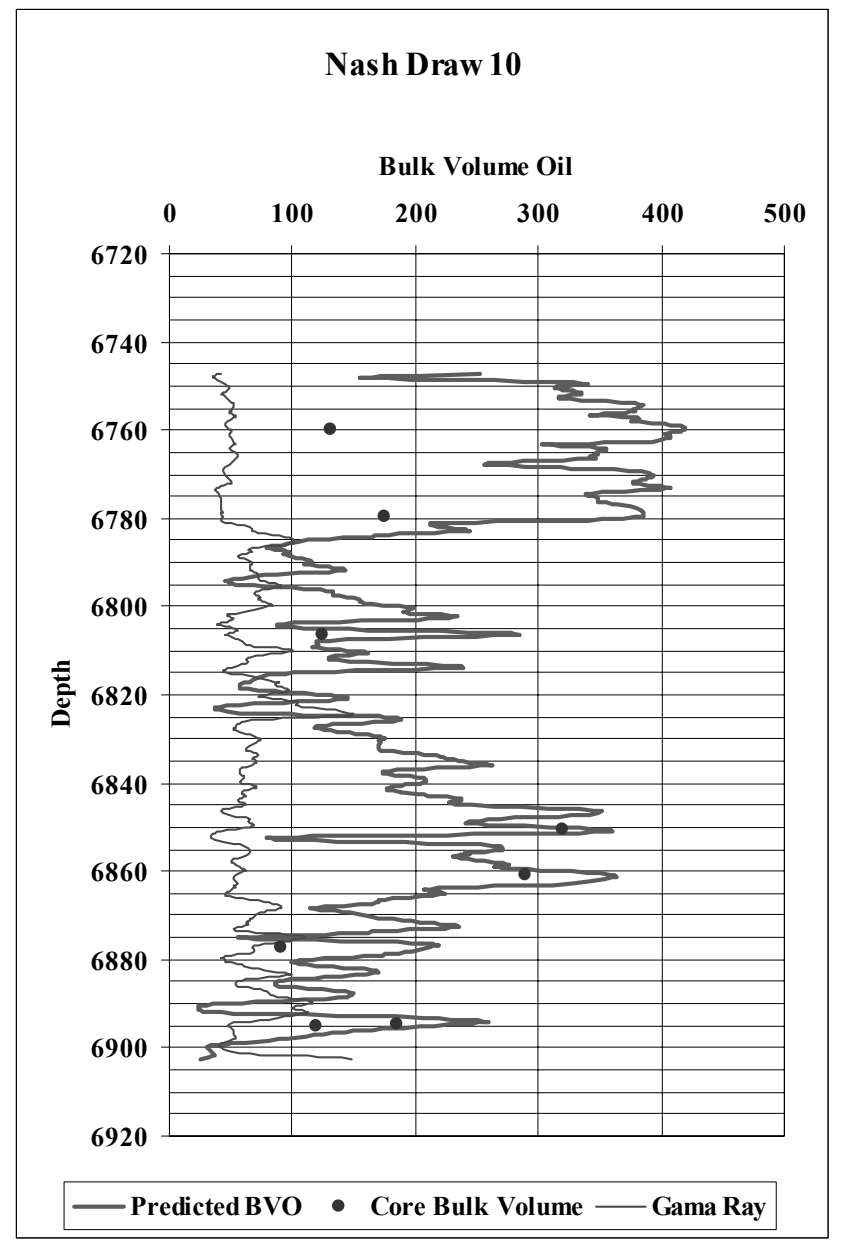

Fig. BVO-5. Network used to generate bulk volume oil log.

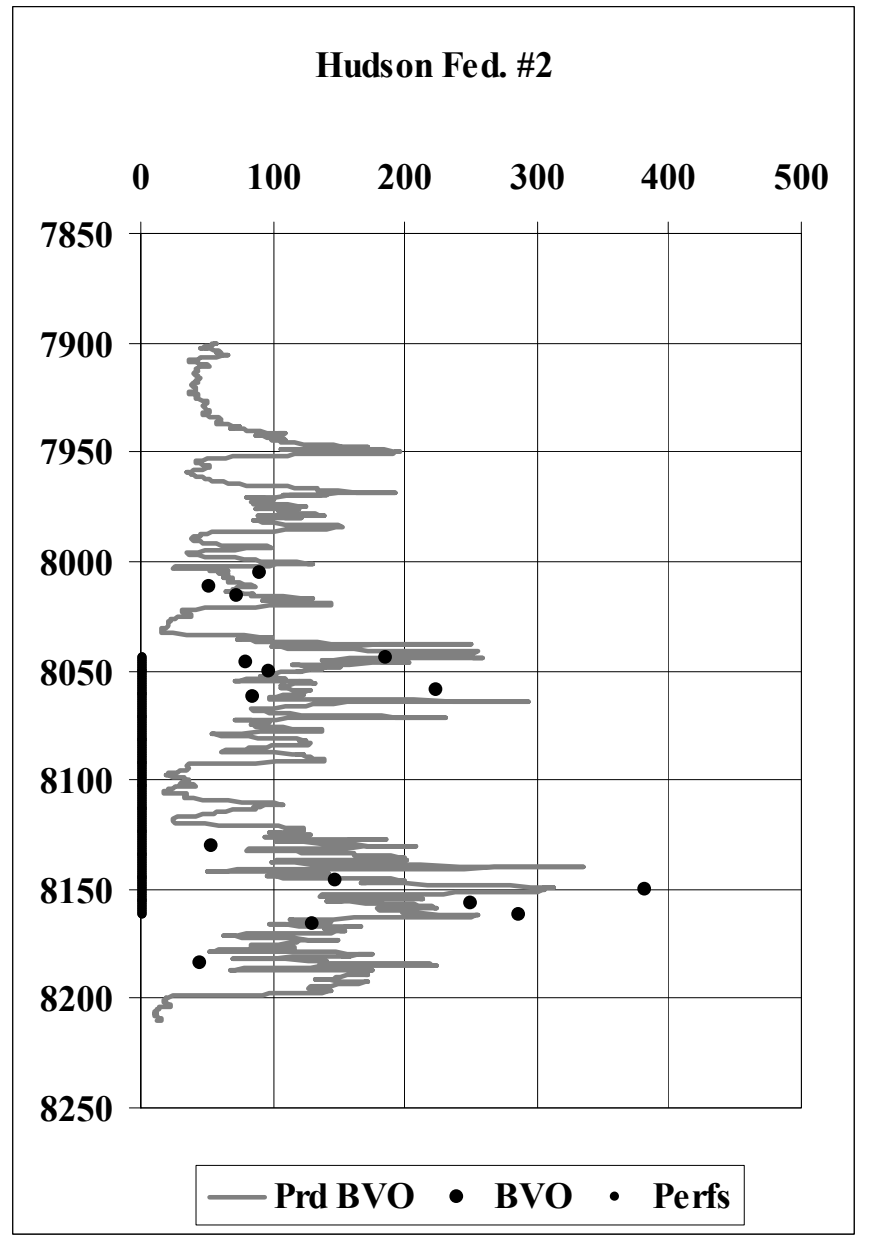

Fig. BVO-6. Blind testing with logs from a well 30 miles distant to training well. 


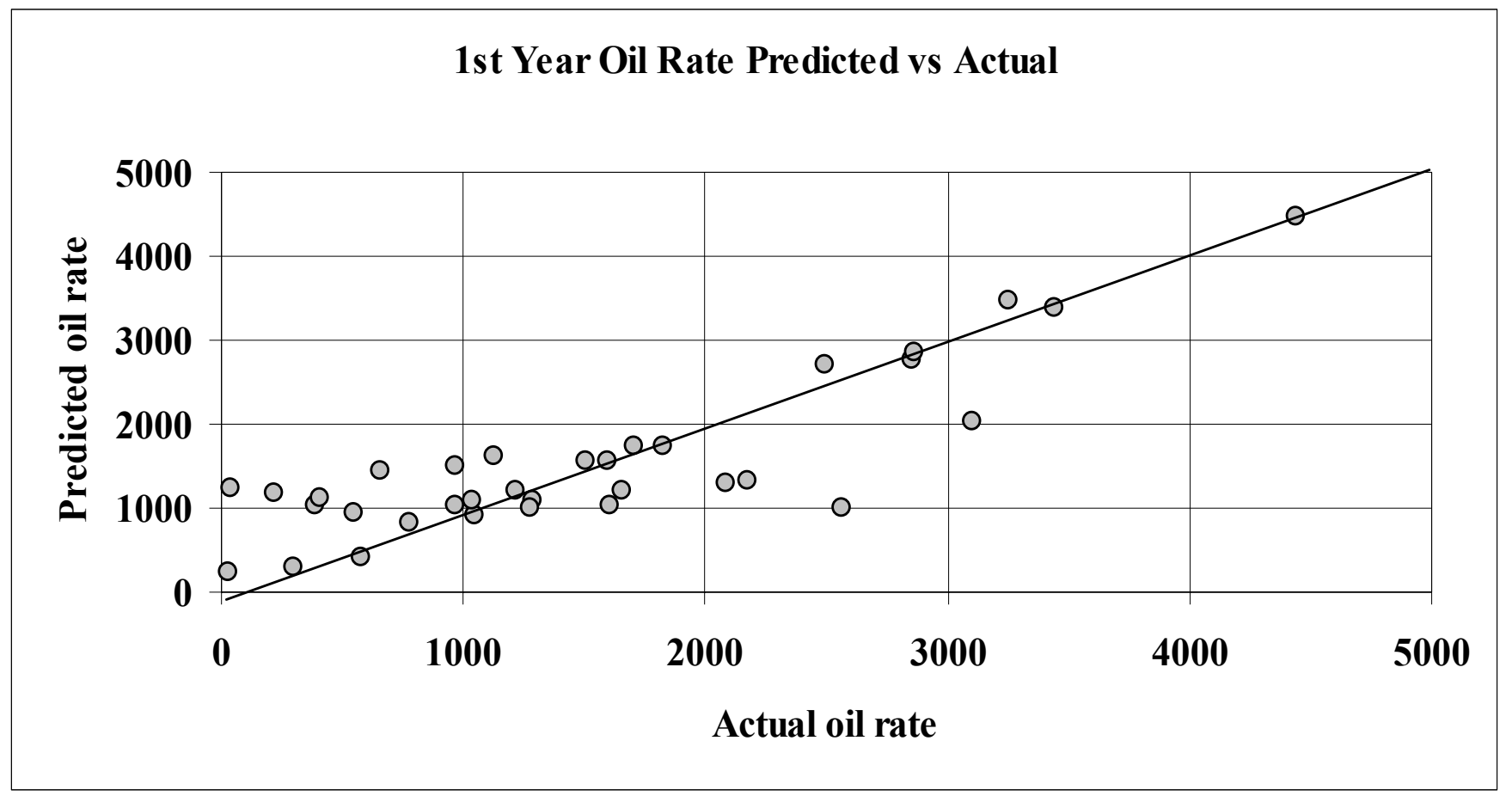

Fig. BVO-7. Accuracy of 34-well training.

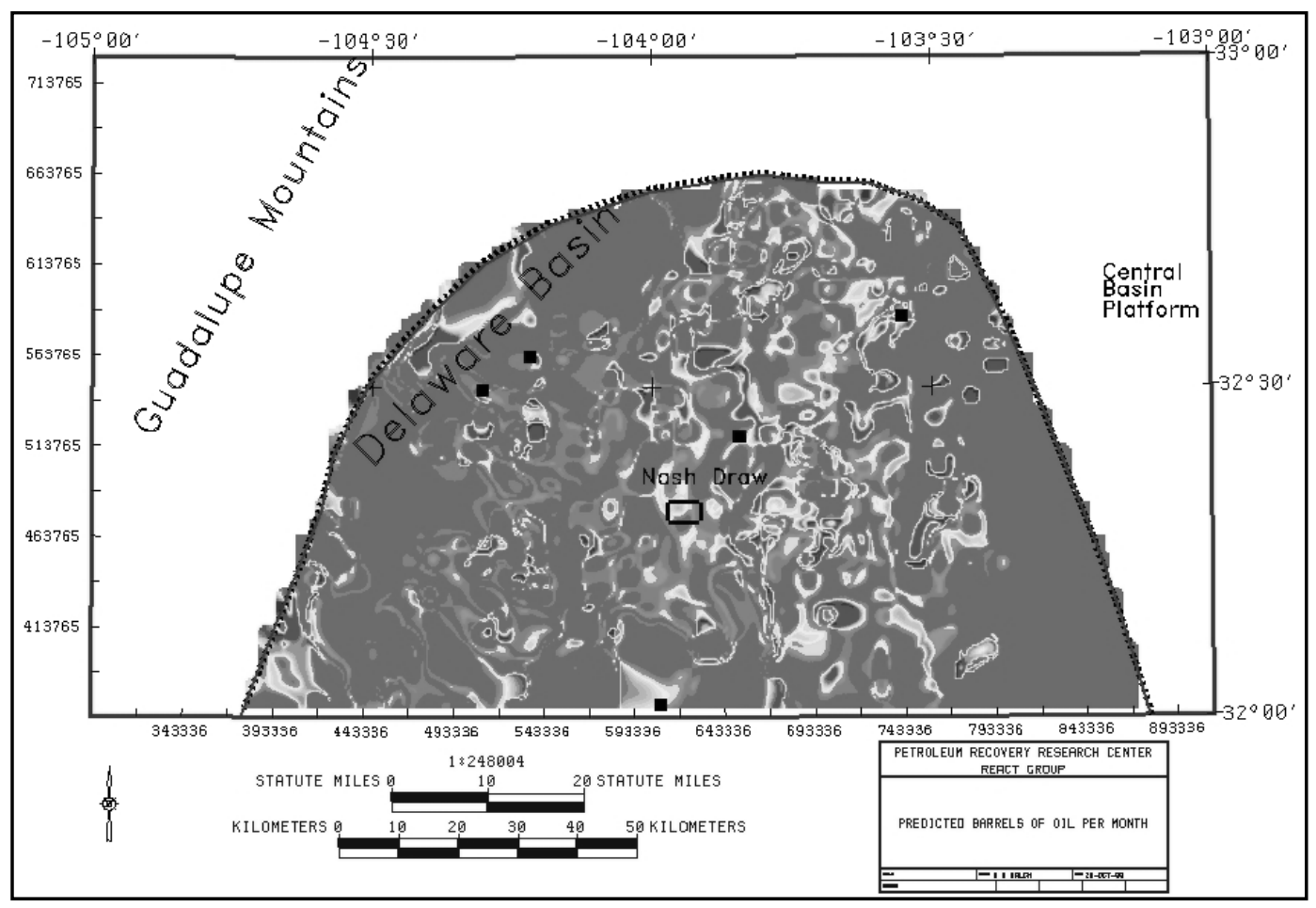

Fig. RL-1. Map of predicted production potential based on the trained and tested neural network regression. 


\section{BOPM}

\begin{tabular}{|l|}
\hline 500 \\
\hline 1000 \\
\hline 1500 \\
\hline 2000 \\
\hline 2500 \\
\hline 3000 \\
\hline 3500 \\
\hline 4000 \\
\hline 4500 \\
\hline 5000 \\
\hline 5500 \\
6000 \\
6500 \\
\hline
\end{tabular}

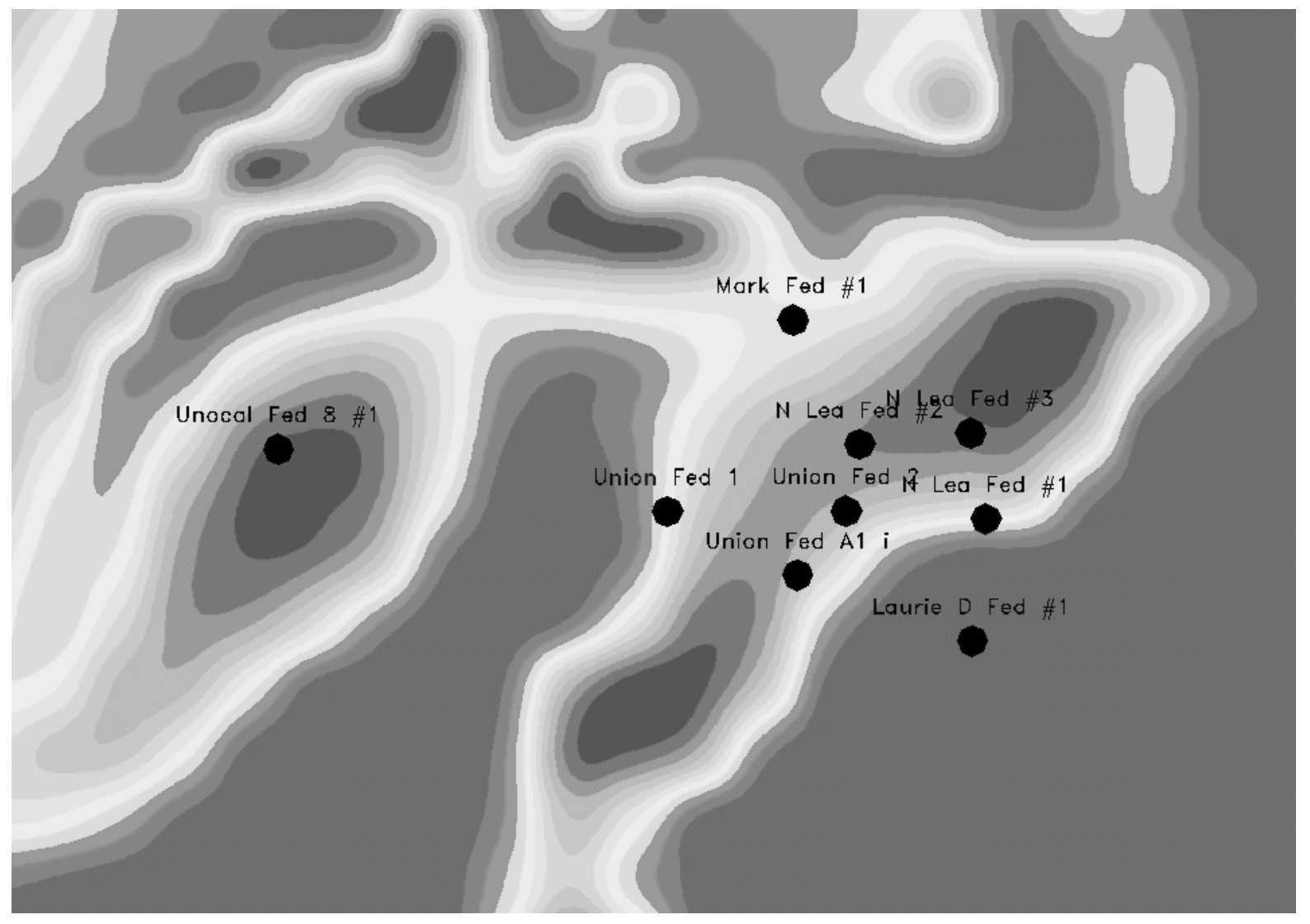

Fig. RL-2. NE Lea area zoom map. 


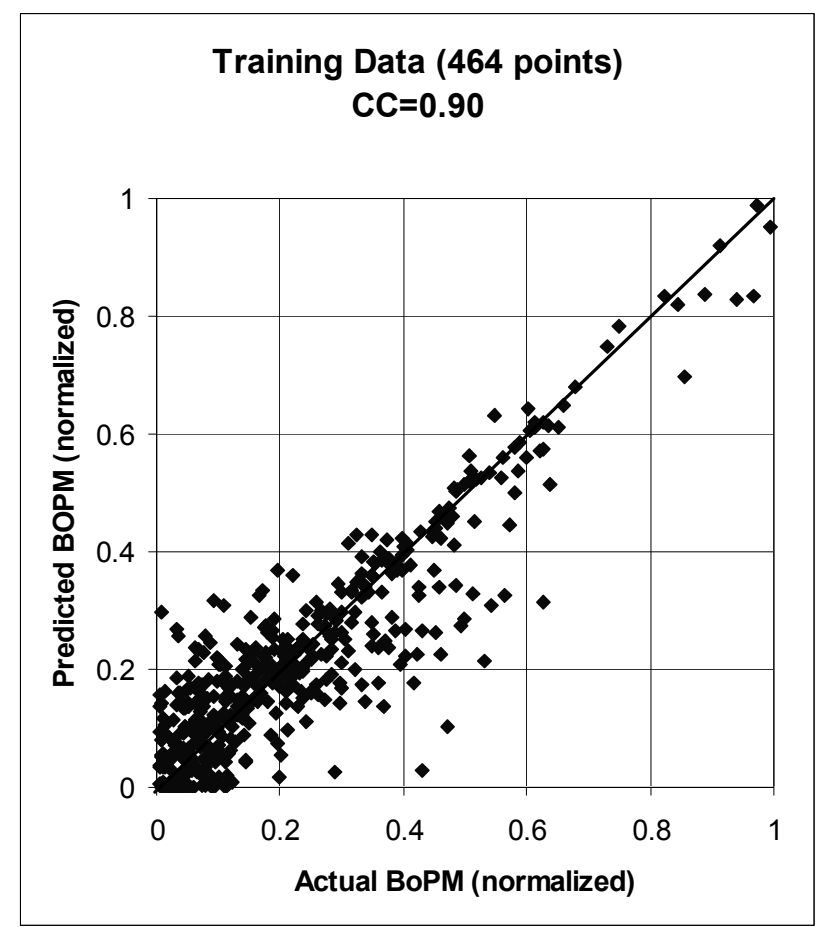

Fig. CI-1. Crossplot of neural network training using the inputs identified via FuzzyOnline.

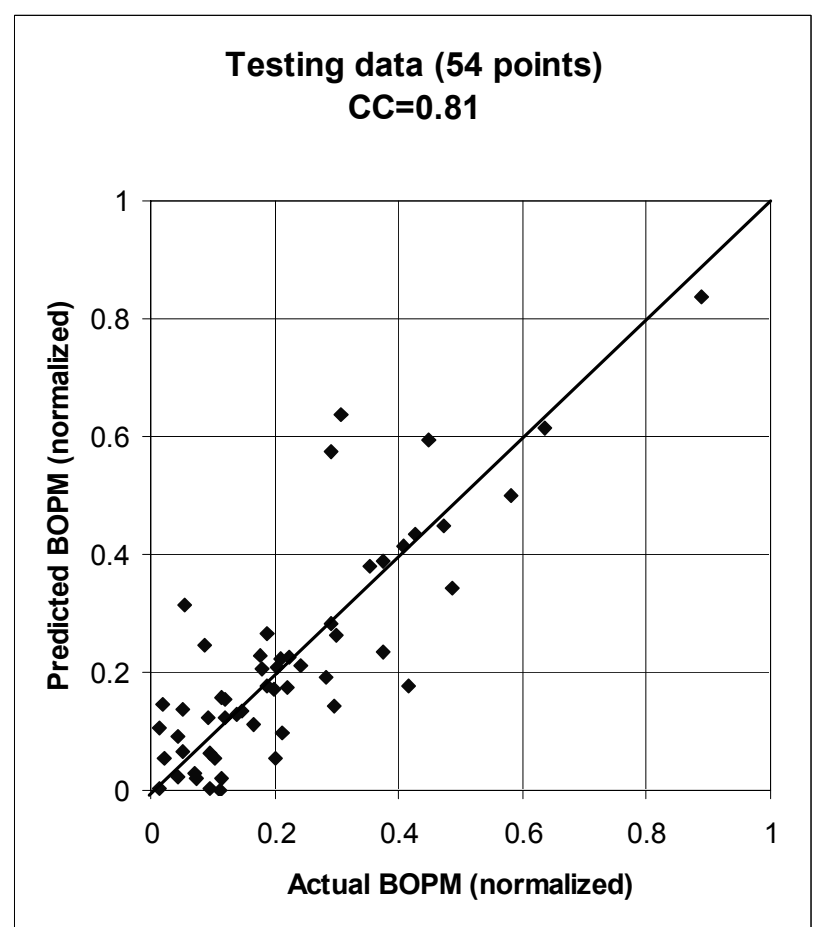

Fig. CI-2. Crossplot of testing data for the trained neural network of Fig. CI-1. 


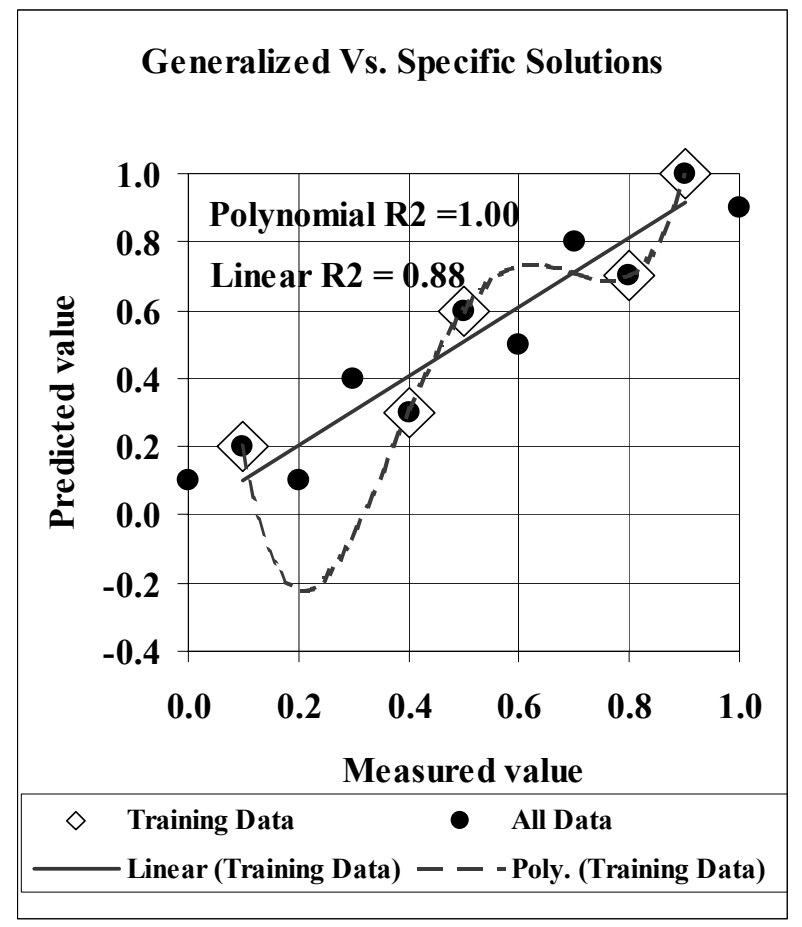

Fig. CI-3.This figure demonstrates the benefits of neural network regressions for complex problems where forecasts need to be made. Assuming only the five points enclosed by diamonds are known to start, it is quite easy to fit a polynomial that exactly fits the training data but poorly fits the true data distribution. Neural networks can bypass this problem if a sufficient sample exists for training by creating a generalized solution.

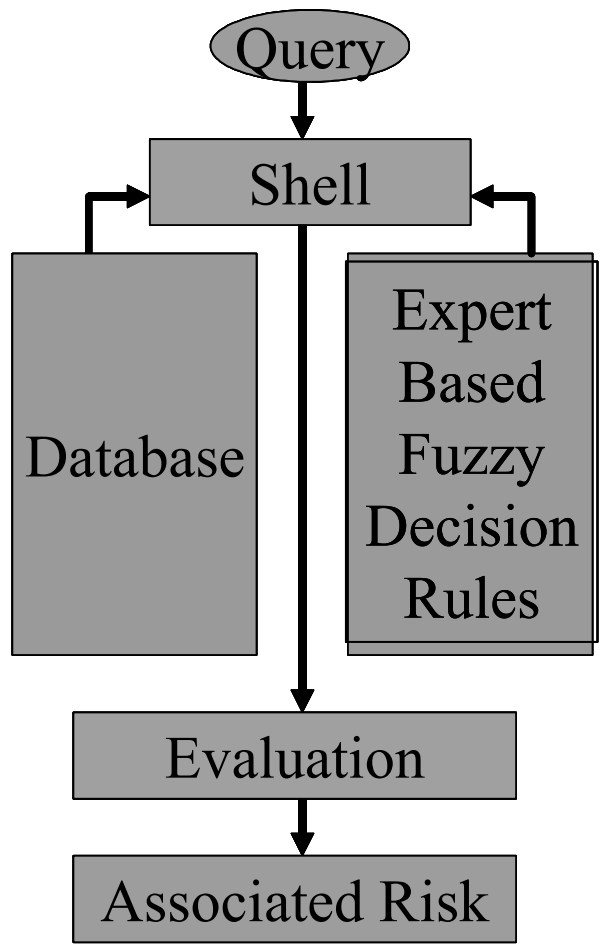

Fig. CI-4. The original schematic for the fuzzy expert system shell. 


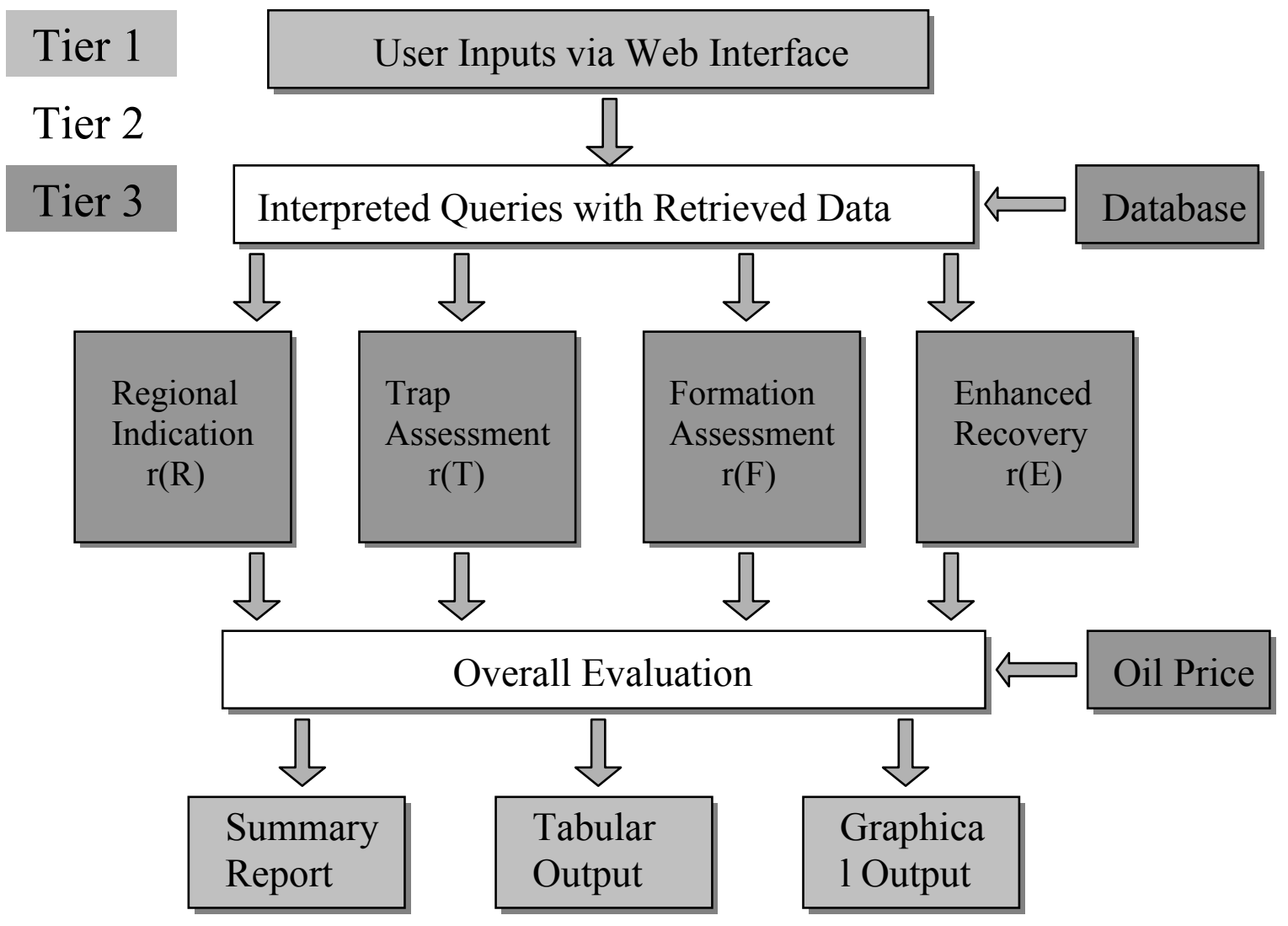

Fig. CI-5. More complicated system, which breaks the analysis into several separate categories to simplify calculations and customization.

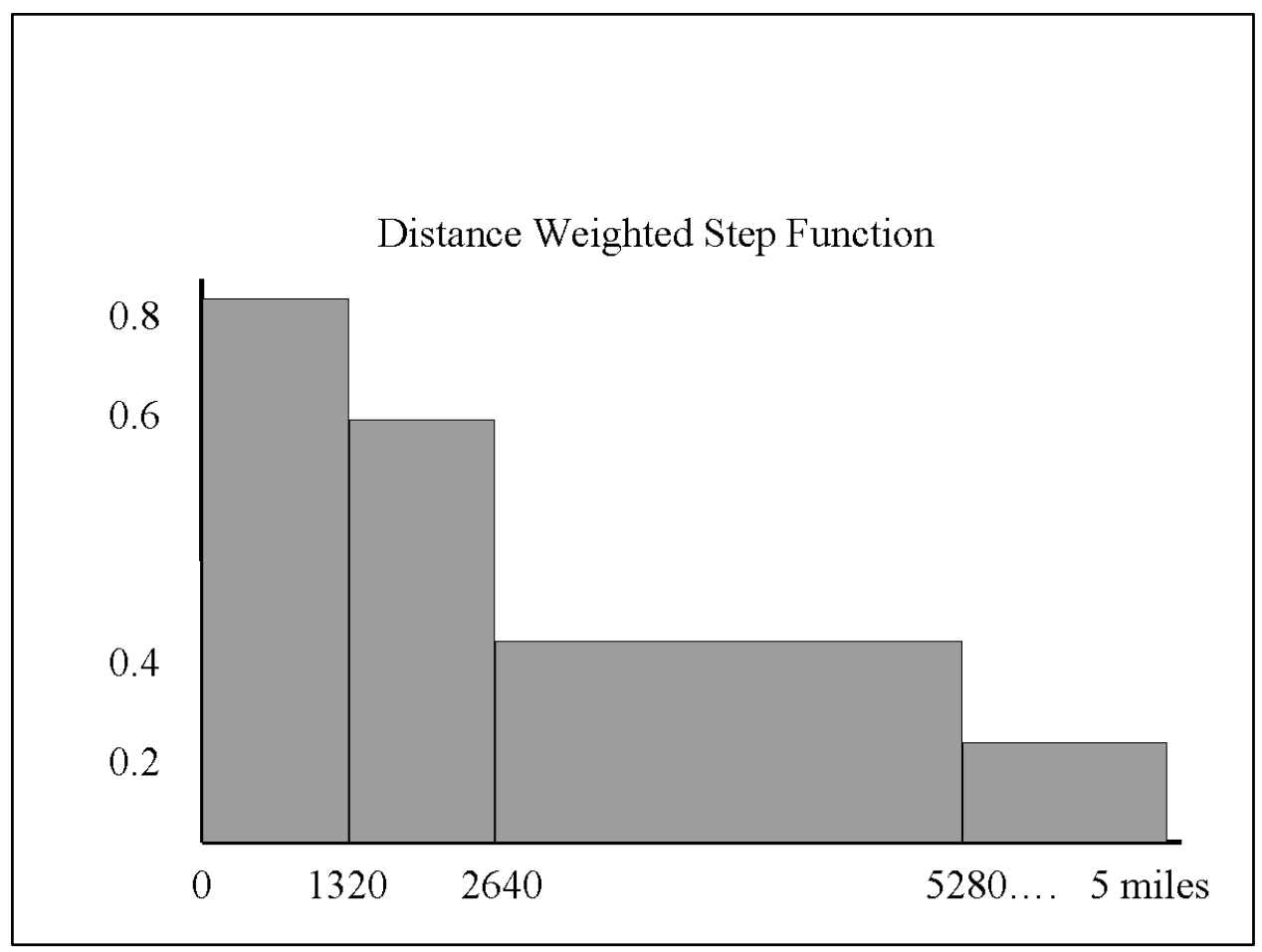

Fig CI-6. Distance weighted step function for proximity to established production. 


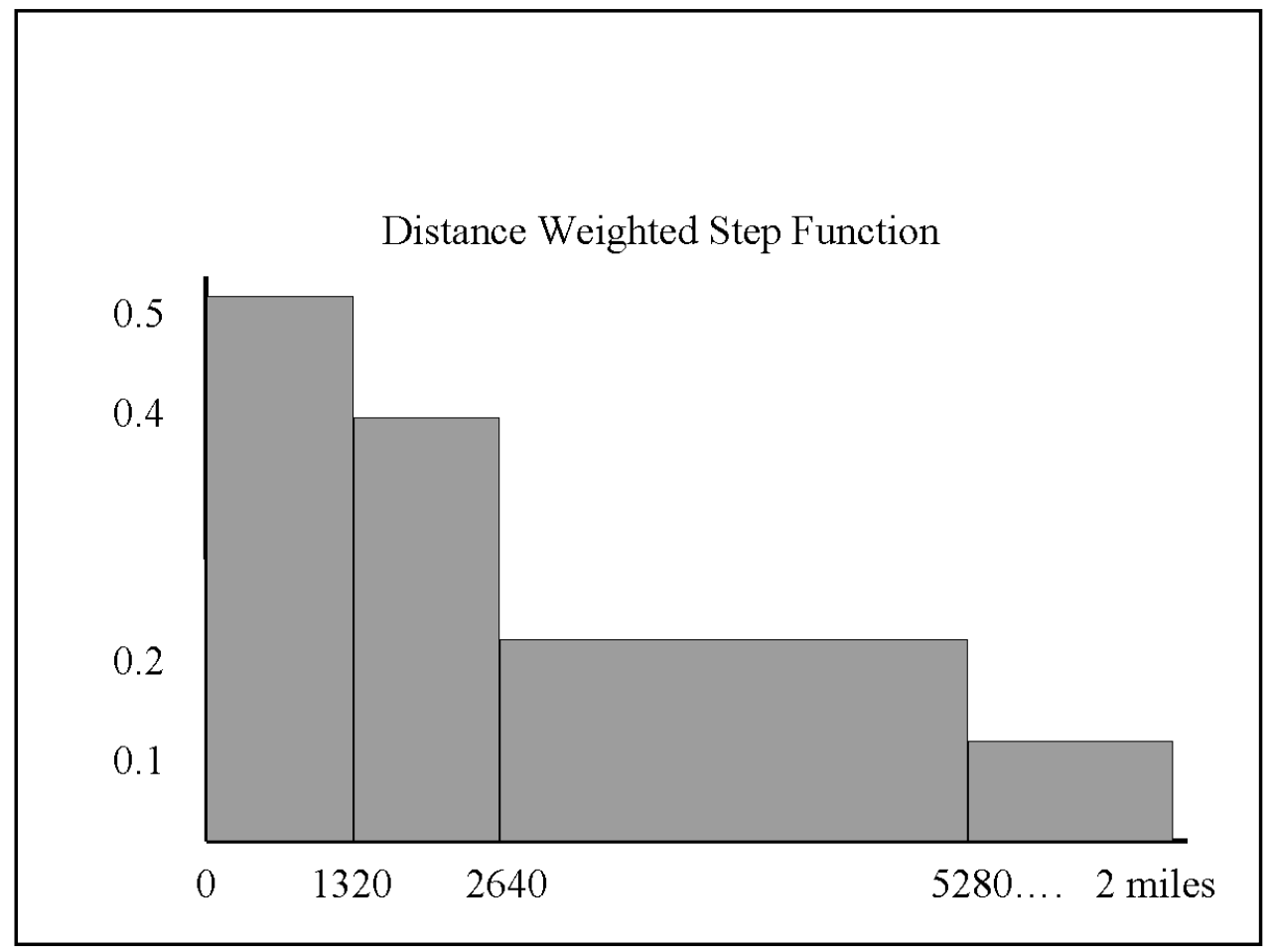

Fig CI-7. Distance weighted step function for proximity to oil shows, used when production data is not available within 5 miles.

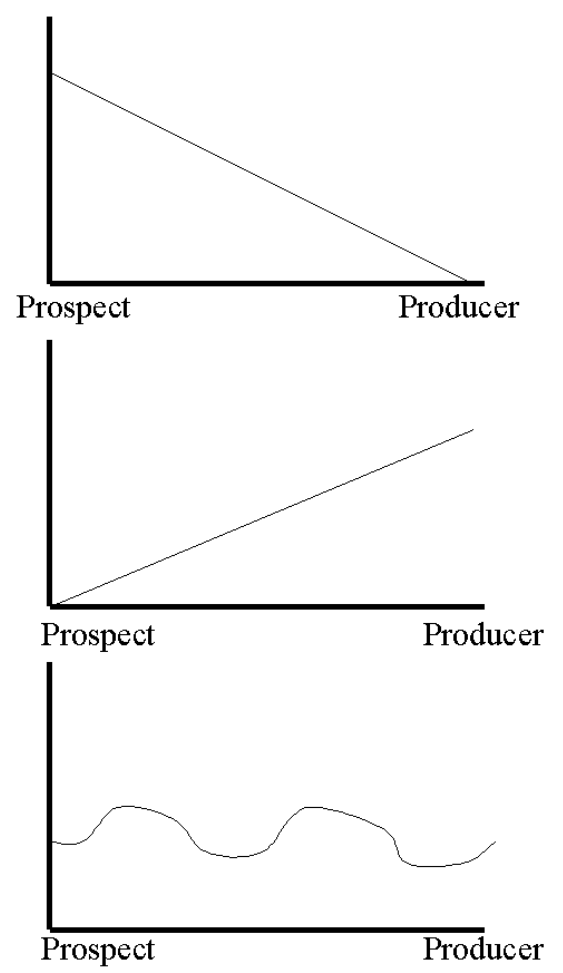

Case 1: Prospect Updip

Case 2: Prospect Downdip

Case 3: Prospect on unrelated structure

Fig CI-8. Illustration of the possible types of dip from one point to another considered by the expert system. 


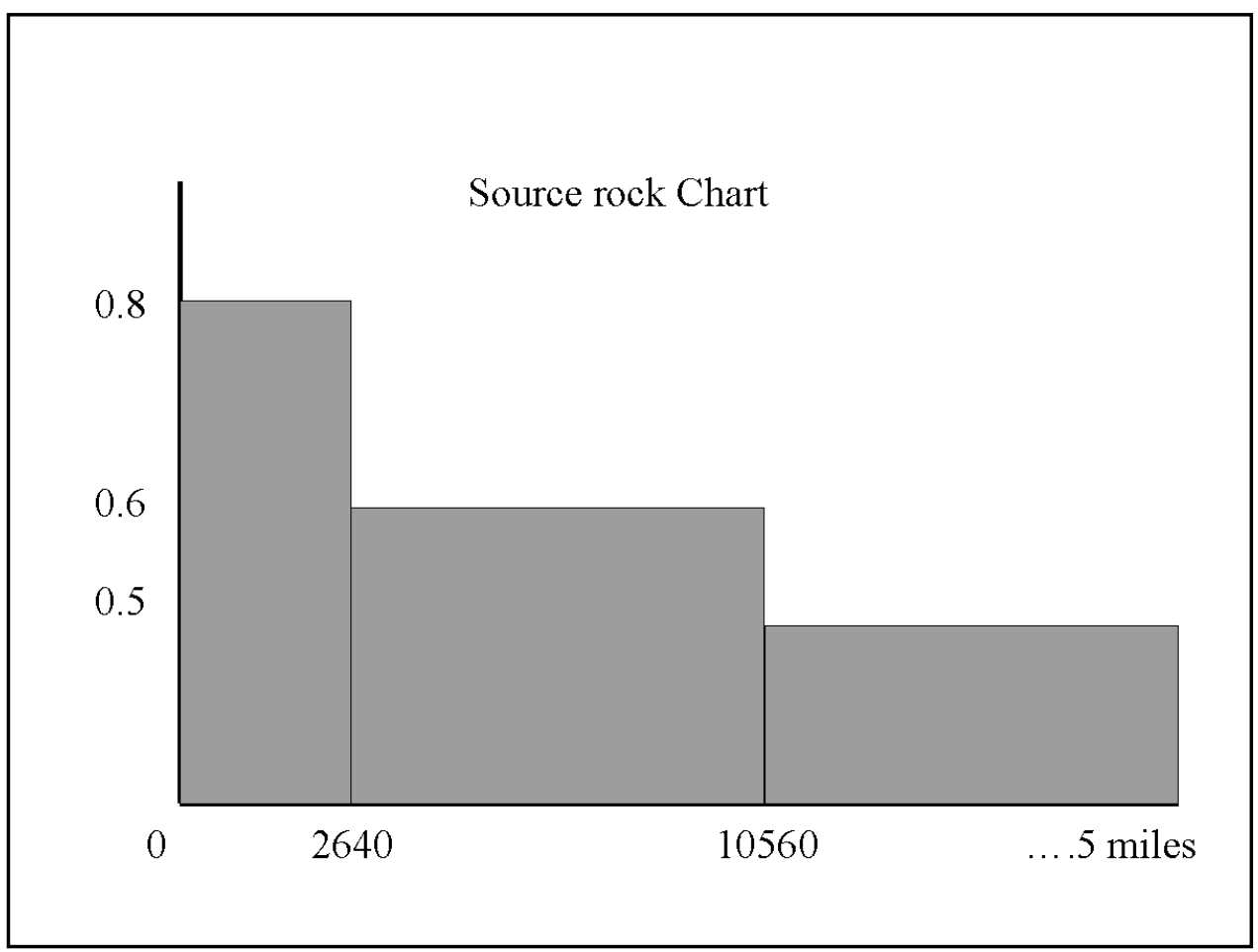

Fig CI-9. Distance weighted step function for proximity to source rocks with TOC $>5 \%$.

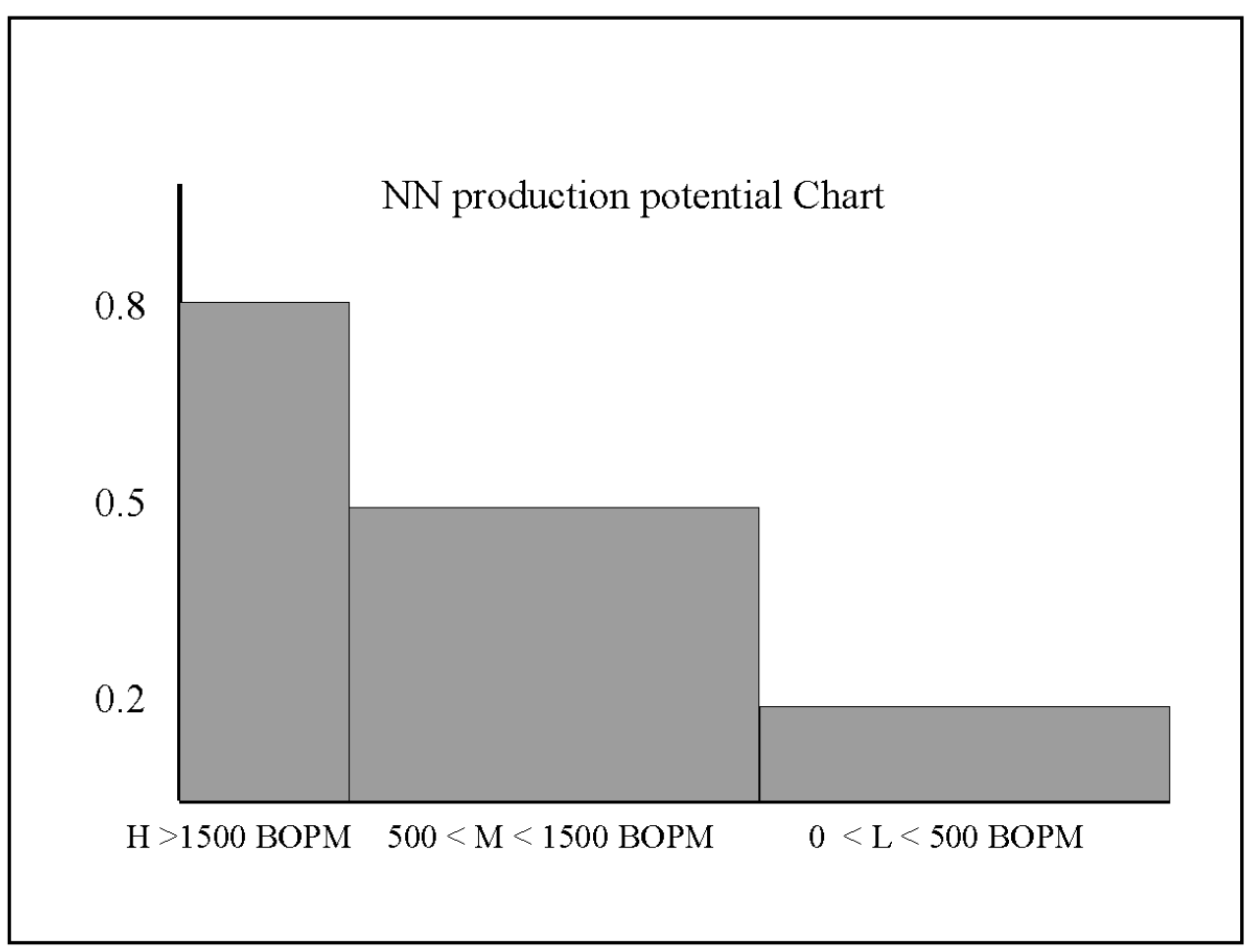

Fig CI-10. Step chart showing ranges for neural network predicted production potential. Three ranges are defined, High (H), Medium (M), and Low (L). 


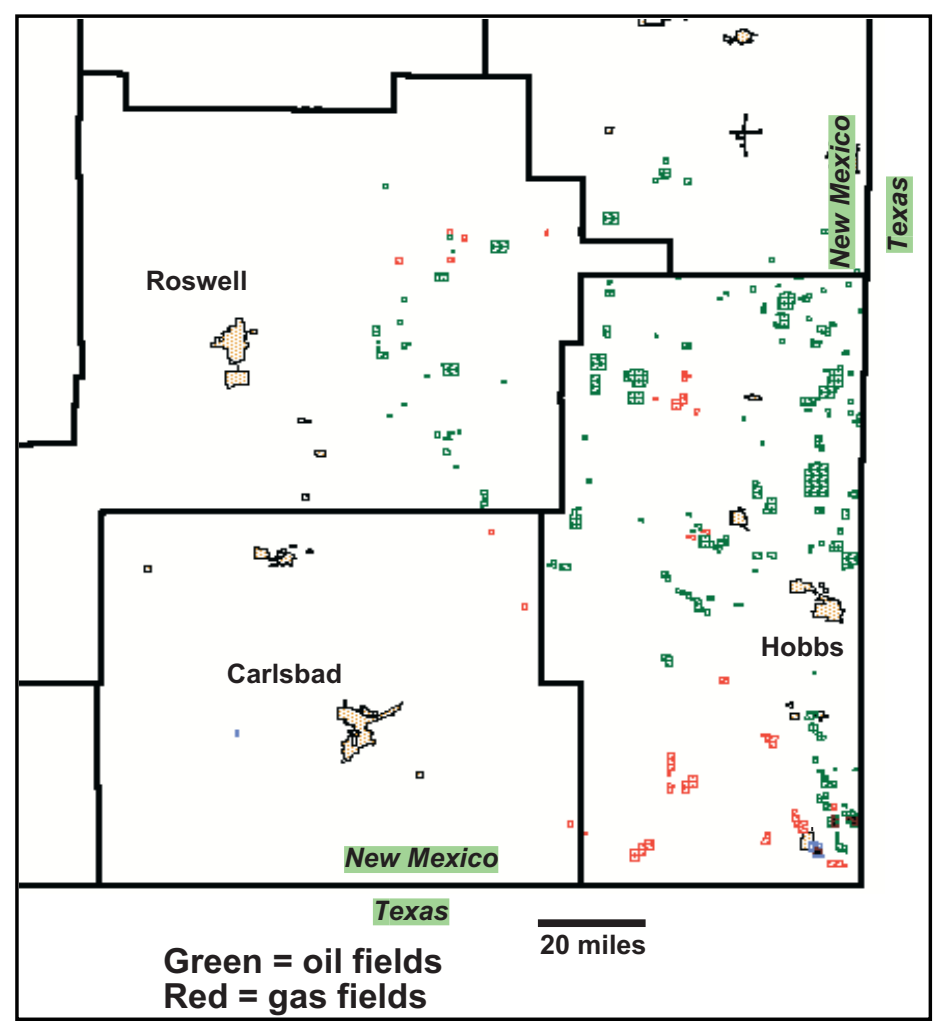

Fig. D-1 Oil and gas fields producing from Siluro-Devonian carbonates reservoirs in southeast New Mexico.

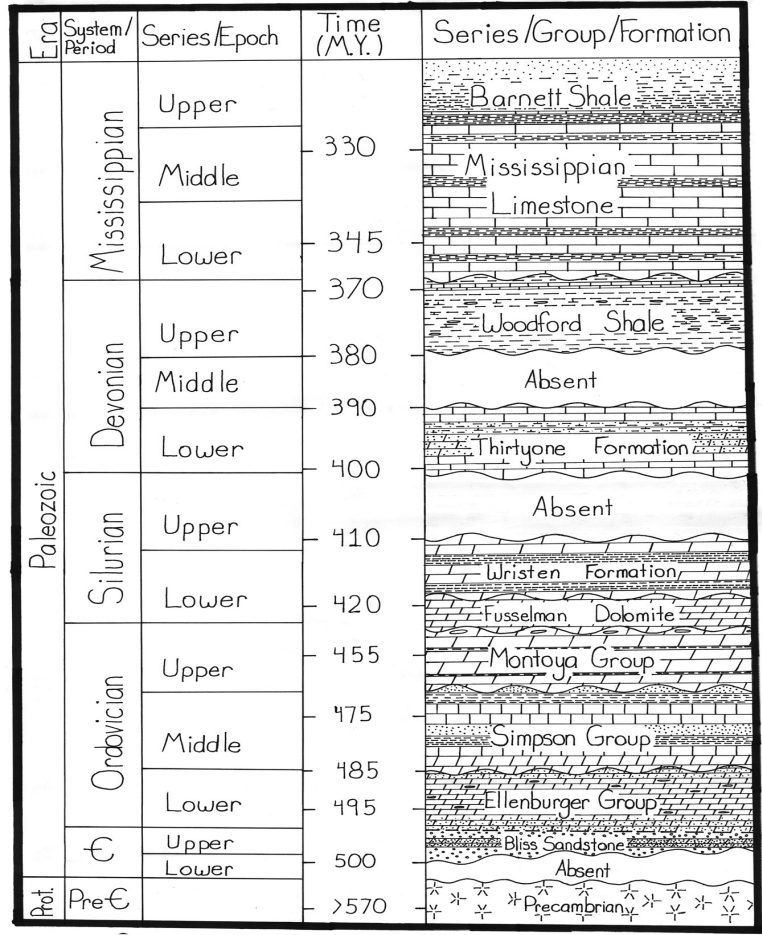

Figure D-2. Stratigraphic column of lower Paleozoic strata in southeast New Mexico. Production in the Siluro-Devonian section is obtained from several zones within the Thirtyone, Wristen, and Fusselman Formations. Modified from Hill (1986). 


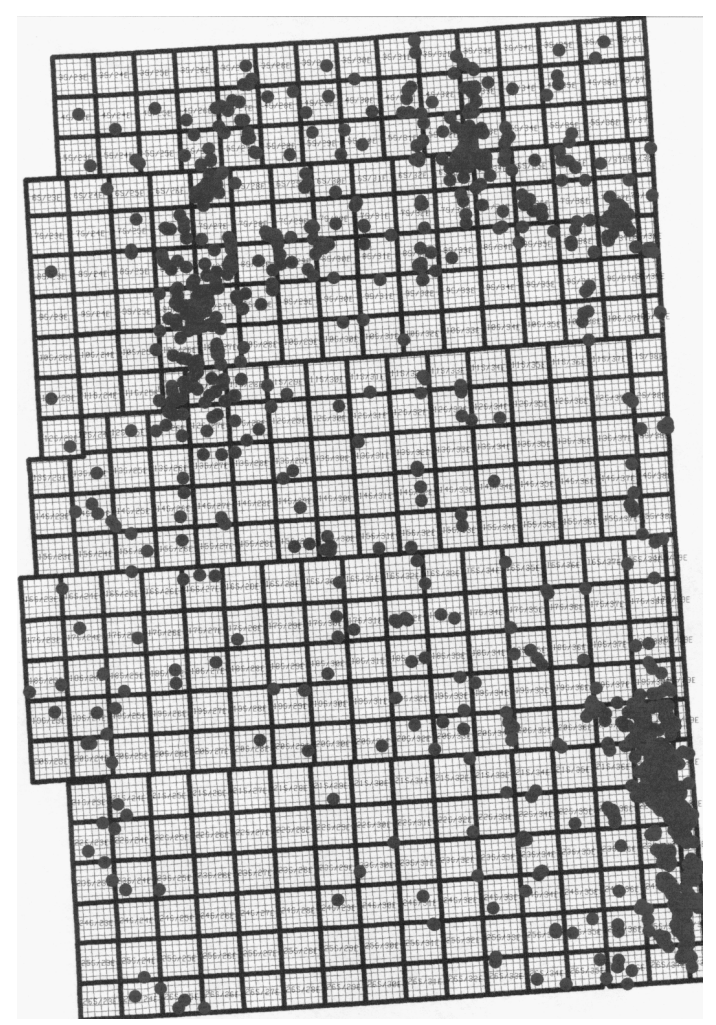

Fig. D-3. Wells penetrating sub-Woodford Devonian strata in southeast New Mexico.

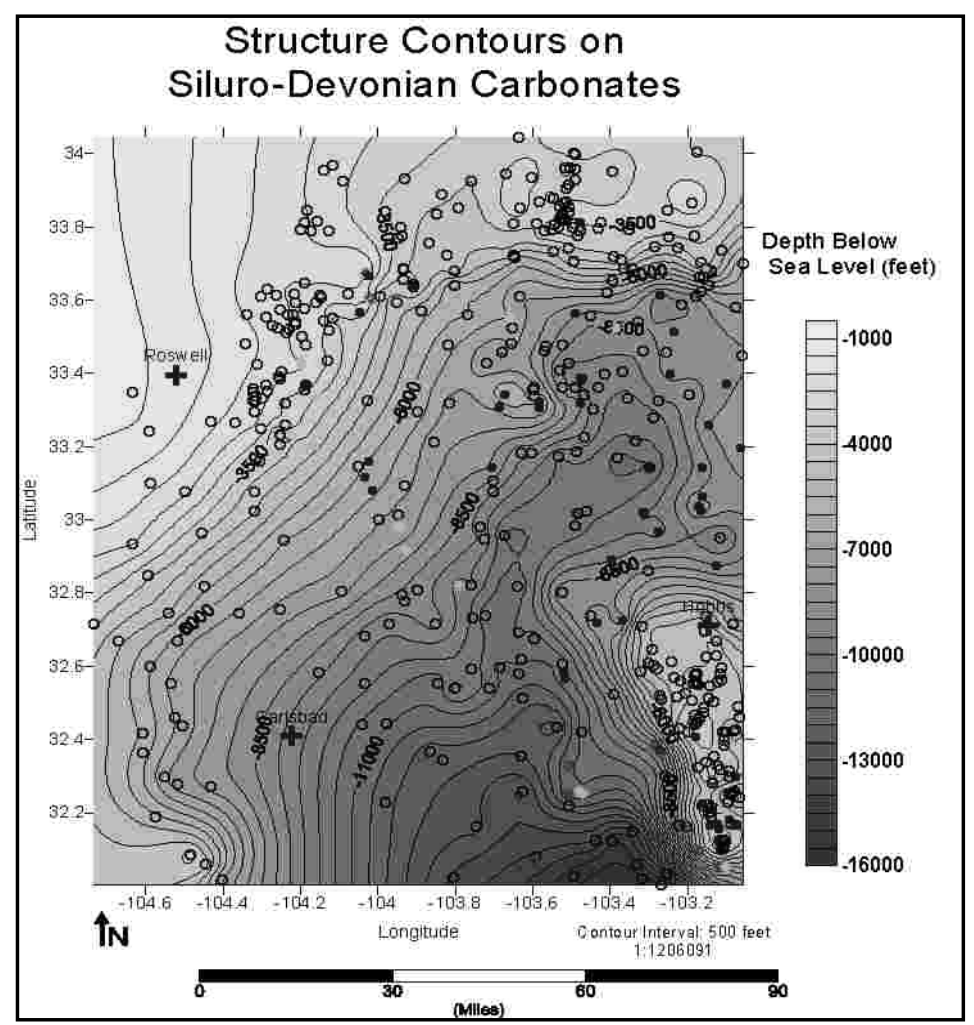

Fig. D-4. Structure contour map of Siluro-Devonian carbonates. 


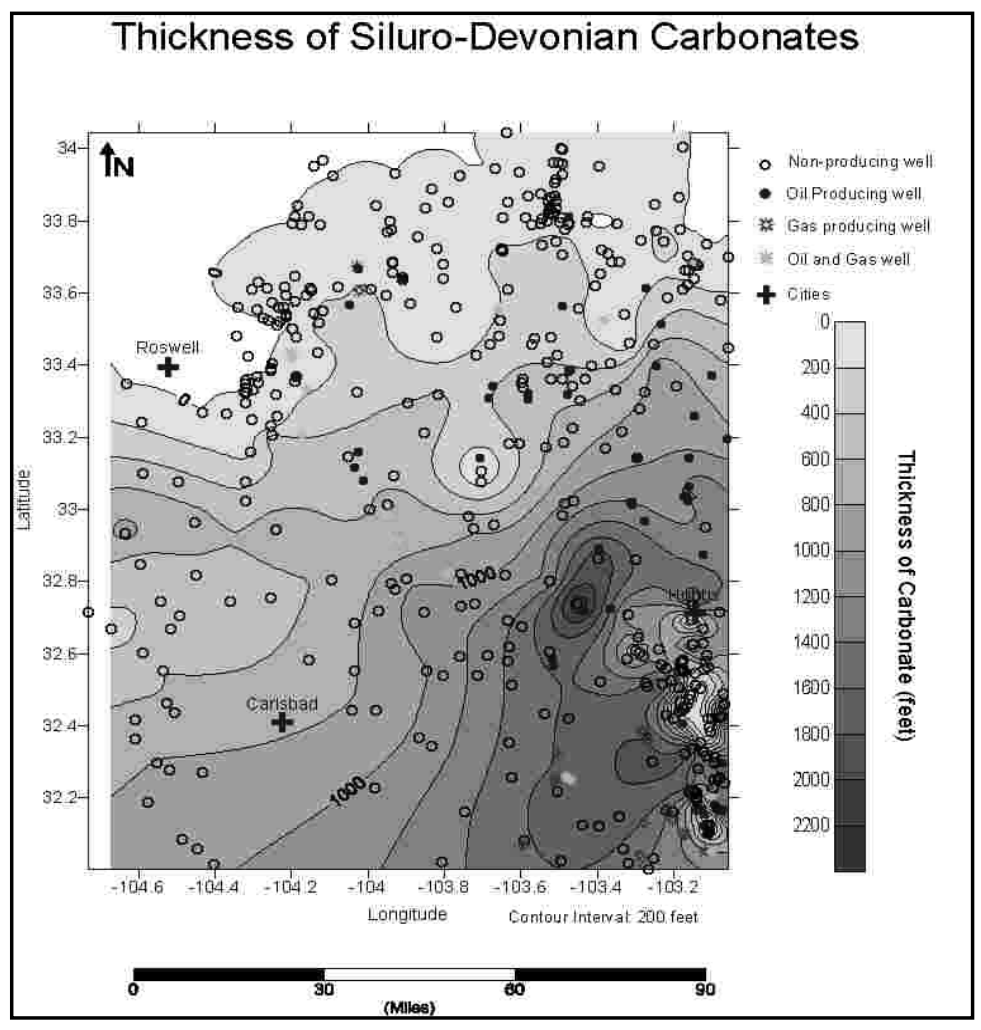

Fig. D-5. Isopach map of Siluro-Devonian strata in southeastern New Mexico. 